Marcia Maria Pires Camargo Novelli

\title{
Validação da escala de qualidade de vida (QdV-DA) para pacientes com doença de Alzheimer e seus respectivos cuidadores/familiares
}

Tese apresentada à Faculdade de Medicina da Universidade de São Paulo para obtenção do título de Doutor em Ciências

Área de concentração: Neurologia

Orientador: Prof. Dr. Paulo Caramelli

São Paulo

2006 


\section{FICHA CATALOGRÁFICA}

Preparada pela Biblioteca da

Faculdade de Medicina da Universidade de São Paulo

Creprodução autorizada pelo autor

Novelli, Marcia Maria Pires Camargo

Validação da escala de qualidade de vida (QdV-DA) para pacientes com doença de Alzheimer e seus respectivos cuidadores/familiares / Marcia Maria Pires Camargo Novelli. -- São Paulo, 2006.

Tese(doutorado)--Faculdade de Medicina da Universidade de São Paulo.

Departamento de Neurologia.

Área de concentração: Neurologia.

Orientador: Paulo Caramelli.

Descritores: 1.ESCALAS 2.VALIDADE 3.QUALIDADE DE VIDA 4.DOENÇA DE ALZHEIMER 5.REPRODUTIBILIDADE DE RESULTADOS 6.DEMÊNCIA

USP/FM/SBD-103/06 


\section{CERTEZA}

"De tudo ficaram 3 coisas:

A certeza de que estamos sempre começando;

A certeza de que precisamos continuar;

A certeza de que seremos interrompidos antes de terminar.

Portanto, devemos:

Fazer da interrupção um caminho novo;

Da queda, um passo de dança;

Do medo, uma escada;

Do sonho, uma ponte;

Da procura, um encontro"

Fernando Pessoa 
DEDICATÓRIA

À minha família, pelo amor, carinho, paciência e constante incentivo em todos os momentos dessa jornada. 


\section{AGRADECIMENTOS}

A todos os que me apoiaram e possibilitaram minha chegada até aqui.

São muitos e eu espero que as palavras sejam suficientes para exprimir minha gratidão.

Ao meu marido, Marcelo, com quem compartilho todos os momentos de minha vida. Obrigada pelo amor e carinho nos momentos de fragilidade.

Aos meus filhos, Raphael e Beatriz, que entraram comigo nesta jornada e foram, constantemente, fontes de amor, ternura e paz, o meu amor e minha gratidão.

Aos meus pais, Ary e Eurydice, que, se estivessem aqui, estariam orgulhosos de mais esse passo.

Aos meus pais de "coração", Walter e Sônia, por fazerem parte de minha vida.

Aos meus amigos, agradeço pelas palavras de carinho e de paz nos momentos mais difíceis desta caminhada.

Ao meu orientador e amigo, Prof. Dr. Paulo Caramelli, meu muito obrigado. O seu profissionalismo e constante incentivo me impulsionaram para novos caminhos, antes desconhecidos. Obrigada por me ensinar a ser pesquisadora e por ter compartilhado comigo todos os momentos desta trajetória. 
Ao Prof. Dr. Ricardo Nitrini, com quem muito aprendi: o meu respeito e a minha admiração, além do meu agradecimento por proporcionar as condições necessárias para a realização deste trabalho.

A Dra. Rebecca Logsdon, por ter compartilhado comigo seu conhecimento durante toda a execução deste trabalho.

Aos colegas do Grupo de Neurologia Cognitiva e do Comportamento, em especial à Teresa, Renata e Heloísa, por me auxiliarem com suas discussões e pelos momentos de ajuda efetiva na realização do estudo.

A D. Mary, pelo profissionalismo com o qual executa seu trabalho e por generosamente me auxiliar na marcação e agendamento das avaliações.

À Coordenação de Aperfeiçoamento de Pessoal de Nível Superior (CAPES) e ao Conselho Nacional de Pesquisa (CNPQ), pelo auxílio financeiro no decorrer do trabalho.

E finalmente, a todos os pacientes e cuidadores/familiares que participaram da realização do estudo, e com quem aprendi e aprendo muito, meu sincero agradecimento. 
LISTA DE ABREVIATURAS

LISTA DE FIGURAS

LISTA DE QUADROS

LISTA DE TABELAS

RESUMO

ABSTRACT

1. INTRODUÇÃO

2. CONTEXTUALIZANDO DOENÇA DE ALZHEIMER E QUALIDADE

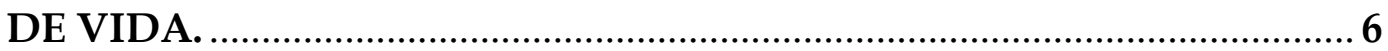

2.1 Doença de Alzheimer..........................................................................

2.2 Aspectos conceituais e metodológicos do constructo de qualidade de vida.

2.3 Classificação dos instrumentos de avaliação de qualidade de vida ....11

2.4 Qualidade de vida na demência................................................................. 13

2.5 Caracterização da escala de QV na doença de Alzheimer ...................... 18

3. ETAPAS DE VALIDAÇÃO DE UMA ESCALA DE AVALIAÇÃO .........23

3.1 Propriedades de medida de uma escala de avaliação............................... 24

3.1.1 Fidedignidade de um instrumento de medida............................... 26

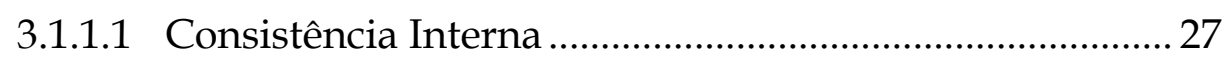

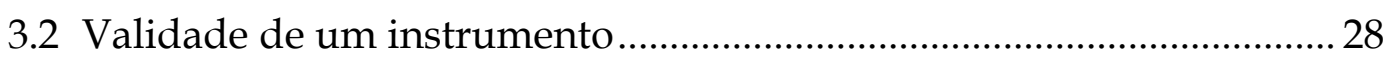

3.2.1 Validade de conteúdo..................................................................... 28

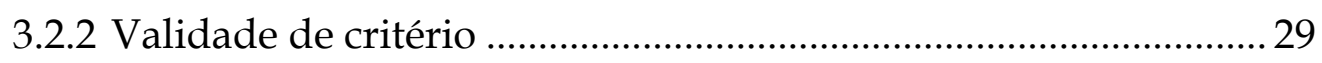

3.2.3 Validade de constructo.......................................................................... 30

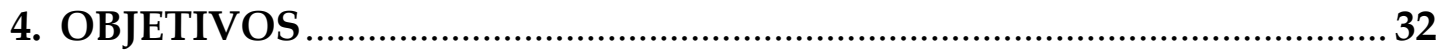

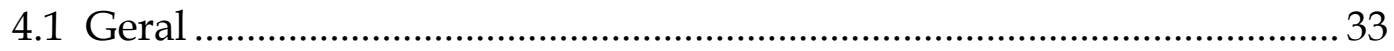

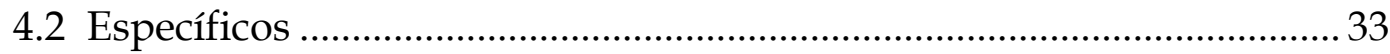


5.1 Caracterização do local e do período do estudo ..................................... 36

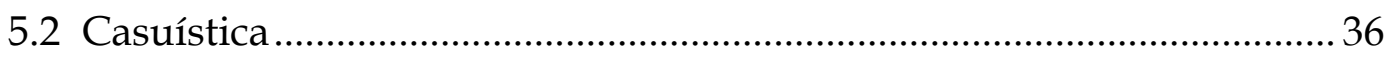

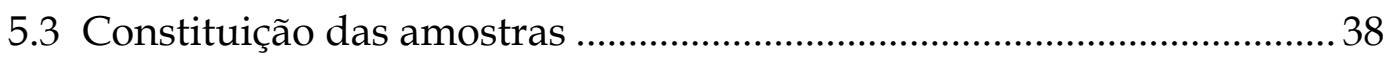

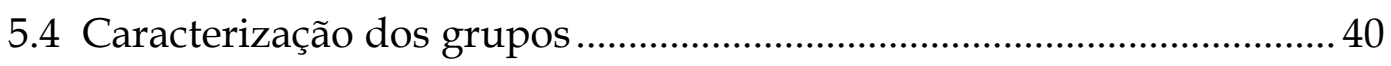

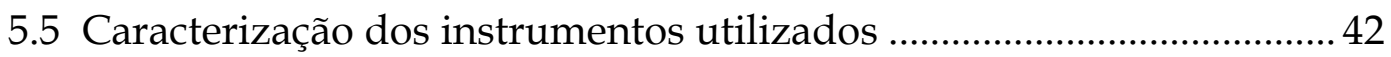

5.6 Avaliação das propriedades de medida da escala QdV-DA................. 44

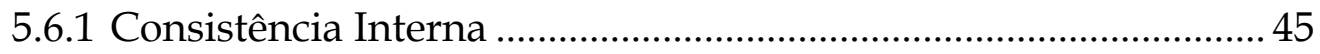

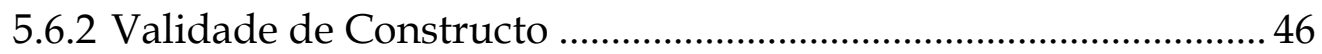

5.6.3 Avaliação do impacto do prejuízo cognitivo sobre a confiabilidade e a validade da escala QdV-DA..............................48

5.7 Procedimento de coleta de dados ...........................................................49

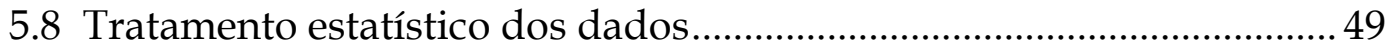

5.9 Hipóteses de correlações entre a escala QdV-DA e os outros instrumentos de avaliação 50

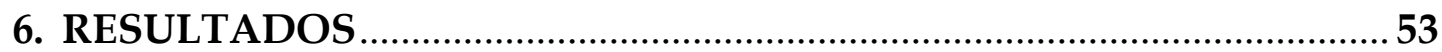

6.1 Análise da aplicação dos instrumentos de avaliação utilizados .......... 54

6.2 Análise das propriedades de medida da QdV-DA ...............................56

6.2.1 Consistência Interna ........................................................................ 56

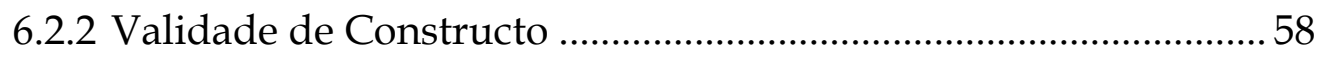

6.2.3 Avaliação do impacto do prejuízo cognitivo sobre a confiabilidade e a validade da escala QdV-DA............................ 64

6.3 Comparação entre os relatos dos pacientes e dos cuidadores ............... 76

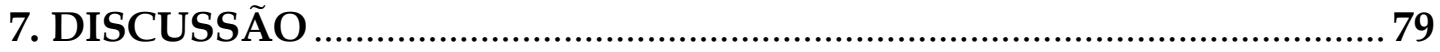

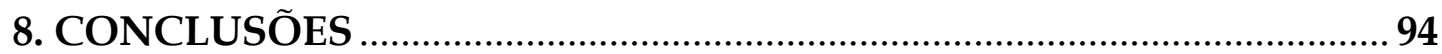

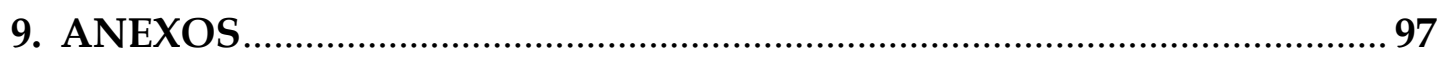

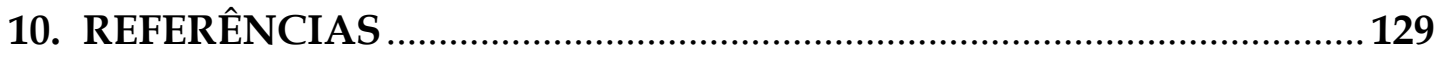




\section{LISTA DE ABREVIATURAS}

ABVDs

ADCS - ADL

AIVDs

APA

AVDs

C-PQdV

CQdV

DA

D-QOL

DSM- IV

DSM-III-R

GDS

HADS

HCFMUSP

IBGE

ICC
Atividades Básicas da Vida Diária

Escala de habilidades funcionais

Atividades Instrumentais da Vida Diária

American Psychiatric Association

Atividades de Vida Diária

Versão do cuidador sobre a qualidade de vida do paciente na escala de avaliação de qualidade de vida na doença de Alzheimer

Versão do cuidador sobre sua própria qualidade de vida na escala de avaliação de qualidade de vida na doença de Alzheimer

Doença de Alzheimer

Dementia Quality of Life scale

Manual Diagnóstico e Estatístico dos Transtornos Mentais versão IV

Manual Diagnóstico e Estatístico dos Transtornos Mentais versão III - Revisada

Escala de Depressão Geriátrica

Escala de Depressão e Ansiedade

Hospital das Clínicas da Faculdade de Medicina de São Paulo

Instituto Brasileiro de Geografia e Estatística

Coeficiente Intraclasse 
MEEM

MOS

NINCDS-ADRDA National Institute of Neurological and Communicative Disorders and Stroke - Alzheimer Disease and Related Disorders Association

INP

OMS

PQdV

QdV-DA

QOL-AD

QV

SAC

WHOQOL -100

WHOQOL-breve

WHOQOL GROUP

WHOQOL-OLD

Mini-exame do Estado Mental

Medical Outcomes Study

Inventário Neuropsiquiátrico

Organização Mundial de Saúde

Versão do paciente na escala de avaliação da qualidade de vida na doença de Alzheimer

Escala de avaliação da qualidade de vida na doença de Alzheimer

Quality of life in Alzheimer Disease

Qualidade de vida

Scientific Advisory Committee of Medical Outocomes Trust

Instrumento de avaliação da qualidade de vida da Organização Mundial da Saúde

Instrumento abreviado de avaliação da qualidade de vida

World Health Organization Quality of Life Group

Instrumentos para avaliação da qualidade de vida em adultos idosos 


\section{LISTA DE FIGURAS}

Figura 1- Modelo teórico de Lawton de QV em idosos...

14 


\section{LISTA DE QUADROS}

Quadro 1: Esquema de constituição das amostras.............................................. 39

Quadro 2: Esquema de verificação da consistência interna da QdV-DA ....... 45

Quadro3: Esquema de verificação da validade de constructo da QdV-DA... 47 


\section{LISTA DE TABELAS}

Tabela 1 - Perfil sociodemográfico dos participantes dos Grupos I e II 40

Tabela 2 - Perfil sociodemográfico dos participantes do grupo III

Tabela 3 - Associações entre os itens da escala QdV-DA e os domínios do WHOQOL-breve

Tabela 4 - Valores (médias e desvio-padrão) obtidos nas avaliações administradas aos pacientes e cuidadores/familiares dos grupos I e II......... 54

Tabela 5 - Índices de correlação entre os itens e a consistência interna da QdV-DA.

Tabela 6 - Validade de constructo das versões PQdV, C-PQdV e da versão composta.

Tabela 7 - Validade de constructo da versão CQdV.

Tabela 8 - Validade de constructo da versão PQdV: índices de correlação entre os itens e os domínios do WHOQOL-breve.

Tabela 9 - Validade de constructo da versão C-PQdV: índices de correlação entre os itens e os domínios do WHOQOL-breve

Tabela 10 - Validade de constructo da versão CQdV: índices de correlação entre os itens com os domínios do WHOQOL-breve

Tabela 11 - Índices de correlação entre os itens e a consistência interna da QdV-DA em pacientes com DA leve.

Tabela 12 - Índices de correlação entre os itens e a consistência interna da QdV-DA em pacientes com DA moderada....

Tabela 13 - Validade de constructo das versões PQdV, C-PQdV e da versão composta nos pacientes com DA leve

Tabela 14 - Validade de constructo das versões: PQdV, C-PQdVA e a versão composta nos pacientes com DA moderada

Tabela 15 - Validade de constructo da versão CQdV nos cuidadores de pacientes com DA leve e moderada 
Tabela 16 - Validade de constructo da versão PQdV no grupo de pacientes leves: índices de correlação entre os itens com os domínios do WHOQOLbreve

Tabela 17 - Validade de constructo da versão C-PQdV no grupo de pacientes leves: índices de correlação entre os itens com os domínios do WHOQOL-breve

Tabela 18 - Validade de constructo da versão CQdV no grupo de pacientes leves: índices de correlação entre os itens com os domínios do WHOQOLbreve

Tabela 19 - Validade de constructo da versão PQdV: índices de correlação entre os itens no grupo de pacientes com DA moderada

Tabela 20 - Validade de constructo da versão C-PQdV: índices de correlação entre os itens no grupo de pacientes com DA moderada

Tabela 21 - Validade de constructo da versão CQdV: índices de correlação entre os itens no grupo de pacientes com DA moderada

Tabela 22 - Médias, desvios-padrão e correlações entre os relatos dos pacientes com DA leve e seus respectivos cuidadores/familiares

Tabela 23 - Médias, desvios-padrão e correlações entre os relatos dos pacientes com DA moderada e seus respectivos cuidadores/familiares

Tabela 24 - Valores de $p$ dos testes estatísticos relativos à influência das variáveis demográficas sobre as versões PQdV, C-PQdV e CQdV

Tabela 25 - Distribuição das médias e desvios-padrão do tempo de aplicação em minutos nos grupos de pacientes com DA leve e moderada.... 78

Tabela 26 - Comparação dos resultados de confiabilidade (alfa de Cronbach) da escala QDV-DA com os dados da literatura

Tabela 27 - Comparação dos resultados de validação de constructo da escala QdV-DA com os dados da literatura. 


\section{RESUMO}

Novelli MMPC. Validação da escala de Qualidade de Vida (QdV-DA) para pacientes com doença de Alzheimer e seus respectivos cuidadores/familiares [tese]. São Paulo: Faculdade de Medicina da Universidade de São Paulo; 2006. 138p.

O fenômeno qualidade de vida $(\mathrm{QV})$ vem sendo amplamente estudado em ensaios clínicos e pesquisas científicas de doenças crônico-degenerativas e demências. Não há ainda disponível, em nossa cultura, um instrumento confiável e válido para avaliar $\mathrm{QV}$ nos quadros demenciais $\mathrm{e}$, especificamente, na doença de Alzheimer (DA). O presente estudo tem por objetivos: avaliar as propriedades de medida da versão em Português da escala "Quality of Life-AD (QOL-AD)", avaliando a confiabilidade e a validade de constructo das três versões (PQdV, C-PQdV e CQdV) e também o impacto do comprometimento cognitivo sobre as propriedades de medida. A escala QOL-AD foi desenvolvida por Logsdon et al. em 1999. O instrumento é composto de 13 itens quantificados em uma escala de quatro pontos, sendo a pontuação 1 atribuída à qualificação ruim e a pontuação 4 , à excelente. A pontuação total varia de 13 a 52, em que os índices mais altos indicam melhor QV. A escala possui três versões de avaliação de QV: o relato do paciente sobre sua QV (PQdV), o relato do cuidador/familiar sobre a QV do paciente (C-PQdV) e a versão do cuidador/familiar sobre sua própria QV $(\mathrm{CQdV})$. A escala foi administrada a uma amostra de 60 pacientes com diagnóstico de DA provável, segundo os critérios do NINCDS-ADRDA, sendo 30 pacientes com grau leve e 30 pacientes com grau moderado de demência, segundo os critérios do DSM-III-R, e a seus respectivos cuidadores/familiares $(n=60)$. A confiabilidade da escala foi avaliada através do alfa de Cronbach. Para a verificação da validade de constructo, as três versões da escala foram associadas às avaliações do funcionamento cognitivo, desempenho funcional, alterações de comportamento, sintomas depressivos e de nível socioeconômico e ao instrumento genérico de avaliação de QV (WHOQOL-breve). A confiabilidade da escala foi elevada, tanto para a versão do PQdV, como para a versão C-PQdV (alfa=0,80 e 0,83, respectivamente), quanto para a versão CQdV (alfa $=0,86)$. Na validade de constructo da versão PQdV encontramos correlações significativas com: sintomas depressivos (GDS $(-0,59, p<0,01)$ e Cornell $(-0,49, p<0,01)$ ), alterações de comportamento $(-0,36, p<0,01)$, com a questão número $1(0,67$, $p<0,01)$ e o somatório do WHOQOL-breve $(0,88, p<0,01)$. Na versão C-PQdV, foram encontradas correlações significativas com: comprometimento cognitivo $(0,41, p<0,01)$, sintomas depressivos (GDS $(-0,36, p<0,01)$ e Cornell $(-0,68, p<0,01))$, desempenho funcional (AIVDs $(-0,52, p<0,01)$ e ABVDs $(-0,51$, $p<0,01)$, alterações de comportamento $(-0,71, p<0,01)$, com a questão número $1(0,61, p<0,01)$ e o somatório do WHOQOL-breve $(0,71, p<0,01)$. Na versão $\mathrm{CQdV}$, as correlações encontradas foram com sintomas depressivos (Cornell $(-0,30, p<0,05)$ e Inventário de depressão de Beck $(-0,59 p<0,01))$, alterações de 
comportamento $(-0,39, p<0,01)$, desempenho funcional (AIVDs $(-0,41, p<0,01)$ e $\operatorname{ABVDs}(-0,32, p<0,01)$,com a questão número $1(0,55, p<0,01)$ e o somatório do WHOQOL-breve $(0,81 \quad p<0,01)$. A confiabilidade e a validade de constructo da escala foram mantidas independentemente do aumento da gravidade da doença. $\mathrm{O}$ gasto médio na aplicação da escala foi de aproximadamente seis minutos para cada uma das três versões. Os resultados indicam a confiabilidade e a validade constructo da versão em Português da escala de avaliação de QV na população estudada. 


\section{SUMMARY}

Novelli MMPC. Validation of the Brazilian version of the Quality of Life scale for patients with Alzheimer's Disease and their caregivers/family members (QOL-AD) [thesis]. São Paulo: "Faculdade de Medicina, Universidade de São Paulo"; 2006. 138p.

The concept quality of life (QOL) has been extensively studied in clinical trials and in research of chronic-degenerative diseases and dementia. We do not have in our culture instruments available to evaluate $\mathrm{QOL}$ in dementia and, particularly, in Alzheimer's disease (AD). This study has the following objectives: to evaluate the psychometric properties of the Portuguese version of the scale, evaluating the reliability and construct validity of the three versions (PQdV, C-PQdV e CQdV), and the evaluation of the impact of cognitive performance on the psychometric properties. The scale "Quality of Life-AD (QOL-AD)" was developed by Logsdon et al. in 1999. The instrument is composed of 13 items quantified in a scale of four points, with the score 1 being attributed to the qualification poor and the score 4 , to excellent. The total score varies from 13 to 52, with the highest indexes indicating better QOL. The scale has three versions of QOL evaluation: the QOL indexes from the patient's report on his/her own QOL (PQdV), the caregivers/family report on the patient's QOL (C-PQdV) and the version on QOL of the caregivers/family (CQdV). The scale was administered to a sample of 60 patients with diagnosis of probable $\mathrm{AD}$, according to the NINCDS-ADRDA criteria, being 30 patients with mild dementia and 30 patients with moderate dementia, according to the DSM-III-R criteria, respectively, and to their caregivers/family members $(n=60)$. The scale reliability was evaluated through Alfa's Cronbach. The construct validation was accomplished based on the correlations of the three scale versions with cognitive evaluation, functional performance, behavior disturbances, depressive symptoms and socioeconomic level and with a generic instrument of QOL (WHOQOL-brief). The scale reliability was high, both for the PQdV and for the C-PQdV version (alfa $=0.80$ and 0.83 , respectively), as much as for the CQdV version $(a l f a=0.86)$. We observed significant correlations in the construct validity of PQdV version: with depressive symptoms (GDS (-0.59, $\mathrm{p}<0.01)$ and Cornell $(-0.49, \mathrm{p}<0.01))$, behavior disturbances $(-0.36, \mathrm{p}<0.01)$, with the first item $(0.67, \mathrm{p}<0.01)$ and with the total score of WHOQOL-brief $(0.88, \mathrm{p}<0.01)$. We obtained significant correlations in the construct validity of the C-PQdV version: with cognitive impairment $(0.41, \mathrm{p}<0.01)$, depressive symptoms (GDS $(-0.36, \mathrm{p}<0.01)$ and Cornell $(-0.68, \mathrm{p}<0.01)$ ), functional performance (AIVDs $(-0.52, \mathrm{p}<0.01)$ ABVDs $(0.51, \mathrm{p}<0.01)$, behavior disturbances $(-0.71, \mathrm{p}<0.01)$, with the first item $(0.61, \mathrm{p}<0.01)$ and with the total score of WHOQOL-brief $(0.71, \mathrm{p}<0.01)$. In the CQdV scale, the significant correlations were related to depressive symptoms (Cornell $(-0.30$, 
$\mathrm{p}<0.05)$ and Beck Depression Inventory $(-0.59, \mathrm{p}<0.01)$, behavior disturbances $(-0.39, \mathrm{p}<0.01)$, functional performance (AIVDs $(-0.41, \mathrm{p}<0.01)$ e ABVDs $(-0.32, p<0.01)$, with the first item $(0.55, \mathrm{p}<0.01)$ and the total score of WHOQOL-brief $(0.81, \mathrm{p}<0.01)$. The scale reliability and construct validity were kept independently from the disease level. The scale took, on average, six minutes for each of the three versions. The results indicate reliability and construct validity of the Brazilian version of QOL-AD in the sample studied. 
1. INTRODUÇÃO 
O envelhecimento populacional é um fenômeno mundial que tem sido alvo de estudos e pesquisas em vários âmbitos. $\mathrm{O}$ processo de envelhecimento e sua conseqüência natural, a velhice, é uma das preocupações da humanidade desde o início da civilização (Papaléo, 2002). O Brasil é um dos países com maior aceleração do crescimento populacional de idosos nos últimos anos, enfatizando-se que, desde 1940, o grupo etário de 60 anos ou mais é o que mais cresce na população brasileira (Ramos et al., 1987).

Os dados do Perfil dos Idosos Responsáveis pelos Domićlios no Brasil 2000 apontam para que, nos próximos 20 anos, essa população possa ultrapassar os 30 milhões de pessoas (IBGE, 2005). Estimativas mostram que em 2025 “o Brasil poderá ter a sexta população de idosos do mundo em termos absolutos" (Kalache et al., 1987; Veras, 2000; Ramos, 2002).

Uma explicação para esse crescimento é a diminuição nas taxas de mortalidade associada à redução das taxas de natalidade, quando passamos a observar uma população de idosos maior do que a de jovens.

Esse aumento expressivo da expectativa de vida da população faz com que questionamentos relacionados às perdas e ganhos no processo de envelhecimento e as buscas por um envelhecimento bem sucedido façam parte dos estudos desenvolvidos na área da Gerontologia.

A busca pelo envelhecimento bem sucedido está diretamente associada a um envelhecer com qualidade de vida $(\mathrm{QV})$, tema que tem sido foco de estudo nas mais diversas áreas, que vão desde a economia e as ciências políticas, até a área da saúde.

Apesar de o crescente aumento na expectativa de vida ser visto como uma das conquistas mais significativas do século passado, também é o 
principal fator de risco para o desenvolvimento de doenças associadas ao envelhecimento, como as doenças crônico-degenerativas, dentre as quais algumas formas de demência (Lopes e Bottino, 2002; Nitrini et al., 2004).

A demência se caracteriza por declínio progressivo da memória e de outras funções cognitivas, de intensidade suficiente para interferir no desempenho das atividades sociais e/ou profissionais do indivíduo (American Psychiatric Association - APA, 1994). Dentre as síndromes demenciais, a mais prevalente é a doença de Alzheimer (DA) (Herrera et al., 2002; Lopes e Bottino, 2002).

Existem inúmeras pesquisas sobre QV em saúde e a discussão do tema na DA é nova e polêmica. As dúvidas mais comuns questionam a importância da realização de estudos sobre QV, quais os domínios que a compõem, quais os aspectos considerados fundamentais para uma boa QV e de que forma estes se inter-relacionam, qual a forma mais eficaz para mensurar essa variável e, para finalizar, quais os benefícios de estudos nesta área e as futuras direções deles.

Em demência, observamos uma evolução no conceito de QV. Inicialmente, os parâmetros utilizados eram os propostos para a população em geral. À medida que os estudos foram sendo desenvolvidos, fatores específicos ligados a essa população foram sendo incluídos.

Atualmente, a definição de QV em demência mais aceita é a proposta por Whitehouse e Rabins (1992), que a consideram como sendo a integração do funcionamento cognitivo, atividades de vida diária, interação social e do bem-estar psicológico.

Muitos pesquisadores e clínicos acreditam que a variável QV deva ser incluída como medida de eficácia nas mais diversas formas de pesquisa sobre intervenções terapêuticas (Guillemin et al., 1993; Lawton, 1997; Walker e Salek, 1998; Logsdon et al., 2000). 
Existem disponíveis instrumentos genéricos e específicos para avaliar QV, cada um dos tipos com suas vantagens e desvantagens. Os genéricos são mais utilizados para estudos populacionais e para a avaliação ampla de QV. Os instrumentos específicos, por sua vez, se prestam a avaliar o impacto de uma determinada doença sobre a QV. A seleção do tipo de medida depende da proposta do estudo, do propósito para o qual o instrumento será usado, e de suas propriedades psicométricas.

Quando falamos em avaliar QV na demência, alguns critérios adicionais devem ser incluídos, em função de a capacidade de compreensão poder estar reduzida, como a extensão dos itens no instrumento selecionado e de suas escalas de qualificação, bem como a linguagem utilizada na formulação das questões.

As formas utilizadas para avaliar QV envolvem múltiplas perspectivas: do paciente (auto-relato), do cuidador/familiar (proxy) e os modelos de observação de comportamento. A proposta de utilização de cada forma vai depender do grau de comprometimento do indivíduo avaliado.

Para a efetiva mensuração do fenômeno QV, nesta população específica, faz-se necessária a identificação de um instrumento fidedigno e válido para ser utilizado na avaliação.

$\mathrm{Na}$ busca por uma medida que contemplasse os critérios citados anteriormente, identificamos um instrumento específico de avaliação de QV na doença de Alzheimer (QOL-AD), proposto por Logsdon et al. (1999). Essa escala engloba duas das três formas utilizadas para avaliar QV: a versão do paciente e do cuidador/familiar sobre a QV do paciente e a versão do cuidador sobre sua própria QV. Objetivando minimizar os efeitos do comprometimento cognitivo, a escala utiliza uma linguagem simples, com respostas diretas. É composta de 13 itens quantificados em uma escala de quatro pontos, com a pontuação 1 sendo atribuída à qualificação ruim e a pontuação 4, à excelente. A pontuação total varia de 13 a 52. 
As propriedades de medida dessa escala já foram avaliadas por alguns estudos (Logsdon et al., 1999 e 2002; Thorgrimsen et al., 2003; Hoe et al., 2005; Matsui et al., 2006) onde foram verificadas a confiabilidade e a validade do instrumento. Os resultados destes estudos demonstraram uma alta confiabilidade e validade.

Devido à praticidade de aplicação dessa escala, aos dados apresentados pelos estudos de confiabilidade e validade e por não termos disponível em Português um instrumento de avaliação de QV em demência, esse instrumento foi previamente selecionado para um estudo de adaptação transcultural (Novelli, 2003; Novelli et al., 2005). A conclusão deste estudo foi que a escala traduzida e adaptada para o Português (QdV-DA) mostrou-se de fácil e rápida aplicação, com excelente estabilidade e confiabilidade.

A literatura aponta que a confiabilidade de um instrumento pode ser afetada pela sua validade, mas uma boa confiabilidade não pressupõe um instrumento válido (Menezes e Nascimento, 2000). Neste contexto, a necessidade de verificação da validade da escala traduzida e adaptada justifica a continuidade do estudo. 
2. CONTEXTUALIZANDO DOENÇA DE ALZHEIMER E QUALIDADE DE VIDA. 


\subsection{Doença de Alzheimer}

Um estudo realizado por Herrera et al. (2002) em Catanduva, cidade do interior do estado de São Paulo, identificou prevalência de demência de 1,6\% na faixa etária de 65 a 69 anos, aumentando para 38,9\% nas idades superiores a 84 anos. Refletindo nossa realidade, temos que o índice de prevalência observado foi maior em analfabetos $(12,2 \%)$ contra $3,5 \%$ em idosos com escolaridade igual ou superior a oito anos. Constatou-se também uma maior prevalência de demência em mulheres do que em homens, em uma proporção de 2:1. Em relação às causas de demência nesta população, a DA respondeu por $55,1 \%$ dos casos.

Outro estudo brasileiro, realizado por Montaño et al. (2005) na cidade de São Paulo, também identificou prevalência de demência de 7,1\%, e, da mesma forma, ela aumentou significativamente com a idade e foi mais alta entre indivíduos com baixo nível educacional.

A DA é atualmente reconhecida como um dos maiores problemas de saúde da população idosa (Walker e Salek, 1998). Os critérios diagnósticos de DA propostos por McKhann et al. (1984) (Anexo A) qualificam a DA como provável, possível ou definida e têm ajudado a padronizar a avaliação destes pacientes (Cummings e Mega, 2003). A DA definida preenche os critérios clínicos e é confirmada pelo exame anátomo-patológico. A DA provável refere-se ao déficit de memória com evolução progressiva, associado ao comprometimento de uma ou mais funções cognitivas, como atenção, 
linguagem, habilidades visual-espaciais e construtivas, além de alterações de comportamento, sem outras causas que determinem essa condição. A DA possível apresenta curso atípico ou associação de outros fatores que poderiam causar a demência.

A história natural da DA é variável: o sintoma inicial principal, na maioria das vezes, é a perda de memória, acompanhada por outros sintomas cognitivos e, eventualmente, por alterações de comportamento, desde apatia até delírios, alucinações e agitação/agressividade (Brucki, 2000).

Por apresentar características progressivas, a doença pode ser classificada em três fases - leve, moderada e grave - de acordo com o grau de comprometimento cognitivo e funcional (DSM-III-R) (Anexo B).

Nos estágios iniciais da doença (DA leve), além da dificuldade de memória, podem ocorrer também problemas de atenção, concentração, orientação temporal e espacial, dificuldades visual-espaciais e o aparecimento de sintomas depressivos ou mesmo agitação (Bressan, 2005). O indivíduo passa a apresentar dificuldades para desempenhar algumas atividades instrumentais da vida diária (AIVDs), mas ainda é capaz de realizar atividades básicas (ABVDs), mantendo-se independente (Bottino et al., 2002).

$\mathrm{Na}$ fase intermediária (DA moderada), há comprometimento mais acentuado da memória e das demais funções cognitivas, e o indivíduo geralmente apresenta dificuldades importantes para desempenhar as AIVDs, além de necessitar de suporte para a realização das ABVDs.

Na fase avançada da doença (DA grave), o paciente passa a ter limitações para deambular, necessitando de assistência integral. Neste estágio, podem ocorrer dificuldades de deglutição, mioclonias e crises convulsivas, além de incontinência urinária e fecal (Bottino e Almeida, 1995). 
Com a evolução da doença, a dependência de um cuidador torna-se inevitável. Estudos como os de Pavarini et al. (2000) e de Novelli et al. (2001) têm demonstrado o desgaste físico, emocional, social e até financeiro dos cuidadores/familiares diante da progressão da doença em nosso país.

Avaliar até que ponto as propostas de tratamento disponíveis têm impacto sobre as dificuldades apresentadas no curso da doença e sobre a QV das pessoas envolvidas no processo - pacientes e cuidadores/familiares - é considerado um fator de importância crescente.

\subsection{Aspectos conceituais e metodológicos do constructo de qualidade de vida.}

O conceito QV vem ganhando espaço e se ampliando nos últimos anos. O constructo tem emergido como atributo importante da investigação clínica e da formulação das políticas de saúde. Antes mesmo de o conceito ser incorporado às ciências da saúde, ele era discutido por outras áreas, como economia, ciências sociais e políticas (Paschoal, 2002).

Há diversos indicadores, objetivos e subjetivos, que expressam alguma dimensão da QV (Minayo et al., 2000). Os indicadores objetivos referem-se a aspectos como renda, emprego/desemprego, consumo alimentar, domićlios com saneamento básico, acesso a transporte, disponibilidade de energia elétrica, entre outros (Minayo et al., 2000). Já os de natureza subjetiva se relacionam a como as pessoas se sentem ou o que pensam de suas vidas.

Há inúmeras conceituações de QV e cada indivíduo tem sua própria percepção do que é uma boa QV. Essa percepção é diretamente influenciada pela classe social, por sua cultura e valores, e pode variar em um mesmo indivíduo quando são considerados fatores como o estado emocional, as 
características de personalidade e os fatos vivenciados no cotidiano. Isso reflete o quão abstrato, circunstancial, heterogêneo e dinâmico é este conceito.

A relatividade da definição de $\mathrm{QV}$ tem pelo menos três fóruns de referência:

- Histórico: em determinado tempo, uma sociedade tem um parâmetro de QV diferente da mesma sociedade em outra etapa histórica;

- Cultural: valores e necessidades são construídos e hierarquizados diferentemente pelos povos, revelando suas tradições;

- Estratificações ou classes sociais: a idéia de QV está relacionada ao bemestar das camadas superiores e à passagem de um limiar a outro (Minayo et al., 2000).

Muitos pesquisadores frequentemente se referem à QV, estado de saúde e estado funcional como conceitos similares (Guyatt et al., 1993; Gill e Feinstein, 1994; Smith et al., 1999). A definição de saúde proposta pela Organização Mundial de Saúde (OMS), em que “Saúde não é somente a ausência de doenças, mas um estado de bem-estar físico, mental e social" também serviu como ponto inicial para definir QV (Smith et al., 1999).

Na ausência de um consenso sobre se QV e estado de saúde essencialmente representam o mesmo contructo ou constructos diferentes, Smith et al. (1999) conduziram um estudo de meta-análise que buscou identificar a relação existente entre QV, estado de saúde percebido e três domínios de funcionamento (físico, mental e social). Os resultados mostraram que, a partir da perspectiva do paciente, QV e estado de saúde são domínios diferentes. Quando avaliavam a QV, os pacientes davam grande ênfase ao estado mental, enquanto na avaliação de estado de saúde o funcionamento físico era o aspecto mais importante.

Apesar da dificuldade de se estabelecer uma definição consensual de QV e do fato de os estudos identificarem a utilização de diferentes constructos de forma similar, pontos de concordância entre os pesquisadores parecem 
emergir relacionados à subjetividade, multidimensionalidade e bipolaridade (WHOQOL Group, 1995). A subjetividade ressalta a importância da percepção do indivíduo, permeada por fatores externos presentes no meio em que vive. Em relação à multidimensionalidade, o WHOQOL Group inclui pelo menos três dimensões: física, psicológica e social. Por último, a bipolaridade relacionada às dimensões positivas e negativas do conceito.

Assim, qualquer avaliação de QV deve contemplar todas essas dimensões, enfatizando a percepção do indivíduo sobre elas. Segundo o WHOQOL Group, uma medida de QV deve incluir questões globais a respeito dos comportamentos, estados e capacidades das pessoas e de sua satisfação/insatisfação com esses três aspectos. Esse tipo de avaliação pressupõe um processo interno complexo abrangendo emoções, desejos, julgamento e expectativas.

\subsection{Classificação dos instrumentos de avaliação de qualidade de vida}

Atualmente, existe uma preocupação em traduzir, de forma eficaz, as dimensões de QV em instrumentos de avaliações confiáveis. Vários instrumentos com características diversificadas têm sido criados e testados em suas propriedades psicométricas.

O conhecimento das categorias dos instrumentos, dos propósitos dos diferentes tipos de avaliação e do constructo que permeia a elaboração dos vários instrumentos disponíveis, permite ao pesquisador uma seleção mais adequada de qual instrumento utilizar.

Guyatt et al. (1993) propõem quatro critérios que devem ser considerados na escolha de um instrumento de avaliação de QV:

1. Definir o propósito para o qual o instrumento será usado;

2. Determinar a categoria do instrumento; 
3. Selecionar o formato adequado para o estudo;

4. Avaliar as propriedades psicométricas do instrumento como: confiabilidade, validade, capacidade de resposta e normatização.

Em relação ao campo de aplicação, os instrumentos podem ser classificados como genéricos ou específicos.

Os instrumentos genéricos se propõem a avaliar várias funções e questões de bem-estar independentemente do estado de doença e podem avaliar diversas populações (Devinsky e Cramer, 1997). Para Souza (2004), o instrumento genérico, além de poder ser aplicado em várias populações, nos permite fazer comparações entre grupos de indivíduos com diagnóstico de diferentes afecções ou submetidos a tratamentos distintos. Para Minayo et al. (2000), esses instrumentos são usados como questionários de base populacional sem especificar doenças, sendo mais apropriados a estudos epidemiológicos, planejamentos e avaliação do sistema de saúde.

Alguns exemplos de instrumentos genéricos que possuem versão em Português são:

- Quality of Life Index de Ferrans e Powers (Ferrans e Powers, 1985), traduzido e validado por Kimura (1999).

- Flanagan's Quality of Life (FQOLS) (Flanagan, 1982), traduzido para o Português por Hashimoto et al. (1996) (apud Lentz et al., 2000).

- WHOQOL -100 (WHOQOL Group, 1995; Fleck et al., 1999), o WHOQOL-breve, (WHOQOL, 1998; Fleck et al., 2000) e o WHOQOLOLD (WHOQOL Group, 1998; Fleck et al., 2003; Trentini, 2004), criados dentro de uma perspectiva transcultural.

- The MOS 36-item short-form health survey (SF-36) (Ware e Sherbourne, 1992), traduzido e validado por Ciconelli $(1997,1999)$.

Uma desvantagem na aplicação de instrumentos genéricos em ensaios clínicos é que esses instrumentos são menos sensíveis para detectar mudanças ou respostas às intervenções (Devinsky e Cramer, 1997; Fayers e 
Machin, 2000; Hyland, 2003). Por outro lado, a vantagem no seu uso é a amplitude do instrumento na avaliação do fenômeno QV.

Os instrumentos específicos surgem para medir aspectos selecionados do estado de saúde. Para Devinsky e Cramer (1997) são o único caminho para avaliar o impacto de uma doença sobre a QV do indivíduo, com maior capacidade de detecção de melhora ou de piora de um estado específico. Podem ser direcionados para uma determinada função (capacidade física, sono, função sexual), para uma dada população (idosos, jovens) ou para determinada alteração (dor) (Guyatt, 1995; Paschoal, 2002).

As desvantagens no uso de instrumentos específicos estão associadas: 1. à dificuldade para fazer comparações quando outras afecções ou condições estão presentes, principalmente se essas condições não se associarem ao desenho do instrumento; 2. à dificuldade de compreensão do fenômeno QV no geral; 3. à possibilidade de não considerarem aspectos ou dimensões importantes para a QV do indivíduo, por serem restritos aos domínios de relevância para a doença, para a população ou função. (Guyatt et al., 1993). As vantagens se relacionam à capacidade de detectar particularidades da QV de uma condição específica e a resposta a uma intervenção, característica importante desse tipo de instrumento.

\subsection{Qualidade de vida na demência}

Existem diferentes opiniões sobre o conceito atual de QV, e o problema está em desenvolver uma definição adequada para seu uso em demência, porque a QV nesta situação pode ser influenciada por fatores muito diferentes daqueles observados em indivíduos sem comprometimento cognitivo (Walker e Salek, 1998). Além disso, não é somente a QV do 
paciente que é afetada pelo diagnóstico e pelo tratamento, mas também a QV do cuidador/familiar (Walker e Salek, 1998).

Revisando os conceitos de QV em demência apresentados na literatura vemos citações relacionadas ao modelo teórico de QV para idosos proposto por Lawton (1983), que apresenta quatro domínios inter-relacionados.

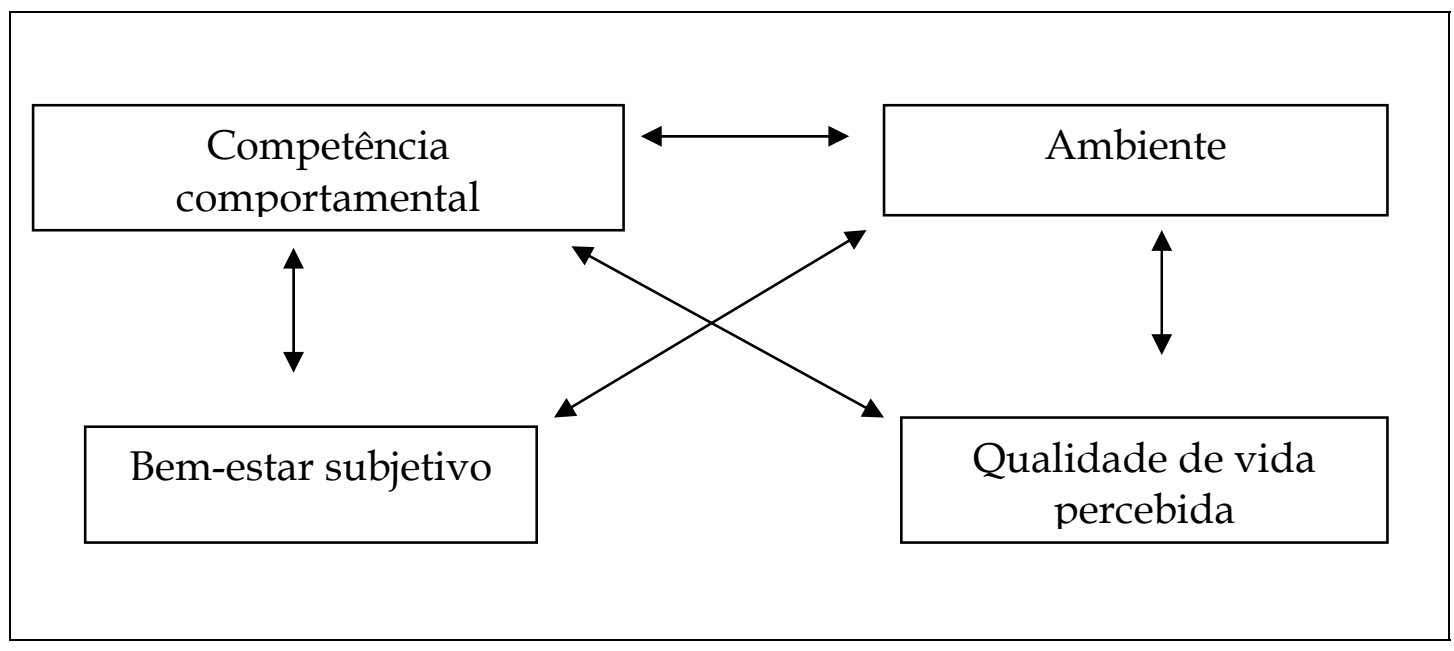

Figura 1- Modelo teórico de Lawton de QV em idosos

O primeiro domínio é a competência comportamental que se relaciona à capacidade do indivíduo de lidar com as diferentes situações de sua vida. $\mathrm{O}$ segundo se relaciona às condições ambientais. $\mathrm{O}$ terceiro reflete a capacidade do indivíduo de avaliar sua QV, denominada QV percebida, baseada na auto-avaliação das condições de vida, incluindo fatores pessoais, sociais e econômicos. E o quarto e último domínio é o bem-estar psicológico, que reflete a satisfação em relação aos aspectos da vida (Lawton, 1983; Logsdon e Albert, 2000). 
Lawton (1997) propõe domínios considerados relevantes para a pessoa com demência, como auto-estima, satisfação com o cuidado de saúde, tempo livre, uso significativo do tempo e engajamento social.

Outra definição de QV, proposta por Birren e Deutchman (apud Logsdon e Albert, 2000), é a de um conceito multidimensional, incluindo questões sociais, ambientais, saúde, estado emocional e aspectos espirituais (religiosidade). Whitehouse e Rabins (1992) acrescentam a essa definição: trabalho, atividades de lazer ou hobbies, habilidade cognitiva, sucesso econômico, bem-estar psicológico e finalizam ressaltando que a QV é determinada pela avaliação do indivíduo sobre a relativa importância de cada um desses fatores.

A definição utilizada no presente estudo é a proposta por esses últimos autores, onde QV é considerada como a integração do funcionamento cognitivo, atividades da vida diária, interação social e do bem-estar psicológico (Whitehouse e Rabins, 1992).

QV tem sido uma área controversa de estudo na demência e na $\mathrm{DA}$, e podemos dizer que se encontra ainda em fase inicial quando comparada a outras áreas da Medicina (Brod et al., 2000; Whitehouse e Rabins, 1992; Whitehouse, 2000; Whitehouse, 2003). Com a disponibilidade de novos tratamentos para melhorar o funcionamento cognitivo, retardar o avanço da doença e tratar os problemas de comportamento, muitos investigadores e clínicos têm reconhecido que, paralelamente à melhora do sintoma específico, é importante também avaliar a extensão na qual a intervenção beneficia a QV do paciente (Guillemin et al., 1993; Whitehouse e Rabins, 1992; Logsdon et al., 1999; Whitehouse, 2000; Logsdon e Albert, 2000; Logsdon et al., 2002).

Em segundo plano, temos que a avaliação de QV pode oferecer uma medida de satisfação com o tratamento e com o cuidado recebidos, tanto por parte do indivíduo como por parte do cuidador/familiar, equivalendo a uma medida de avaliação de consumidor (Whitehouse, 2000). As informações 
obtidas com as avaliações de QV vêm sendo utilizadas nas decisões sobre alocação de recursos na área da saúde (Kimura, 1999).

A QV é uma medida única entre os diversos métodos de avaliação de pacientes com DA, porque inclui o componente subjetivo como aspecto fundamental (Whitehouse, 1992; Walker e Salek, 1998).

Quando nos deparamos com quadros de demência, que reconhecidamente afetam a capacidade do indivíduo de fazer julgamentos e expressar conteúdos subjetivos, a avaliação da QV torna-se uma tarefa difícil. Um dos pontos importantes é a definição do grau de prejuízo cognitivo até o qual o indivíduo é capaz de avaliar sua QV. Atualmente, os estudos de QV na demência têm se concentrado no desenvolvimento de instrumentos acurados de avaliação (Whitehouse, 2000).

As formas comumente utilizadas para avaliar QV em pacientes com demência envolvem múltiplas perspectivas: a do paciente (auto-relato) (Logsdon et al., 1999; Selai et al., 2000), a do familiar e/ou do cuidador formal (proxy) (Rabins et al., 2000; Albert et al., 2000; Sano et al., 2000) e modelos de observação de comportamentos (Lawton et al., 2000; Volicer et al., 2000). Cada uma dessas formas tem seus aspectos positivos e negativos quando do seu uso em idosos com alterações cognitivas e que geralmente estão associados à gravidade da doença da pessoa que está sendo avaliada (Whitehouse et al., 1997).

O auto-relato enfatiza a perspectiva do indivíduo de avaliar suas experiências (Weyerer e Schäufele, 2003). Para que este tipo de avaliação seja útil, é necessário o desenho de medidas que facilitem a resposta do indivíduo a despeito do prejuízo cognitivo (Weyerer e Schäufele, 2003).

Os estudos têm mostrado que nos estágios leves de demência os indivíduos, além de conseguirem avaliar sua QV, também participam da proposição de itens considerados importantes na avaliação (Logsdon e Albert, 2000; Brod et al., 2000). 
Outra abordagem utilizada por alguns pesquisadores (Brod et al., 2000; Selai et al., 2000; Logsdon et al., 1999), tentando minimizar a eventual dificuldade do indivíduo em julgar sua QV, é a avaliação composta pelo relato do paciente e do cuidador/familiar.

Uma forma alternativa de avaliação, utilizada em indivíduos mais comprometidos, é a entrevista exclusiva do familiar/cuidador formal (proxy). Esse tipo de avaliação tem se mostrado como um bom recurso para a obtenção de informações quando estamos diante de pacientes com alterações cognitivas importantes ou com dificuldades de comunicação (Logsdon et al., 1999; Albert et al., 2000).

As limitações dessa forma de avaliação decorrem do fato de o cuidador/familiar utilizar parâmetros pessoais para avaliar a QV do indivíduo, o que gera divergências em relação à opinião dos pacientes (Logsdon et al., 1999; Logsdon et al., 2002). A presença de depressão no cuidador e a sobrecarga de cuidado também influenciam na avaliação de QV do indivíduo afetado (Logsdon et al., 1999; Selai et al., 2000).

Uma última forma de avaliação são os modelos de observação de comportamento propostos para avaliar QV em casos com demência grave e que se baseiam nas reações dos pacientes aos eventos propostos. Essas reações podem ser qualificadas como positivas ou negativas, conforme a expressão facial do indivíduo. Apesar de a capacidade cognitiva e a de comunicação verbal estarem bastante reduzidas nestes pacientes, a habilidade para demonstrar preferências e aversões persiste através da expressão emocional (Lawton et al., 2000; Volicer et al., 2000).

Os métodos combinados, utilizando mais de uma das formas de avaliação de QV descritas, parecem ser os mais adequados. 


\subsection{Caracterização da escala de QV na doença de Alzheimer}

Logsdon et al. (1999) propuseram uma escala de avaliação de QV na DA considerando características importantes de avaliação nesta população (Anexo C).

A escala engloba a versão do paciente (PQOL) e do cuidador/familiar sobre a QV do paciente (C-PQOL) e a versão do cuidador sobre sua própria QV (CQOL). Ela foi desenhada para explorar domínios identificados como importantes, incluindo funcionamento interpessoal, ambiental, físico e psicológico.

Para minimizar o efeito do comprometimento cognitivo advindo da doença, a escala foi estruturada utilizando-se linguagem simples e com respostas diretas. A $Q O L-A D$ foi revista pelos pacientes e cuidadores, assim como por especialistas no campo da Geriatria e Gerontologia, de forma a maximizar a validade de conteúdo e assegurar que os domínios de QV avaliados eram importantes na DA. Isso inclui aspectos relacionados à memória, ao relacionamento do paciente com amigos e família, preocupações relativas a finanças, condição física, humor e uma avaliação global da QV.

O instrumento é composto de 13 itens quantificados em uma escala de quatro pontos, com a pontuação 1 sendo atribuída à qualificação ruim e a pontuação 4, à excelente. A pontuação total varia de 13 a 52. Pontuações separadas podem ser calculadas para os relatos do paciente e do cuidador e esses relatos podem ser combinados em um escore composto, que incorpora a versão do paciente e do cuidador/familiar (Logsdon et al., 1999; 2002). Como o foco da avaliação é o paciente, a pontuação total é calculada pela multiplicação da pontuação obtida com o relato do paciente por 2, somandose os pontos do relato do cuidador/familiar e dividindo-se o resultado por 3 . Essa escala apresenta ainda uma versão que avalia a QV do cuidador/familiar. 
As primeiras informações sobre os dados de confiabilidade e validade do instrumento foram publicadas em 1999 (Logsdon et al., 1999) e a mesma análise, porém com uma amostra ampliada, em 2002 (Logsdon et al., 2002). As respostas de 77 pacientes inicialmente e, posteriormente, de 177 pacientes e de seus cuidadores, foram utilizadas como base para estimar as propriedades do instrumento. A confiabilidade da $Q O L-A D$, analisada através do coeficiente alfa de Cronbach, obteve índices de consistência de 0,88 e 0,89 para o relato do paciente e do cuidador, respectivamente. No relato do cuidador sobre sua $Q V$, o índice de consistência interna foi de 0,89 (Logsdon, comunicação pessoal).

O estudo correlacionou os relatos do paciente e do cuidador em cada item do $Q O L-A D$ e na pontuação total. Os resultados dessa correlação demonstraram uma concordância razoavelmente boa entre os relatos do paciente e do cuidador nos itens: humor $(r=0,40, p<0,001)$, disposição $(r=0,45, p<0,001)$, saúde física $(r=0,35, p<0,01)$, família $(r=0,24, p<0,05$ amigos $(r=0,26, p<0,05)$, "você em geral" $(r=0,31, p<0,01)$, dinheiro $(r=0,29$, $p<0,01)$ e "vida em geral" $(r=0,22, p<0,05)$, enquanto que nos itens mais afetados pela demência, como memória e habilidade para fazer tarefas, a correlação foi baixa. Na pontuação total, a concordância foi adequada, com um coeficiente de correlação de 0,40 (p<0,001).

No teste-reteste foram avaliados 30 pacientes e seus respectivos cuidadores com uma semana de intervalo, e o coeficiente de correlação (ICC) foi de 0,76 para os pacientes e de 0,92 para os cuidadores/familiares.

$\mathrm{Na}$ avaliação da validade da escala a versão PQOL apresentou correlações significativas com Mini-exame do Estado Mental (MEEM) $(r=0,24, p<0,05)$, ABVDs $(r=-0,33, p<0,01)$, sintomas depressivos apresentados pelo paciente (Escala de Depressão Geriátrica $(r=-0,40, p<0,001)$ e Escala de Depressão de Hamilton $(r=-0,43, p<0,001)$ e eventos prazerosos $(r=0,30$, $p<0,01)$. 
A versão C-PQOL apresentou correlações com ABVDs $(r=-0,32, p<0,01)$, sintomas depressivos apresentados pelo paciente (Escala de Depressão Geriátrica $(r=-0,57, p<0,001)$ e Escala de Depressão de Hamilton $(r=-0,25$, $p<0,05))$, eventos prazerosos $(r=0,41, p<0,001)$ e sintomas depressivos apresentados pelo cuidador $(r=-0,23, p<0,05)$.

Na pontuação composta, as correlações encontradas foram com ABVDs $(r=-0,37, p<0,001)$, sintomas depressivos apresentados pelo paciente (Escala de Depressão Geriátrica $(r=-0,49, p<0,001)$ e Escala de Depressão de Hamilton $(r=-0,43, p<0,001))$ e eventos prazerosos $(r=0,40, p<0,001)$.

O tempo de aplicação da avaliação foi de cinco minutos para o cuidador e de dez minutos para o paciente.

Outro estudo, conduzido por Thorgrimsen et al. (2003), avaliou a confiabilidade e a validade da escala $Q O L-A D$. Foram utilizados grupos focais de pacientes e cuidadores, e o resultado indicou que nenhum item adicional era requerido e que todos os itens do instrumento foram considerados importantes. A validade de critério foi obtida pela correlação da escala QOL-AD com dois outros instrumentos de avaliação de QV Euroqol-5D scale $(0,54)$ e o $D-Q O L(0,69)$. A validade convergente e divergente foi obtida pela correlação com o $\operatorname{MEEM}(-0,09)$ e com a Escala de Depressão de Cornell $(-0,20)$. A consistência interna foi de 0,82, utilizando-se o coeficiente alfa de Cronbach.

Hoe et al. (2005) avaliaram a utilidade da escala QOL-AD em pessoas com demência grave (MEEM < 12) e em seus cuidadores, assim como a validade de constructo e a consistência interna. A consistência interna da escala, neste estudo, foi de 0,78 , e todos os itens obtiveram uma correlação que variou de 0,35 a 0,81 com a pontuação total. Na avaliação da validade de constructo, a escala $Q O L-A D$ foi correlacionada com instrumentos para medir cognição (MEEM), alterações de comportamento (Inventário Neuropsiquiátrico - INP), humor (Escala de Cornell para depressão e Escala de depressão e ansiedade (HADS), desempenho funcional (ADCS-ADL) e 
um questionário genérico derivado do SF-36 (HSQ-12). As correlações encontradas na validade de constructo foram com apatia $(-0,39)$, desempenho funcional $(0,55)$, domínio saúde mental (HSQ-12; 0,58) e com papel físico (HSQ-12; 0,48). A conclusão do estudo foi que a escala QOL-AD é um instrumento válido e confiável para avaliar QV em indivíduos com DA grave.

Matsui et al. (2006) verificaram a confiabilidade da versão em Japonês da QOL-AD e constataram que a escala apresentou boa consistência interna com coeficientes alfa de Cronbach de 0,84 para a versão do paciente e de 0,82 para a versão do cuidador sobre a QV do paciente. A correlação entre os relatos dos pacientes e dos cuidadores foi moderada, com um coeficiente de 0,60. A confiabilidade teste-reteste foi avaliada utilizando-se o coeficiente intraclasse, e os valores foram de 0,84 para a versão do paciente e de 0,91 para os relatos dos cuidadores.

Devido às características de estabilidade, confiabilidade, validade e por ser uma escala de fácil e rápida aplicação, a escala $Q O L-A D$ foi anteriormente selecionada para um estudo de tradução e de adaptação transcultural para uso no Brasil, devidamente autorizado pela autora (Anexo D).

A escala foi traduzida e adaptada para nosso meio, seguindo uma metodologia rigorosa (Guillemin et al., 1993; Guyatt et al., 1993), que incluiu a tradução e a retrotradução feita por dois tradutores independentes seguida da avaliação de equivalências semântica, idiomática, cultural e conceitual da versão traduzida realizada por um comitê de especialistas. Foram também avaliadas a confiabilidade e a reprodutibilidade do instrumento (Novelli, 2003; Novelli et al., 2005).

A versão final, traduzida e adaptada, foi administrada a uma amostra de 40 pacientes com DA provável, sendo 20 pacientes com DA leve e 20 com DA moderada e a seus cuidadores/familiares. A estabilidade da escala foi avaliada através do teste-reteste intra-examinador $(n=17)$ e interexaminador $(n=13)$, com intervalo de duas semanas. A aplicação mostrou-se fácil e rápida 
(média de seis minutos para a avaliação do paciente e de cinco minutos para a do cuidador/familiar). A estabilidade do instrumento foi excelente, tanto na avaliação intra-examinador quanto na interexaminador, e, da mesma forma foi bastante elevada a sua confiabilidade.

Existe consenso na literatura de que a validade de uma medida é limitada pela confiabilidade, mas uma alta confiabilidade não é suficiente para garantir a validade (Menezes e Nascimento, 2000). Apesar de a escala adaptada ter apresentado alta confiabilidade, as propriedades relacionadas à sua validade não foram verificadas, justificando-se assim a continuidade do estudo. 
3. ETAPAS DE VALIDAÇÃO DE UMA ESCALA DE AVALIAÇÃO 
Em sua proposta, Guillemin (1993) aponta que existem controvérsias em relação à verificação das propriedades de medida do instrumento adaptado. A controvérsia emerge de duas correntes de pensamento: uma que pressupõe que uma equivalência transcultural adequada e corretamente conduzida traz consigo as propriedades de medida do instrumento original e uma outra que defende a idéia de que, em decorrência do processo de adaptação, o instrumento traduzido possui propriedades de medidas desconhecidas na cultura para a qual foi adaptado.

Por acreditarmos que o processo de tradução e adaptação de um instrumento possa influenciar as propriedades de medida da versão adaptada, optamos por verificar as propriedades psicométricas da escala $Q O L-A D$, que em Português passou a se chamar QdV-DA.

\subsection{Propriedades de medida de uma escala de avaliação}

Na avaliação das propriedades de medida do instrumento adaptado, Guillemin (1993) propõe a avaliação da confiabilidade e da validade.

O Scientific Advisory Committee of Medical Outcomes Trust (SAC) foi criado para identificar instrumentos de estado de saúde e de QV e revisá-los segundo um critério rigoroso (SAC, 2002). Na proposta do SAC, oito atributos servem de foco principal para essa revisão: o modelo conceitual e de avaliação, a confiabilidade, a validade, a capacidade de resposta, a interpretação, a responsabilidade do respondente e do administrador, os 
modos alternativos de administração e as adaptações culturais e de linguagem ou traduções. Para cada um desses atributos são propostos critérios de revisão.

O modelo conceitual e de avaliação é baseado no raciocínio e na descrição da teoria utilizada para a estruturação do instrumento, na identificação da população para a qual a medida foi criada e na relação entre esses aspectos. Os critérios de revisão propostos envolvem a definição do conceito a ser mensurado, as bases empíricas para os conteúdos e combinações dos itens, a caracterização da população-alvo e informações sobre a dimensionalidade da escala, entre outros.

Outro atributo é a confiabilidade, que se refere à reprodutibilidade de uma medida, e os critérios propostos envolvem a avaliação da consistência interna e da reprodutibilidade do instrumento ao longo do tempo.

A validade é definida pelo grau com que o instrumento mede o que se propõe a medir e pode ser dividida em validade de conteúdo, de constructo e de critério.

A capacidade do instrumento de detectar mudanças ao longo do tempo é outro atributo importante quando os estudos propõem o acompanhamento do indivíduo; isso é denominado de capacidade de resposta, que alguns pesquisadores chamam de sensibilidade (Fletcher et al., 1996; Herndon, 1997). É verificada pela evidência de mudanças nas pontuações do instrumento ou pela informação longitudinal, que compara um grupo para o qual são esperadas mudanças com um grupo que permanece estável.

A interpretação associa-se ao grau com que a pontuação do instrumento pode ser facilmente entendida. Os critérios de revisão propostos se referem às informações sobre como os resultados podem ser relatados e utilizados.

A responsabilidade associa-se ao tempo utilizado na administração do instrumento, o efeito que essa administração causa nas pessoas envolvidas e outras demandas colocadas sobre o indivíduo avaliado (responsabilidade do respondente) ou sobre o examinador (responsabilidade na administração). 
Em relação à responsabilidade do respondente, os critérios de revisão se relacionam às informações sobre o tempo necessário para completar o instrumento, nível de compreensão e de leitura exigido do respondente. Outros critérios são considerados, como o peso físico e emocional e em quais circunstâncias o instrumento não é conveniente para o respondente. $\mathrm{Na}$ responsabilidade pela administração, os critérios de revisão sugeridos envolvem as informações sobre qualquer recurso requerido para a administração do instrumento, como nível de educação e/ou experiência prévia.

Nas alternativas de administração, diferentes formas de aplicação são utilizadas, como auto-relato, entrevista e pontuação através do treino observado. Os critérios utilizados são a evidência de confiabilidade, validade, resposta, interpretação e responsabilidade para cada modelo de administração.

Em relação às adaptações culturais e de linguagem, o atributo envolve dois passos: um que consiste na avaliação da equivalência conceitual e lingüística e outro, na avaliação das propriedades de medida do instrumento. Os critérios de revisão propostos equivalem a métodos para assegurar a equivalência conceitual e lingüística.

\subsubsection{Fidedignidade de um instrumento de medida}

À fidedignidade são dados alguns sinônimos, como precisão e confiabilidade (Fletcher et al., 1996; Duarte, 2001). O termo confiabilidade é utilizado para se referir à reprodutibilidade de uma medida (Guillemin, 1995; Hulley e Cummings, 1998; Menezes e Nascimento, 2000; Hulley et al., 2003).

Segundo Fletcher et al. (1996), confiabilidade (fidedignidade, reprodutibilidade ou precisão) é a extensão com que medidas de um fenômeno 
estável - repetidas por pessoas e instrumentos diferentes em momentos e lugares diferentes - alcançam resultados semelhantes.

Segundo Kimura (1999), a confiabilidade é a primeira característica que um instrumento deve possuir e é usualmente estimada pelo uso dos seguintes procedimentos: teste-reteste (intra e interexaminador) e avaliação de consistência interna.

\subsubsection{Consistência Interna}

A consistência interna é uma forma de medir a confiabilidade do instrumento eliminando a influência da separação temporal e de estimar a confiabilidade a partir de uma única administração do teste (Polgar, 2002).

Para uma escala que contém múltiplos itens, todos eles deveriam ser consistentes e deveriam todos medir a mesma variável. Essa forma de confiabilidade é chamada de confiabilidade interna e é avaliada pela consistência interna (Fayers e Machin, 2000). O processo consiste na verificação da correlação dos itens de um instrumento entre si e com a pontuação total, na expectativa de que apresentem uma congruência entre eles, uma vez que medem o mesmo fenômeno. Essa verificação é comumente feita pela utilização do coeficiente alfa de Cronbach.

Segundo Gifford e Cummings (1999), valores de alfa de Cronbach > 0,8 são considerados excelentes - superiores a 0,7 são considerados bons e menores que 0,4 , ruins.

Ressaltamos que, apesar de a validade de um instrumento sofrer influência da confiabilidade, para os pesquisadores uma alta confiabilidade não pressupõe necessariamente um instrumento válido (Guillemin, 1995; Hulley e Cummings, 1998; Menezes e Nascimento, 2000; Hulley et al., 2003). 


\subsection{Validade de um instrumento}

A validade é a segunda característica relacionada às propriedades de medida a ser analisada (Duarte, 2001). É definida como a extensão na qual um instrumento mede o que se propõe a medir (Guillemin, 1995; Hernodon, 1997; Hulley e Cummings, 1998; Menezes e Nascimento, 2000; Fayers e Machin, 2000; Hulley et al., 2003). Segundo Pasqualli (1996), é a demonstração da adequação (legitimidade) do instrumento com o que ele diz medir.

A validade envolve um componente conceitual e um componente operacional. O componente conceitual refere-se ao julgamento, por parte do pesquisador, sobre se o instrumento mede o que deveria medir. A validade operacional envolve uma avaliação sistemática do instrumento, geralmente comparando com um critério considerado "padrão-ouro" (Menezes e Nascimento, 2000; Hulley et al., 2003). O "padrão-ouro" seria uma maneira, já estabelecida como válida, para avaliar o fenômeno que o instrumento em fase de validação também pretende mensurar (Menezes e Nascimento, 2000). Existem três tipos de validades operacionais: validade de conteúdo, de critério e de constructo (Fletcher et al., 1996; Pasqualli, 1996; Fayers e Machin, 2000; Menezes e Nascimento, 2000; Hulley et al., 2003).

\subsubsection{Validade de conteúdo}

A validade de conteúdo refere-se ao julgamento sobre se o instrumento realmente cobre os diferentes aspectos do que se pretende mensurar (Menezes e Nascimento, 2000). Fayers e Machin (2000) propõem uma outra definição, que é relativa à extensão na qual os itens são sensíveis e refletem os domínios de interesse. Essa validação de conteúdo envolve um exame crítico 
da estrutura básica do instrumento e uma revisão dos procedimentos usados no desenvolvimento do questionário. Não há procedimentos estatísticos para estabelecer validade de conteúdo (Menezes e Nascimento, 2000; Polgar, 2002). As etapas iniciais no estabelecimento desta validade ocorrem quando o conteúdo do teste é definido durante o desenvolvimento do teste (SAC, 2002; Polgar, 2002). Menezes e Nascimento (2000) e Polgar (2002) apontam que essa avaliação é feita por meio de consenso entre especialistas e/ou pesquisadores da área. Aspectos fundamentais da validade de conteúdo incluem a adequação e abrangência dos itens e a forma como os itens avaliam a variável de interesse (Paschoal, 2000).

\subsubsection{Validade de critério}

A validade de critério descreve a relação empírica entre uma medida e um critério confiável denominado "padrão-ouro", tais como outros instrumentos ou qualquer tipo de indicador que determine uma situação como verdadeira (Pachoal, 2000; Fayers e Machin, 2000; Duarte, 2001; SAC, 2002; Hulley et al., 2003). Para Pasqualli (1996) é o grau de eficácia de um teste em predizer o desempenho específico de um indivíduo. É essencial que esse critério externo tenha propriedades psicométricas bem estabelecidas (Polgar 2002). Essa validade pode ser dividida em validade concorrente (congruente e concomitante) e validade preditiva (Fayers e Machin, 2000).

A validade concorrente (congruente e concomitante) compara os valores obtidos com um instrumento ou procedimento com os valores obtidos com outro instrumento ou procedimento (Paschoal, 2000; Fayers e Machin, 2000; Duarte, 2001). 
A validade preditiva se refere à habilidade do instrumento em predizer o futuro estado de saúde, futuros eventos ou futuros resultados de um indivíduo (Paschoal, 2000; Fayers e Machin, 2000; Duarte, 2001).

Em geral a validade de critério é estimada estatisticamente e é expressa por meio de sua sensibilidade (proporção de casos positivos identificados corretamente) e especificidade (proporção de casos negativos identificados corretamente) (Fletcher et al., 1996; Menezes e Nascimento, 2000). A preferência por privilegiar a sensibilidade ou a especificidade vai depender dos objetivos do estudo.

Como não há disponível um "padrão-ouro" para avaliar QV em demência e, mais especificamente, na DA, ainda não é possível avaliar a validade de critério (Walker e Salek, 1998). A validade de constructo, nessas situações, é o postulado comumente utilizado.

\subsubsection{Validade de constructo}

A validade de constructo é uma das mais importantes propriedades do instrumento (Fayers e Machin, 2000). Essa validade é a mais difícil de ser medida, e uma das formas de avaliá-la é através da análise por hipóteses (Pasquali, 1996; Paschoal, 2000).

Para Hulley et al. (2003), validade de constructo é a capacidade de uma medida se encaixar dentro de uma concepção teórica (constructo) sobre o fenômeno em estudo.

A validade de constructo envolve inicialmente a formação de um modelo teórico, descrevendo os constructos que serão avaliados e postulando suas relações (Fayers e Machin, 2000). Os dados são coletados e a avaliação é feita através do grau com que as relações hipotetizadas são confirmadas. 
Dois aspectos da validade de constructo são as validades convergente e discriminante.

A validade convergente-discriminante parte do princípio de que, para demonstrar a validade de constructo de um teste, é preciso determinar duas coisas: 1) o teste deve se correlacionar significativamente com outras variáveis com as quais o constructo medido pelo teste deveria, pela teoria, estar relacionado (validade convergente); e 2) não se correlacionar com variáveis das quais ele teoricamente deveria diferir (validade discriminante). (Pasqualli, 1996).

Nos estudos de Paschoal (2000) e Duarte (2001), a validade discriminante avalia o grau com que um instrumento discrimina indivíduos que diferem em relação ao que está sendo avaliado.

A validade de constructo de instrumentos de avaliação de QV em demência é feita pela comparação da escala ou instrumento de avaliação de QV com outras formas de avaliação comumente utilizadas. Espera-se que alguns fatores (medidas cognitivas, funcionais, de estados depressivos, alterações de comportamento, entre outros) devam apresentar associação muito forte com os resultados de QV (Walker e Salek, 1998; Logsdon et al., 1999; Logsdon et al., 2002; Thorgrimsen et al., 2003; Logsdon et al., 2004). 
4. OBJETIVOS 


\subsection{Geral}

1. Verificar a confiabilidade e validade da escala QdV-DA, por meio de sua aplicação em uma amostra de pacientes com DA provável e seus respectivos cuidadores/familiares.

\subsection{Específicos}

1. Avaliar a confiabilidade, através da consistência interna, da escala QdV-DA em suas três versões (PQdV, C-PQdV e CQdV).

2. Verificar a validade de constructo da escala QdV-DA em suas três versões (PQdV, C-PQdV e CQdV) e em sua versão composta, correlacionando os resultados obtidos nesta aplicação com outras medidas de avaliação dos pacientes e dos cuidadores.

3. Verificar a validade de constructo (validade convergente) da escala QdV-DA em suas três versões (PQdV, C-PQdV e CQdV), correlacionando os resultados obtidos nesta aplicação com resultados da aplicação de um instrumento genérico de QV (WHOQOL-breve).

4. Avaliar o impacto do comprometimento cognitivo sobre a confiabilidade e validade da escala QdV-DA. 
5. Comparar os dados obtidos na avaliação de QV a partir dos relatos dos pacientes (PQdV) e dos cuidadores/familiares (C-PQdV). sobre a QV do paciente.

6. Avaliar a influência de fatores demográficos (idade, gênero e escolaridade) sobre a QV dos pacientes e dos cuidadores/familiares. 
5. MÉTODOS 


\subsection{Caracterização do local e do período do estudo}

O estudo foi realizado no Ambulatório de Neurologia Cognitiva e do Comportamento da Divisão de Clínica Neurológica do Hospital das Clínicas da Faculdade de Medicina da Universidade de São Paulo (HCFMUSP).

A coleta de dados foi realizada no período de janeiro a dezembro de 2004, após a aprovação do estudo pelo Comitê de Ética para Análise de Projetos de Pesquisa da Faculdade de Medicina da Universidade de São Paulo (Anexo E).

\subsection{Casuística}

O estudo incluiu a participação de dois grupos populacionais, selecionados de forma aleatória dentre a população atendida no serviço especificado anteriormente. O primeiro grupo, denominado "pacientes", constituído por indivíduos com o diagnóstico de DA provável, segundo os critérios do NINCDS-ADRDA (McKhann et al., 1984), e gravidade de demência variando de leve a moderada, segundo os critérios do DSM-III-R (American Psychiatric Association, 1987). O segundo grupo populacional, denominado "cuidadores/familiares", foi composto pelos respectivos cuidadores/familiares responsáveis pelos pacientes do primeiro grupo. 
Os critérios de inclusão no estudo foram:

1. Os pacientes deveriam ter diagnóstico de DA provável, de acordo com os critérios do NINCDS-ADRDA (McKhann et al., 1994), com gravidade leve a moderada, segundo os critérios do DSM-III-R (American Psychiatric Association, 1987) e a pontuação no MEEM (Folstein e McHugh, 1975; Bertolucci et al., 1994; Brucki et al., 2003);

2. Ter idade de 60 anos ou mais;

3. Ter a presença de um cuidador/familiar. Este estudo considerou como cuidador, o familiar responsável pela assistência ao paciente que tivesse um contato mínimo de 24 horas semanais com ele, visando à coleta de informações fidedignas em relação ao estado do paciente;

4. Não poderiam apresentar comprometimento grave de linguagem baseado em avaliação fonoaudiológica e pelo pesquisador no momento da entrevista, através da observação da compreensão e expressão de idéias;

5. Aceitar participar do estudo, assinando o termo de consentimento livre e esclarecido (Anexo F).

Vale ressaltar que todos os pacientes que participaram do estudo foram avaliados por uma equipe de profissionais composta por médicos, neuropsicólogos e fonoaudiólogos visando o estabelecimento do diagnóstico e da gravidade da doença segundo os critérios citados acima.

Em relação aos aspectos éticos, o estudo foi devidamente aprovado pelo Comitê de Ética e Pesquisa do HCFMUSP. Todos os participantes foram informados dos objetivos do trabalho, consultados sobre a sua disposição em participar, assegurados do sigilo das informações obtidas e da continuidade do tratamento caso desistissem de participar do estudo, após o que foi assinado o termo de consentimento. 
Foram avaliados neste período 60 pacientes e seus respectivos cuidadores/familiares, que preencheram os critérios de inclusão e foram submetidos ao mesmo protocolo de avaliação.

\subsection{Constituição das amostras}

Para a realização deste estudo foram utilizadas duas amostras para coleta de dados. A primeira constituída por 120 indivíduos, subdivididos em três grupos distintos:

Grupo I: Trinta pacientes com DA provável, com grau leve de demência, atendidos no Ambulatório de Neurologia Cognitiva e do Comportamento da Divisão de Clínica Neurológica do HCFMUSP.

Grupo II: Trinta pacientes com DA provável, com grau moderado de demência, atendidos no Ambulatório de Neurologia Cognitiva e do Comportamento da Divisão de Clínica Neurológica do HCFMUSP.

Grupo III: Sessenta cuidadores/familiares dos pacientes dos grupos I e II.

A segunda amostra, selecionada aleatoriamente a partir da primeira amostra, foi constituída de 10 pacientes com DA provável com intensidade leve e seus respectivos cuidadores/familiares, e um outro grupo de 10 pacientes com DA provável com intensidade moderada e seus respectivos cuidadores/familiares. O quadro 1 ilustra a composição das amostras. 
Quadro 1: Esquema de constituição das amostras

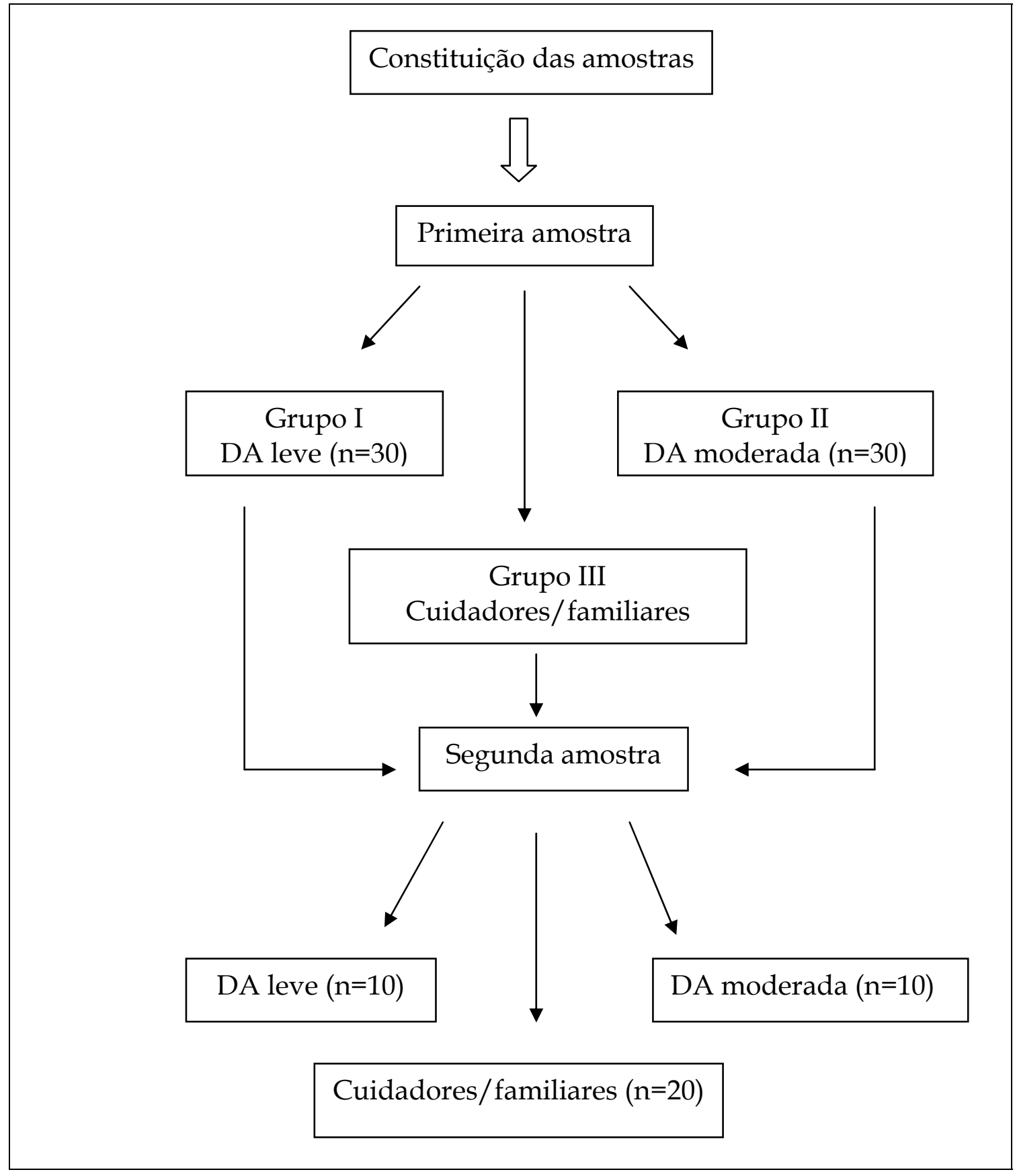


Na primeira amostra foram coletados os dados relativos à confiabilidade e validade do instrumento: consistência interna e validade de constructo. $\mathrm{Na}$ segunda amostra, foram coletados os dados relativos à validade de constructo (validade convergente) comparando-se a escala de qualidade de vida (QdV-DA) com um instrumento genérico de avaliação de QV (WHOQOL-breve).

Os grupos de pacientes leves e moderados foram emparelhados para as variáveis idade, gênero e escolaridade, resultando em uma correspondência de $86,66 \%$ na amostra total, sem diferença estatística entre os grupos em relação à distribuição dessas variáveis sociodemográficas.

\subsection{Caracterização dos grupos}

Os resultados obtidos foram agrupados segundo as variáveis sociodemográficas (faixa etária, escolaridade e gênero), e distribuídos por gravidade da doença. As características sociodemográficas de cada grupo serão apresentadas a seguir.

Tabela 1 - Perfil sociodemográfico dos participantes dos Grupos I e II

\begin{tabular}{lcc}
\hline $\begin{array}{c}\text { Variáveis } \\
\text { sociodemográficas }\end{array}$ & $\begin{array}{c}\text { Grupo I } \\
\text { (DA leve; }(\mathbf{n}=\mathbf{3 0}))\end{array}$ & $\begin{array}{c}\text { Grupo II } \\
\text { (DA moderada; (n=30)) }\end{array}$ \\
\hline Idade & $75,5^{\mathrm{a}} \pm 6,7^{\mathrm{b}}$ & $76,2^{\mathrm{a}} \pm 6,2^{\mathrm{b}}$ \\
Gênero & Fem $-73,3 \%$ & Fem $-66,7 \%$ \\
& Masc $-26,7 \%$ & Masc $-33,3 \%$ \\
Escolaridade & $6,5^{\mathrm{a}} \pm 4,3^{\mathrm{b}}$ & $6,0^{\mathrm{a}} \pm 4,3^{\mathrm{b}}$ \\
\hline
\end{tabular}

a Médias

b Desvios-padrão 
A idade dos pacientes do Grupo I variou de 58 a 86 anos e de 64 a 89 anos no Grupo II. A escolaridade nos Grupos I e II variou de 1 a 15 anos, com predominância do sexo feminino em ambos os grupos.

No Grupo III há uma diferenciação nas variáveis sociodemográficas, pois nos referimos ao perfil sociodemográfico dos cuidadores/familiares distribuídos em função da gravidade da doença. As variáveis sociodemográficas são as mesmas dos grupos anteriores acrescentando o grau de parentesco com o paciente. A Tabela 2 apresenta esses resultados.

Tabela 2 - Perfil sociodemográfico dos participantes do grupo III

\begin{tabular}{lcc}
\hline $\begin{array}{c}\text { Variáveis } \\
\text { sociodemográficas }\end{array}$ & $\begin{array}{c}\text { Cuidadores de pacientes } \\
\text { com DA leve }(\mathbf{n}=30)\end{array}$ & $\begin{array}{c}\text { Cuidadores de pacientes } \\
\text { com DA moderada (n=30) }\end{array}$ \\
\hline Idade & $59,5^{\mathrm{a}} \pm 15,4^{\mathrm{b}}$ & $60,1^{\mathrm{a}} \pm 14,5^{\mathrm{b}}$ \\
Gênero & Fem $-80,0 \%$ & Fem $-66,7 \%$ \\
Escolaridade & Masc $-20,0 \%$ & Masc $-33,3 \%$ \\
Grau de parentesco & $10,0^{\mathrm{a}} \pm 4,4 \mathrm{~b}$ & $9,1^{\mathrm{a}} \pm 4,0 \mathrm{~b}$ \\
& Esposa $-20,0 \%$ & Esposa $-30,0 \%$ \\
& Irmã $-20,0 \%$ & Irmã $-6,7 \%$ \\
& Filha $-36,7 \%$ & Filha $-30,0 \%$ \\
& Marido $-16,7 \%$ & Marido $-16,7 \%$ \\
& Filho - 3,3\% & Filho $-13,3 \%$ \\
& Neta $-3,3 \%$ & Neto $-3,3 \%$ \\
\hline
\end{tabular}

a Médias

b Desvios-padrão

A idade dos cuidadores de pacientes com DA leve variou de 27 a 80 anos e nos cuidadores de pacientes com DA moderada, de 35 a 78 anos. A escolaridade dos cuidadores de pacientes com DA leve variou de 1 a 15 anos e no Grupo II, de 3 a 15 anos. Observamos nos dois grupos de cuidadores uma predominância de pessoas do sexo feminino. 
O grau de parentesco dos cuidadores com os pacientes indica que, na sua grande maioria, são parentes de primeiro grau, havendo uma diferenciação nas porcentagens de distribuição.

Essa caracterização da amostra nos permite conhecer o perfil sociodemográfico da população incluída na avaliação das propriedades de medida da escala QdV-DA.

\subsection{Caracterização dos instrumentos utilizados}

Com base nos objetivos do estudo e visando à coleta de informações para posterior análise, foram utilizados os seguintes instrumentos:

a) Caracterização da amostra de pacientes (Anexo G) - contém dados de identificação do paciente (nome, data de nascimento, endereço e telefone para contato), informações sociodemográficas (gênero, escolaridade, profissão e tempo de aposentadoria), dados sobre a família (grau de parentesco com o cuidador).

b) Caracterização da amostra de cuidadores (Anexo H) - contém dados de identificação e variáveis sociodemográficas dos cuidadores (nome, idade, gênero, endereço, telefone para contato e escolaridade).

c) Escala QdV-DA (Logsdon et al., 1999, 2002; Novelli, 2003; Novelli et al., 2005) (Anexo C) - escala desenvolvida para avaliar QV na DA. Apresenta três versões de avaliação de QV (PQdV, C-PQdV e CQdV). A pontuação varia de 13 a 52 pontos - pontuações mais altas predizem melhor QV.

d) MEEM (Folstein e McHugh, 1975; Bertolucci et al., 1994; Brucki et al., 2003) (Anexo I) - teste de rastreio de comprometimento cognitivo 
amplamente utilizado e que fornece uma pontuação total que varia de 0 a 30 pontos; pontuações mais baixas indicam pior desempenho.

e) Escala de Automanutenção Física e Instrumental (AVDs) (Lawton, 1969) (Anexo J) - escala que avalia o desempenho em ABVDs, tais como banho, higiene pessoal, alimentação e vestuário, e em AIVDs, tais como compras, transporte, uso de medicamentos e gerenciamento da casa; pontuações mais altas indicam pior desempenho funcional.

f) Inventário Neuropsiquiátrico (INP) (Cummings, 1994) (Anexo K) tem por objetivo avaliar as alterações de comportamento presentes no paciente, quantificando a freqüência e a intensidade dos sintomas apresentados, bem como o grau de desgaste que proporcionam no cuidador - pontuações mais altas indicam maior comprometimento neuropsiquiátrico.

g) Escala de Depressão Geriátrica (GDS) (Yesavage et al.; 1983; Almeida e Almeida, 1999) (Anexo L) - escala com 30 itens, útil e confiável para avaliar sintomas depressivos em idosos - pontuações mais altas indicam humor deprimido.

h) Escala de Depressão de Cornell (Alexopoulos et al., 1988, Alexopoulos e Chester, 1992; Carthery et al., 2003) (Anexo M) - é um instrumento que foi desenvolvido para avaliar sintomas depressivos em idosos com demência - pontuações mais altas indicam humor deprimido.

i) Classificação socioeconômica (Graciano et al., 1999) (Anexo N) - avalia o nível socioeconômico do indivíduo.

j) Inventário de Depressão de Beck (Beck et al., 1961 e 1988; Gorenstein e Andrade, 2000) (Anexo O) - é uma medida de auto-avaliação de depressão, amplamente utilizada em pesquisas clínicas, em que pontuações mais altas indicam humor deprimido. 
k) Instrumento abreviado de avaliação da QV (WHOQOL-breve) (WHOQOL Group, 1998; Fleck et al., 2000) (Anexo P) - instrumento genérico de avaliação de QV criado através de uma proposta transcultural, com 26 questões; pontuações mais altas indicam melhor QV.

Os pacientes dos grupos I e II responderam à escala de QV (PQdV) por meio de entrevista e os cuidadores dos pacientes, de ambos os grupos, responderam à escala de QV (C-PQdV e CQdV) no formato de questionário auto-administrado.

O MEEM e a GDS foram administrados aos pacientes conjuntamente com a escala QdV-DA.

As escalas que avaliam o desempenho funcional dos pacientes, a presença de alterações de comportamento, sintomas depressivos e nível socioeconômico foram respondidas pelo cuidador/familiar.

Os cuidadores, além das informações pertinentes aos pacientes, responderam também à escala de QdV-DA $(\mathrm{CQdV})$ e ao Inventário de Depressão de Beck no formato de questionário auto-administrado.

\subsection{Avaliação das propriedades de medida da escala QdV-DA}

Dentre as propriedades de medida da escala QdV-DA que foram analisadas, temos:

- Consistência interna;

- Validade de constructo; 


\subsubsection{Consistência Interna}

Para a avaliação da consistência interna, da escala QdV-DA, foi utilizada a amostra total de 120 indivíduos. O coeficiente alfa de Cronbach foi utilizado na avaliação da confiabilidade das três versões da escala QdV-DA. O Quadro 2 apresenta o esquema utilizado na avaliação da consistência interna da QdV-DA.

Quadro 2: Esquema de verificação da consistência interna da QdV-DA

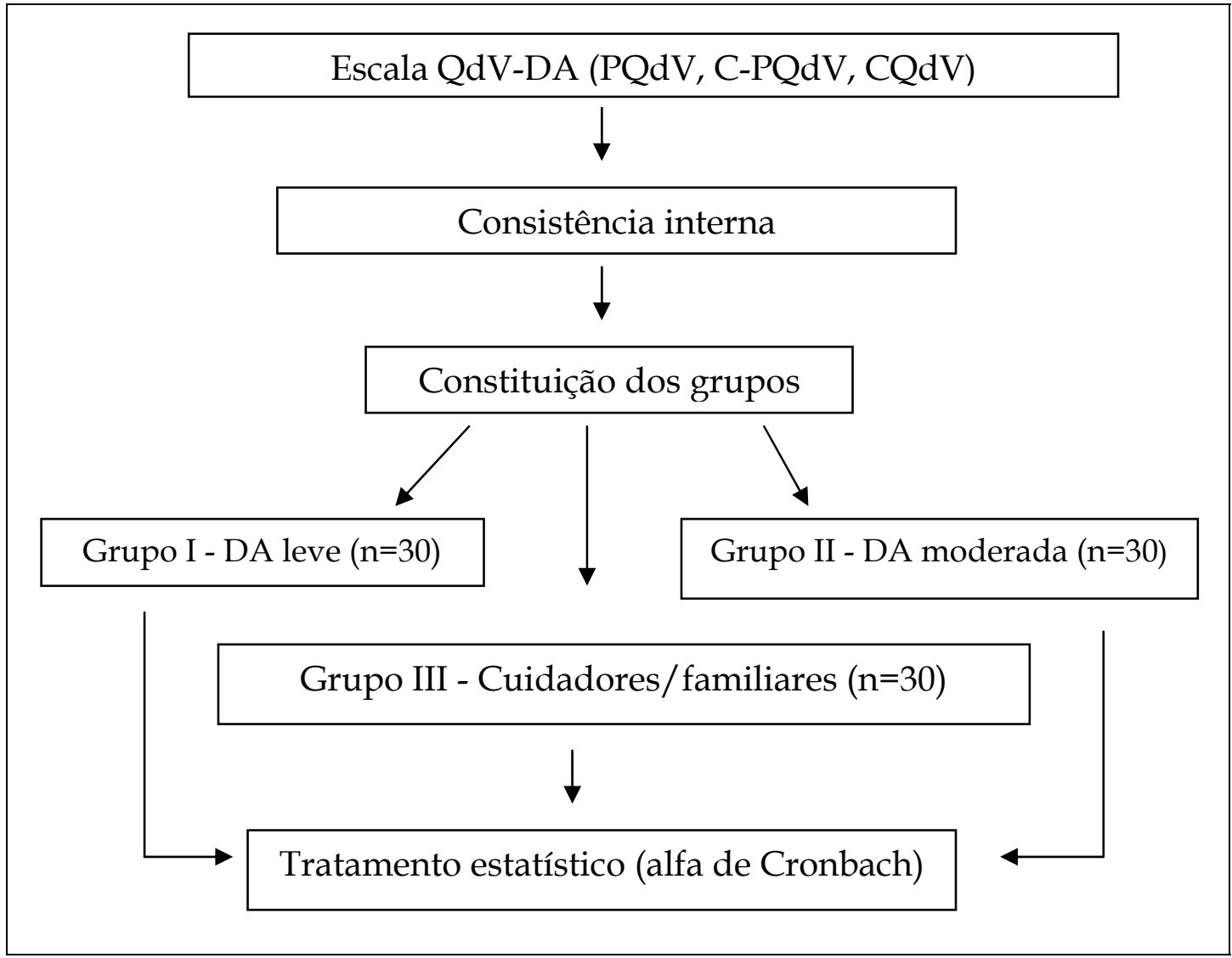




\subsubsection{Validade de Constructo}

A validade de constructo da escala QdV-DA foi avaliada através da correlação dos resultados obtidos com a escala com outros instrumentos de medida comumente utilizados na avaliação de pacientes com DA. Na avaliação da validade de constructo da QdV-DA, foi utilizada a mesma amostra de 120 indivíduos empregada na verificação da consistência interna da escala. Os resultados obtidos com as avaliações de QV dos pacientes e dos cuidadores sobre a QV do paciente foram associados às avaliações do funcionamento cognitivo, desempenho funcional (AIVDs e ABVDs), alterações de comportamento, sintomas depressivos e nível socioeconômico. Os resultados obtidos com as avaliações de QV dos cuidadores/familiares foram associados às avaliações de QV do paciente e a sintomas depressivos apresentados pelos cuidadores/familiares.

Uma análise complementar foi incluída na avaliação da validade de constructo (validade convergente) da escala QdV-DA, através da comparação com um instrumento abreviado de avaliação de QV (WHOQOLbreve). Como possuímos três versões na escala QdV-DA, o WHOQOL-breve foi aplicado utilizando-se a mesma metodologia com três versões: o relato do paciente sobre sua própria QV, o relato do cuidador/familiar sobre a QV do paciente e o relato do cuidador/familiar sobre sua própria QV. A escolha deste instrumento baseou-se no fato de ser um instrumento de criação transcultural proposto pela OMS e por ser um instrumento reduzido, com 26 itens.

Para essa análise, um grupo aleatório foi selecionado a partir da amostra total: 20 pacientes com DA e seus respectivos cuidadores/familiares $(n=20)$.

O Quadro 3 apresenta o esquema utilizado na avaliação da validade de constructo da QdV-DA. 
Quadro3: Esquema de verificação da validade de constructo da QdV-DA

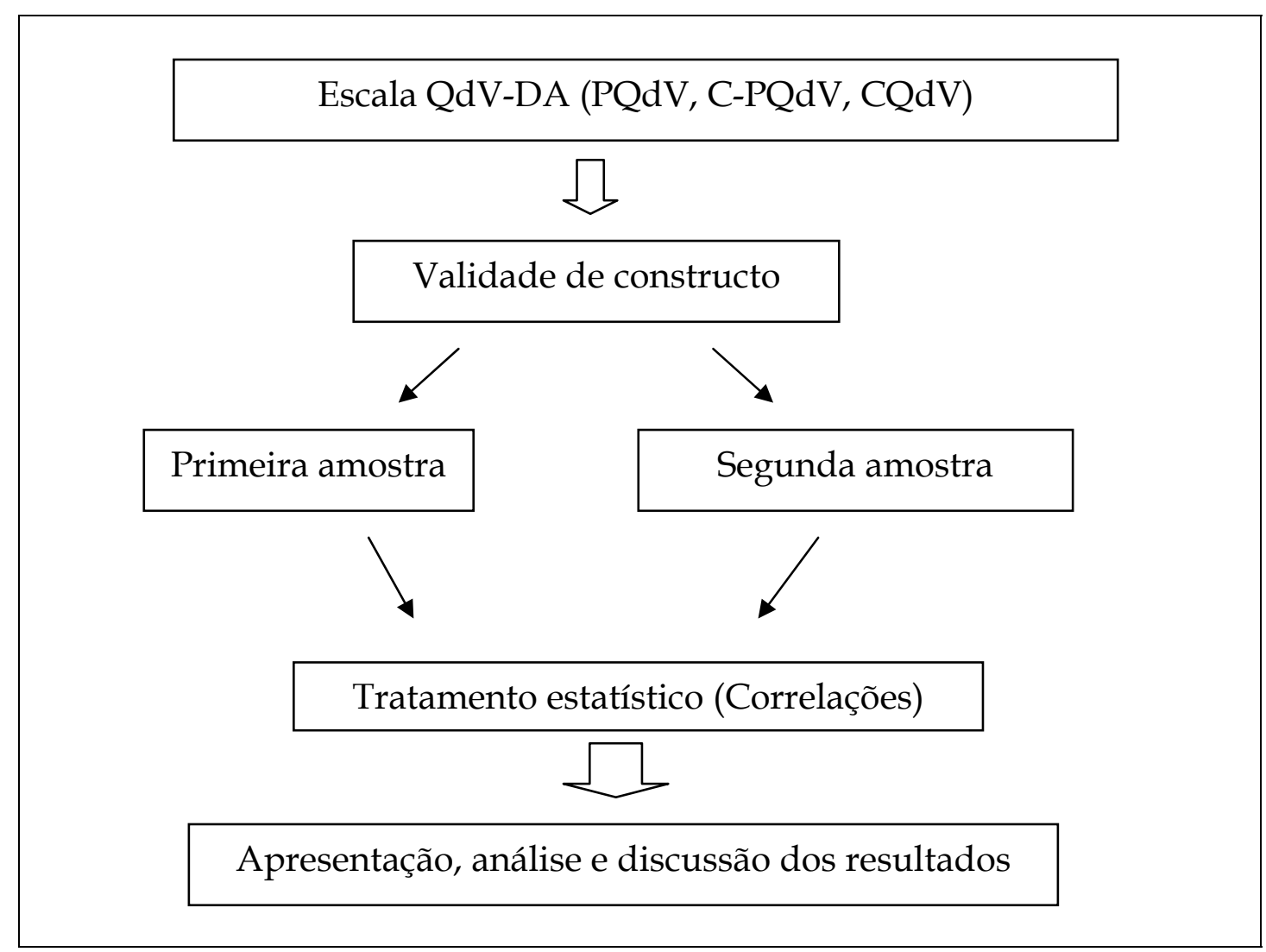

A Tabela 3 apresenta as associações feitas entre a escala QdV-DA e o instrumento WHOQOL-breve.

Tabela 3 - Associações entre os itens da escala QdV-DA e os domínios do WHOQOL-breve

\begin{tabular}{ll}
\hline \multicolumn{1}{c}{ Itens da QdV-DA } & Domínios do WHOQOL-breve \\
\hline Saúde física & Domínio físico \\
Disposição & Domínio físico \\
Humor & Domínio psicológico \\
Moradia & Meio ambiente \\
Memória & Não tem comparação \\
Família & Relações sociais \\
\hline
\end{tabular}


Tabela 3 (Continuação) - Associações entre os itens da escala QdV-DA e os domínios do WHOQOL-breve

\begin{tabular}{ll}
\hline Casamento & Relações sociais \\
Amigos & Relações sociais \\
Você em geral & Não tem comparação \\
Capacidade para fazer tarefas & Domínio físico \\
Capacidade para fazer atividades de & Domínio psicológico, Meio ambiente \\
lazer & Meio ambiente \\
Dinheiro & Questão 1 \\
Pontuação Total & Questão 1 e somatório \\
\hline
\end{tabular}

5.6.3 Avaliação do impacto do prejuízo cognitivo sobre a confiabilidade e a validade da escala QdV-DA

Para a verificação do impacto do prejuízo cognitivo sobre a confiabilidade e a validade da escala QdV-DA, a amostra total de 120 indivíduos foi dividida em subgrupos segundo a gravidade da doença.

As análises de consistência interna e de validade de constructo foram realizadas novamente em todas as três versões da escala nos dois grupos de gravidade da doença.

$\mathrm{Na}$ avaliação da validade de constructo, foram aventadas hipóteses de associação entre a escala QdV-DA e os outros instrumentos de avaliação considerando-se o grau de gravidade da doença.

$\mathrm{Na}$ análise do impacto do prejuízo cognitivo sobre a da validade convergente, o grupo aleatório foi dividido segundo a gravidade da doença: 10 pacientes com DA leve, 10 pacientes com DA moderada e 20 cuidadores/familiares. 


\subsection{Procedimento de coleta de dados}

Ao início da avaliação a pesquisadora fez a leitura do termo de consentimento livre e esclarecido (Anexo F).

Os pacientes com diagnóstico de DA leve consentiram, eles próprios, sua participação no estudo. No caso dos pacientes com DA moderada, a leitura foi feita para o paciente em conjunto com seu cuidador/familiar, sendo obtido consentimento de ambos. Após a assinatura do termo de consentimento, foram feitas as aplicações dos instrumentos descritos.

O processo de aplicação do protocolo de avaliação envolveu duas etapas. Na primeira, foram aplicados os instrumentos de avaliação nos pacientes: caracterização da amostra de pacientes, PQdV, MEEM e a GDS. A segunda etapa consistiu na aplicação do restante dos instrumentos junto aos cuidadores/familiares.

\subsection{Tratamento estatístico dos dados}

Os dados foram digitados em planilhas do programa Excel 2003 para Microsoft Windows XP e analisados por meio do programa estatístico SPSS, versão 10.0 .

Foram feitas análises descritivas (médias e desvios-padrão), das variáveis sociodemográficas e dos dados da caracterização das amostras (Doria Filho, 1999).

$\mathrm{Na}$ análise de consistência interna da escala QdV-DA, foi utilizado o coeficiente alfa de Cronbach (Guillemin et al., 1993; Logsdon et al.,1999; Cummings et al., 2003). Os coeficientes de Pearson (Kinnear e Gray, 2001) e 
Spearman (Kinnear e Gray, 2001) foram utilizados para correlacionar cada um dos itens com a pontuação total, e cada um dos itens com o item "Vida em geral" (item genérico da escala), respectivamente.

A validade de constructo foi obtida pela utilização do coeficiente de correlação de Pearson associando-se a pontuação total na escala QdV-DA com os outros instrumentos de avaliação e com os domínios do WHOQOLbreve. O grau de significância foi fixado para valores de $p<0,05$. Foram considerados como tendência de correlação valores de $p$ entre 0,10 e 0,05 (Sampaio-Barros, Rezende, Marques-Neto e Samara, 1999; Sampaio-Barros, Sâmara e Marques-Neto, 2004).

$\mathrm{Na}$ análise das variáveis demográficas sobre a escala QDV-DA nos grupos de DA leve e moderada, utilizamos os testes Kruskal-Wallis (para idade e escolaridade) e Qui-quadrado (para gênero) (Doria Filho, 1999).

\subsection{Hipóteses de correlações entre a escala QdV-DA e os outros instrumentos de avaliação}

No estudo de validade de constructo da escala QdV-DA foram feitas hipóteses de correlações entre a escala e os outros instrumentos de avaliação aplicados nos pacientes e nos cuidadores/familiares.

Para a versão PQdV, as hipóteses de associação propostas foram de correlações negativas entre a escala e desempenho funcional (AIVDs e ABVDs), alterações de comportamento e sintomas depressivos apresentados pelo paciente e correlação positiva com a versão CQdV.

$\mathrm{Na}$ versão C-PQdV, as hipóteses aventadas foram de que a escala apresentaria as mesmas correlações citadas anteriormente, acrescentando correlação positiva com a versão PQdV. 
As mesmas hipóteses de correlações propostas para as duas versões anteriores foram feitas para a versão composta.

Para a versão $\mathrm{CQdV}$, as hipóteses de associação propostas foram de correlações negativas com desempenho funcional (AIVDs e ABVDs), alterações de comportamento apresentadas pelo paciente e com sintomas depressivos apresentados pelo paciente e pelo cuidador, além de correlação positiva com a versão PQdV.

No estudo de validade convergente esperamos encontrar correlações positivas entre a pontuação total da escala QdV-DA, nas três versões, com o somatório de pontos obtida com aplicação do WHOQOL-breve, também nas três versões.

$\mathrm{Na}$ avaliação do impacto do prejuízo cognitivo sobre a validade de constructo da escala QdV-DA, foram feitas hipóteses de associação considerando-se o grau de comprometimento cognitivo.

Para a versão PQdV, no grupo de pacientes leves, as associações esperadas foram de correlações negativas com sintomas depressivos apresentados pelo paciente, alterações de comportamento e desempenho funcional (AIVDs), e correlação positiva com a versão C-PQdV.

Na versão C-PQdV e na versão composta, no grupo de pacientes leves, as hipóteses de associação foram as mesmas propostas na versão anterior (PQdV).

As hipóteses propostas para a versão $\mathrm{CQdV}$, no grupo de pacientes leves, foram de correlação positiva com a versão PQdV e correlações negativas com desempenho funcional (AIVDs), alterações de comportamento e sintomas depressivos apresentados pelo paciente e pelo cuidador.

No grupo de pacientes moderados, foram hipotetizadas associações negativas com sintomas depressivos apresentados pelo paciente, alterações de comportamento, desempenho funcional (ABVDs) e associações positivas com a versão C-PQdV e com a aversão $C Q d V$, no relato do paciente sobre sua própria QV (PQdV). 
Para a versão C-PQdV e a versão composta, no grupo de pacientes moderados, as correlações esperadas foram as mesmas citadas anteriormente, substituindo-se a versão do relato do cuidador pelo autorelato do paciente.

As hipóteses de associações propostas para a versão $C Q d V$, no grupo de pacientes moderados, foram de correlações negativas com desempenho funcional (ABVDs), alterações de comportamento e sintomas depressivos apresentados pelo paciente e pelo cuidador, e correlações positivas com a versão PQdV. 
6. RESULTADOS 


\subsection{Análise da aplicação dos instrumentos de avaliação utilizados}

Os valores médios obtidos nas avaliações aplicadas nos pacientes e cuidadores/familiares dos grupos I e II são apresentados na Tabela 4.

Tabela 4 - Valores (médias e desvio-padrão) obtidos nas avaliações administradas aos pacientes e cuidadores/familiares dos grupos I e II

\begin{tabular}{|c|c|c|}
\hline Variáveis & $\begin{array}{c}\text { Grupo I } \\
\text { (DA leve; } n=30)\end{array}$ & $\begin{array}{c}\text { Grupo II } \\
(\text { DA moderada; } n=30)\end{array}$ \\
\hline PQdVa & $36,8 \pm 5,2$ & $36,1 \pm 5,3$ \\
\hline C-PQdVb & $33,3 \pm 5,0$ & $28,3 \pm 6,0$ \\
\hline CQdVc & $38,6 \pm 6,4$ & $35,2 \pm 5,5$ \\
\hline Versão composta ${ }^{\mathrm{d}}$ & $35,6 \pm 4,4$ & $33,52 \pm 4,6$ \\
\hline MEEMe & $20,2 \pm 2,6$ & $14,0 \pm 2,8$ \\
\hline AIVDs (Lawton) ${ }^{\mathrm{f}}$ & $16,5 \pm 4,9$ & $23,3 \pm 3,4$ \\
\hline ABVDs (Lawton)g & $7,5 \pm 1,2$ & $9,5 \pm 2,3$ \\
\hline INPh & $10,0 \pm 11,2$ & $21,6 \pm 15,5$ \\
\hline GDSi & $8,1 \pm 5,3$ & $8,6 \pm 6,0$ \\
\hline $\begin{array}{l}\text { Escala de Depressão - } \\
\text { Cornell }\end{array}$ & $5,4 \pm 4,9$ & $8,9 \pm 4,8$ \\
\hline Nível socioeconômicoj & $\begin{array}{l}\text { Média }-10 \% \\
\text { Média Inferior }-36,7 \% \\
\text { Baixa Superior }-36,7 \% \\
\text { Baixa Inferior }-16,7 \%\end{array}$ & $\begin{array}{c}\text { Média - } 10 \% \\
\text { Média Inferior - 43,3\% } \\
\text { Baixa Superior }-43,3 \% \\
\text { Baixa Inferior }-3,3 \%\end{array}$ \\
\hline $\begin{array}{l}\text { Inventário de Depressão } \\
\text { de Beck }\end{array}$ & $9,3 \pm 7,1$ & $9,2 \pm 6,0$ \\
\hline
\end{tabular}


Tabela 4 (continuação) - Valores (médias e desvio-padrão) obtidos nas avaliações administradas aos pacientes e cuidadores/familiares dos grupos I e II

Domínios do WHOQOLbreve (Versão do paciente):
a) Físico
$23,7 \pm 3,1$
$23,4 \pm 2,0$
b) Psicológico
$19,0 \pm 2,6$
$19,8 \pm 4,2$
c) Relações Sociais
$10,6 \pm 1,3$
$11,2 \pm 1,3$
d) Meio Ambiente
$27,6 \pm 3,5$
$29,8 \pm 3,8$

Domínios do WHOQOLbreve (Versão do cuidador sobre QV do paciente):
a) Físico
$24,2 \pm 3,0$
$22,3 \pm 2,6$
b) Psicológico
$19,0 \pm 1,6$
$17,2 \pm 2,7$
c) Relações Sociais
$11,4 \pm 0,8$
$10,3 \pm 2,0$
d) Meio Ambiente
$28,7 \pm 2,8$
$26,7 \pm 2,3$

Domínios do WHOQOLbreve (versão do cuidador sobre sua própria QV):
a) Físico
$23,8 \pm 2,2$
$24,7 \pm 2,4$
b) Psicológico
$19,9 \pm 3,8$
$20,4 \pm 2,5$
c) Relações Sociais
$12,1 \pm 1,7$
$11,6 \pm 2,0$
d) Meio Ambiente
$30,4 \pm 4,0$
$29,2 \pm 3,6$

a PQdV (Relato do paciente sobre sua QV); b C-PQdV (Relato do cuidador sobre a QV do paciente); CQdV (Relato do cuidador/familiar sobre sua própria QV); d Versão composta pelo relato do paciente e do cuidador sobre a QV do paciente e Mini-exame do estado Mental; ${ }^{\text {f }}$ Atividades instrumentais da vida diária; gAtividades básicas da vida diária; h Inventário Neuropsiquiátrico; ${ }^{i}$ Escala de Depressão Geriátrica; j Classificação socioeconômica;

Como mostra a Tabela 4, as médias de pontuação total nas avaliações de QV decrescem com o aumento da gravidade da doença, nas três versões e na versão composta da escala QdV-DA.

$\mathrm{Na}$ avaliação do prejuízo cognitivo, também observamos uma diminuição na média de pontuação com o aumento da gravidade da doença.

Em relação ao desempenho funcional (AIVDs e ABVD's), alterações de comportamento e presença de sintomas depressivos apresentados pelo paciente identificamos um aumento na média de pontuação quando comparamos o grupo de pacientes moderados ao grupo de pacientes leves. 
Na avaliação socioeconômica encontramos uma porcentagem maior de indivíduos entre as classes média inferior e baixa superior nos dois grupos de gravidade.

Encontramos uma média similar, em ambos os grupos, quando avaliamos a presença de sintomas depressivos nos cuidadores/familiares.

\subsection{Análise das propriedades de medida da QdV-DA}

\subsubsection{Consistência Interna}

A avaliação da consistência interna foi realizada utilizando-se a amostra total de 120 indivíduos, sendo, para cada versão da escala QdV-DA, o número de participantes de 60 indivíduos.

Foram feitas correlações de cada item da escala QdV-DA, nas três versões, com o item genérico "vida em geral" e também correlações de cada item com a pontuação total

Os resultados da consistência interna e das correlações entre os itens da escala QdV-DA são apresentados na Tabela 5. 
Tabela 5 - Índices de correlação entre os itens e a consistência interna da QdV-DA

\begin{tabular}{|c|c|c|c|c|c|c|}
\hline \multirow[b]{2}{*}{ Itens } & \multicolumn{2}{|c|}{ (1) } & \multicolumn{2}{|c|}{ (2) } & \multicolumn{2}{|c|}{ (3) } \\
\hline & A & B & A & B & $\mathbf{A}$ & B \\
\hline 1. Saúde física & $0,70 * *$ & $0,38^{* *}$ & $0,43^{* *}$ & 0,20 & $0,64^{* *}$ & $0,40^{* *}$ \\
\hline 2. Disposição & $0,70^{* *}$ & 0,23 & $0,67^{* *}$ & $0,33^{*}$ & $0,74^{* *}$ & $0,46^{* *}$ \\
\hline 3. Humor & $0,38^{* *}$ & $0,29 *$ & $0,60 * *$ & $0,49 * *$ & $0,66^{* *}$ & $0,64^{* *}$ \\
\hline 4. Moradia & $0,43^{* *}$ & 0,17 & $0,51^{* *}$ & $0,38^{* *}$ & $0,46^{* *}$ & 0,24 \\
\hline 5. Memória & $0,45^{* *}$ & $0,35^{* *}$ & $0,54^{* *}$ & $0,35^{* *}$ & $0,55^{* *}$ & $0,30^{*}$ \\
\hline 6. Família & $0,46^{* *}$ & $0,29 *$ & $0,66^{* *}$ & $0,42^{* *}$ & $0,61^{* *}$ & 0,25 \\
\hline 7. Casamento & $0,58^{* *}$ & $0,40^{* *}$ & $0,68^{* *}$ & $0,30 *$ & $0,49 * *$ & $0,43^{* *}$ \\
\hline 8. Amigos & $0,27^{*}$ & 0,25 & $0,48^{* *}$ & $0,26^{*}$ & $0,59 * *$ & $0,36^{* *}$ \\
\hline 9. Você em geral & $0,66^{* *}$ & $0,47^{* *}$ & $0,61^{* *}$ & $0,51^{* *}$ & 0,70 ** & $0,54^{* *}$ \\
\hline $\begin{array}{l}\text { 10. Capacidade para } \\
\text { fazer tarefas }\end{array}$ & $0,51^{* *}$ & 0,08 & $0,59 * *$ & $0,40^{* *}$ & $0,61^{* *}$ & 0,22 \\
\hline $\begin{array}{l}\text { 11. Capacidade para } \\
\text { fazer atividades } \\
\text { de lazer }\end{array}$ & $0,65^{* *}$ & $0,26^{*}$ & $0,52^{* *}$ & 0,19 & $0,56^{* *}$ & $0,37^{* *}$ \\
\hline 12. Dinheiro & $0,54^{* *}$ & 0,25 & $0,51^{* *}$ & 0,17 & $0,58^{* *}$ & $0,33^{* *}$ \\
\hline 13. Vida em geral & $0,62^{* *}$ & ----- & $0,66^{* *}$ & ----- & $0,75^{* *}$ & ----- \\
\hline Coeficiente Alfa & 0,80 & & 0,83 & & 0,86 & \\
\hline
\end{tabular}

${ }^{*} P<0,05 ;{ }^{* *} P<0,01 ;$

A - Total; B - "vida em geral";

(1) PQdV (Relato do paciente sobre sua QV);

(2) C-PQdV (Relato do cuidador sobre a QV do paciente);

(3) CQdV (Relato do cuidador/familiar sobre sua própria QV)

Os resultados apresentados na Tabela 5 demonstram índices de correlação de Pearson elevados e estatisticamente significativos para todos os itens com a pontuação total, nas três versões da escala.

Na correlação dos itens com um item genérico, observamos correlações estatisticamente significativas para a maioria dos itens, como "saúde física", "humor", "memória", "família", "casamento", "você em geral" e “capacidade para fazer atividades de lazer", na versão PQdV. Nesta versão, 
três itens apresentaram tendência de correlação, como "disposição" $(p=0,075)$, "amigos" ( $p=0,051)$ e "dinheiro" $(p=0,051)$.

$\mathrm{Na}$ versão $\mathrm{C}-\mathrm{PQdV}$, encontramos correlações significativas nos itens "disposição", "humor", "moradia", "memória", “família", “casamento", "amigos", "você em geral" e "capacidade para fazer tarefas".

Para a versão $C Q d V$, as correlações encontradas foram nos itens "saúde física", "disposição", "humor", "memória", “casamento", "amigos", "você em geral", "capacidade para fazer atividades de lazer" e "dinheiro". Nesta versão, três itens apresentaram tendência de correlação: "moradia" $(p=0,066)$, "família" $(p=0,056)$ e "capacidade para fazer tarefas" ( $p=0,008)$.

Os resultados dos valores de alfa para as três versões foram elevados, sendo considerados excelentes. Na escala PQdV, obtivemos valor de 0,80 . Na escala C-PQdV, valor de 0,83 e na CQdV, valor de 0,86.

\subsubsection{Validade de Constructo}

A validade de constructo da escala de QdV-DA foi obtida pela correlação da escala, nas três versões e da versão composta, com os outros instrumentos de medida propostos no protocolo de avaliação e através da correlação com um instrumento genérico de avaliação de QV.

Iniciaremos a apresentação dos resultados pelas correlações com os instrumentos de avaliação: MEEM, GDS, Escala de Depressão de Cornell, Escala de Automanutenção Física e Instrumental (AIVDs e ABVDs), INP, Classificação socioeconômica e Inventário de Depressão de Beck. Posteriormente, apresentaremos os resultados das correlações obtidas através da associação com o instrumento genérico de avaliação de QV (WHOQOL-breve). 
A Tabela 6 apresenta os resultados da validade de constructo através da associação com as medidas de avaliação das versões: PQdV, C-PQdV e a versão composta.

Tabela 6 - Validade de constructo das versões PQdV, C-PQdV e da versão composta

\begin{tabular}{lccc}
\hline \multicolumn{1}{c}{ Avaliações } & PQdV & C-PQdV & $\begin{array}{c}\text { Versão } \\
\text { Composta }^{\mathbf{d}}\end{array}$ \\
\hline MEEMe & 0,07 & $0,41^{* *}$ & 0,24 \\
GDS $^{f}$ & $-0,59^{* *}$ & $-0,36^{* *}$ & $-0,61^{* *}$ \\
Escala de Depressão de Cornell & $-0,49^{* *}$ & $-0,68^{* *}$ & $-0,67^{* *}$ \\
INPg & $-0,36^{* *}$ & $-0,71^{* *}$ & $-0,58^{* *}$ \\
AIVDs (Lawton) & 0,01 & $-0,52^{\text {h* }}$ & $-0,22$ \\
ABVDs (Lawton)i & $-0,21$ & $-0,51^{* *}$ & $-0,38^{* *}$ \\
Nível socioeconômicoj & 0,22 & 0,06 & 0,19 \\
Inventário de Depressão de Beck & $-0,05$ & $-0,27^{*}$ & $-0,16$ \\
PQdVa & & $0,35^{* *}$ & $0,91^{* *}$ \\
C-PQdVb & $0,35^{* *}$ & - & $0,70^{* *}$ \\
CQdVc & 0,14 & $0,44^{* *}$ & $0,30^{* *}$ \\
\hline
\end{tabular}

${ }^{*} p<0,05 ; * * p<0,01$

a PQdV(Relato do paciente sobre sua QV); b C-PQdV (Relato do cuidador sobre a QV do paciente); c CQdV (Relato do cuidador/familiar sobre sua própria QV); ${ }^{\mathrm{d}}$ Versão Composta pelo relato do paciente e do cuidador sobre a QV do paciente; $\mathrm{e}$ Mini-exame do estado Mental; ${ }^{\mathrm{f}}$ Escala de Depressão Geriátrica; g Inventário Neuropsiquiátrico; h Atividades instrumentais da vida diária; i Atividades básicas da vida diária; ; Classificação socioeconômica;

Como mostra a Tabela 6, a versão PQdV apresenta índices de correlação de Pearson significativos com as variáveis: sintomas depressivos apresentados pelos pacientes, alterações de comportamento e a versão do cuidador sobre a QV do paciente (C-PQdV). Observamos também tendência de correlação com o item nível socioeconômico ( $p=0,095)$. 
$\mathrm{Na}$ versão C-PQdV, encontramos correlações significativas com: comprometimento cognitivo, sintomas depressivos apresentados pelos pacientes, sintomas depressivos apresentados pelos cuidadores, alterações de comportamento, desempenho funcional (AIVDs e ABVDs), PQdV e CQdV.

$\mathrm{Na}$ versão composta, as associações estatisticamente significativas encontradas foram com: sintomas depressivos apresentados pelos pacientes, alterações de comportamento, ABVDs, PQdV, C-PQdV e CQdV. Os resultados apresentam tendência de correlação com o item comprometimento cognitivo $(\mathrm{p}=0,064)$.

A Tabela 7 apresenta a validade de constructo da versão CQdV.

Tabela 7 - Validade de constructo da versão CQdV

\begin{tabular}{|c|c|}
\hline Avaliações & CQdVc \\
\hline PQdVa & 0,14 \\
\hline C-PQdVb & $0,44^{* *}$ \\
\hline Versão compostad & $0,30^{*}$ \\
\hline MEEMe & 0,23 \\
\hline GDSf $^{f}$ & $-0,05$ \\
\hline Escala de Depressão de Cornell & $-0,30^{*}$ \\
\hline INPg & $-0,39 * *$ \\
\hline AIVDs (Lawton) ${ }^{\mathrm{h}}$ & $-0,41^{* *}$ \\
\hline ABVDs (Lawton) ${ }^{\mathrm{i}}$ & $-0,32^{*}$ \\
\hline Nível socioeconômicoj & 0,06 \\
\hline Inventário de Depressão de Beck & $-0,59^{* *}$ \\
\hline
\end{tabular}
${ }^{*} p<0,05 ; * * p<0,01$;

a PQdV (Relato do paciente sobre sua QV); b C-PQdV (Relato do cuidador sobre a QV do paciente); c CQdV (Relato do cuidador/familiar sobre sua própria QV); d Versão Composta pelo relato do paciente e do cuidador sobre a QV do paciente; e Mini-exame do estado Mental; f Escala de Depressão Geriátrica; $\mathrm{g}$ Inventário Neuropsiquiátrico; ${ }^{\mathrm{h}}$ Atividades instrumentais da vida diária; i Atividades básicas da vida diária; ; Classificação socioeconômica; 
$\mathrm{Na}$ versão $\mathrm{CQdV}$, obtivemos correlações estatisticamente significativas com C-PQdV, a versão composta, sintomas depressivos apresentados pelos pacientes, sintomas depressivos apresentados pelos cuidadores, alterações de comportamento, AIVDs e com ABVDs. Os resultados apresentam tendência de correlação com o item comprometimento cognitivo $(p=0,076)$.

A partir da Tabela 8, iniciaremos a apresentação dos resultados obtidos na avaliação da validade convergente da escala.

A Tabela 8 apresenta os índices de correlação entre a versão PQdV e o instrumento WHOQOL-breve.

Tabela 8 - Validade de constructo da versão PQdV: índices de correlação entre os itens e os domínios do WHOQOL-breve

\begin{tabular}{lc}
\hline Itens da PQdV a X Domínios do WHOQOL-breve & Índices de Correlação \\
\hline Saúde física x Domínio físico & 0,12 \\
Disposição x Domínio físico & $0,56^{* *}$ \\
Humor x Domínio psicológico & $0,70^{* *}$ \\
Moradia x Meio ambiente & 0,29 \\
Família x Relações sociais & $0,46^{*}$ \\
Casamento x Relações sociais & $0,55^{*}$ \\
Amigos x Relações sociais & $0,61^{* *}$ \\
Capacidade para fazer tarefas x Domínio físico & 0,27 \\
Capacidade para fazer atividades de lazer x & 0,31 \\
Domínio psicológico & \\
Capacidade para fazer atividades de lazer x Meio & $0,45^{*}$ \\
ambiente & \\
Dinheiro x Meio ambiente & 0,38 \\
Vida em geral x Questão 1 & $0,51^{*}$ \\
Pontuação Total x Questão 1 & $0,67^{* *}$ \\
Pontuação Total x Somatório & $0,88^{* *}$ \\
\hline *p<0,05; ${ }^{* *}<0,01$ & \\
a PQdV (Relato do paciente sobre sua QV); &
\end{tabular}


A versão PQdV apresentou correlações significativas nos itens: “disposição", "humor", "família”, "casamento", "amigos”, "lazer", “vida em geral" e na pontuação total com a questão 1 e com o somatório. Dos 14 itens, nove apresentaram validade de constructo incluindo a pontuação total da escala.

Os itens "moradia" e "dinheiro" apresentaram tendência de correlação $(p=0,094)$.

A Tabela 9 apresenta os resultados da validade de constructo da versão C-PQdV.

Tabela 9 - Validade de constructo da versão C-PQdV: índices de correlação entre os itens e os domínios do WHOQOL-breve

\begin{tabular}{|c|c|}
\hline \multicolumn{2}{|c|}{ Itens da C-PQdV $\mathrm{b}$ Domínios do WHOQOL-breve Índices de Correlaçãc } \\
\hline Saúde física x Domínio físico & 0,10 \\
\hline Disposição x Domínio físico & $0,69^{* *}$ \\
\hline Humor x Domínio psicológico & 0,26 \\
\hline Moradia x Meio ambiente & 0,24 \\
\hline Família x Relações sociais & $0,51^{*}$ \\
\hline Casamento $x$ Relações sociais & $0,51^{*}$ \\
\hline Amigos $x$ Relações sociais & 0,07 \\
\hline Capacidade para fazer tarefas $x$ Domínio físico & $0,53^{*}$ \\
\hline $\begin{array}{l}\text { Capacidade para fazer atividades de lazer } x \\
\text { Domínio psicológico }\end{array}$ & 0,28 \\
\hline $\begin{array}{l}\text { Capacidade para fazer atividades de lazer } x \text { Meio } \\
\text { ambiente }\end{array}$ & 0,24 \\
\hline Dinheiro $x$ Meio ambiente & 0,43 \\
\hline Vida em geral x Questão 1 & $0,73^{* *}$ \\
\hline Pontuação Total x Questão 1 & $0,61^{* *}$ \\
\hline Pontuação Total x Somatório & $0,71^{* *}$ \\
\hline
\end{tabular}


$\mathrm{Na}$ versão C-PQdV, obtivemos correlações significativas nos itens: “disposição", "família", "casamento", "capacidade para fazer tarefas”, "vida em geral", e na pontuação total com a questão 1 e com o somatório. Nesta versão, sete dos 14 itens apresentaram validade de constructo com o instrumento genérico, incluindo a pontuação total da escala. O item "dinheiro" apresentou tendência de correlação $(p=0,068)$.

A Tabela 10 apresenta os dados relativos à validade de constructo da versão CQdV.

Tabela 10 - Validade de constructo da versão CQdV: índices de correlação entre os itens com os domínios do WHOQOL-breve

\begin{tabular}{lc}
\hline Itens da CQdVc X Domínios do WHOQOL-breve & Índices de Correlação \\
\hline Saúde física x Domínio físico & $0,58^{* *}$ \\
Disposição x Domínio físico & $0,46^{*}$ \\
Humor x Domínio psicológico & $0,61^{* *}$ \\
Moradia x Meio ambiente & $0,47^{*}$ \\
Família x Relações sociais & $0,61^{* *}$ \\
Casamento x Relações sociais & $0,54^{* *}$ \\
Amigos x Relações sociais & $0,48^{*}$ \\
Capacidade para fazer tarefas x Domínio físico & $0,58^{* *}$ \\
Capacidade para fazer atividades de lazer & 0,31 \\
Domínio psicológico & \\
Capacidade para fazer atividades de lazer x Meio & $0,59^{* *}$ \\
ambiente & \\
Dinheiro x Meio ambiente & $0,55^{*}$ \\
Vida em geral x Questão 1 & 0,39 \\
$\begin{array}{l}\text { Pontuação Total x Questão 1 } \\
\text { Pontuação Total x Somatório }\end{array}$ & $0,55^{* *}$ \\
${ }^{*} p<0,05 ; * * 0,01$ & $0,81^{* *}$ \\
${ }^{*}$ CQdV (Relato do cuidador/familiar sobre sua própria QV); &
\end{tabular}

A versão CQdV apresentou correlações significativas em quase todos os itens, com exceção do item "lazer" com domínio psicológico. Obtivemos tendência de correlação no item "vida em geral" $(p=0,088)$. 


\subsubsection{Avaliação do impacto do prejuízo cognitivo sobre a confiabilidade e a validade da escala QdV-DA}

Para avaliar o impacto do prejuízo cognitivo sobre a confiabilidade e a validade da escala QdV-DA, todas as análises foram realizadas novamente por grupos de gravidade da doença.

A seguir, são apresentados os resultados de confiabilidade/consistência interna.

A Tabela 11 apresenta as correlações entre os itens e a consistência interna da escala QdV-DA nos pacientes com DA leve.

Tabela 11 - Índices de correlação entre os itens e a consistência interna da QdV-DA em pacientes com DA leve

\begin{tabular}{|c|c|c|c|c|c|c|}
\hline \multirow[b]{2}{*}{ Itens } & \multicolumn{2}{|c|}{ (1) } & \multicolumn{2}{|c|}{ (2) } & \multicolumn{2}{|c|}{ (3) } \\
\hline & $\mathbf{A}$ & B & $\mathbf{A}$ & B & $\mathbf{A}$ & B \\
\hline 1. Saúde física & $0,61^{* *}$ & $0,50 * *$ & 0,32 & 0,11 & $0,63^{* *}$ & 0,26 \\
\hline 2. Disposição & $0,71^{* *}$ & 0,31 & $0,46^{*}$ & 0,29 & $0,83^{* *}$ & 0,50 ** \\
\hline 3. Humor & 0,35 & $0,38^{*}$ & $0,38^{*}$ & 0,32 & $0,70 * *$ & $0,73^{* *}$ \\
\hline 4. Moradia & $0,47^{* *}$ & 0,23 & $0,45^{*}$ & 0,29 & $0,40^{*}$ & 0,17 \\
\hline 5. Memória & $0,51^{* *}$ & $0,42^{*}$ & $0,38^{*}$ & 0,26 & $0,62^{* *}$ & $0,32^{* *}$ \\
\hline 6. Família & $0,50 * *$ & $0,40 *$ & $0,70^{* *}$ & $0,56 * *$ & $0,65^{* *}$ & $0,33^{*}$ \\
\hline 7. Casamento & $0,75^{* *}$ & $0,60^{* *}$ & $0,49^{* *}$ & 0,18 & $0,48^{* *}$ & $0,60^{* *}$ \\
\hline 8. Amigos & $0,41^{*}$ & $0,37^{*}$ & $0,56^{* *}$ & 0,34 & $0,61^{* *}$ & $0,40^{* *}$ \\
\hline 9. Você em geral & $0,65^{* *}$ & $0,36^{* *}$ & $0,52^{* *}$ & $0,51^{* *}$ & $0,76^{* *}$ & $0,56^{* *}$ \\
\hline $\begin{array}{l}\text { 10. Capacidade para } \\
\text { fazer tarefas }\end{array}$ & 0,34 & $-0,08$ & $0,47^{* *}$ & 0,32 & $0,80^{* *}$ & $0,44^{* *}$ \\
\hline $\begin{array}{l}\text { 11. Capacidade para } \\
\text { fazer atividades } \\
\text { de lazer }\end{array}$ & $0,56^{* *}$ & 0,15 & $0,54^{* *}$ & 0,13 & $0,63^{* *}$ & $0,40^{* *}$ \\
\hline 12. Dinheiro & $0,58^{* *}$ & $0,34^{*}$ & $0,52^{* *}$ & 0,20 & $0,56^{* *}$ & 0,22 \\
\hline 13. Vida em geral & $0,68^{* *}$ & ----- & $0,68^{* *}$ & ----- & $0,76^{* *}$ & ----- \\
\hline Coeficiente Alfa & 0,81 & & 0,75 & & 0,88 & \\
\hline $\begin{array}{l}P<0,05 ;{ }^{* *} P<0,01 \\
\text { A - Total; B - “vida em gera } \\
\text { (1) PQdV (Relato do pacient } \\
\text { (2) C-PQdV (Relato do cuid } \\
\text { (3) CQdV (Relato do cuidad }\end{array}$ & il & & $\mathrm{QV})$ & & & \\
\hline
\end{tabular}


Os resultados apresentados na Tabela 11 demonstram índices de correlação de Pearson elevados e estatisticamente significativos para a maioria dos itens com a pontuação total, nas três versões. Na versão PQdV, os itens que não apresentaram significância estatística revelaram tendência de correlação, como "humor" ( $p=0,056)$, "capacidade para fazer tarefas" $(p=0,066)$. Na versão C-PQdV, o item "saúde física" não apresentou correlação significativa mas tendência de correlação $(p=0,082)$. $\mathrm{Na}$ versão CQdV-DA, todos os itens apresentaram correlação com a pontuação total.

$\mathrm{Na}$ correlação dos itens com um item genérico, observamos também correlações estatisticamente significativas para os itens, "saúde física", "humor", "memória", "família", "casamento", "amigos", "você em geral” e "dinheiro" na versão PQdV. A versão C-PQdV apresentou correlação com os itens "família" e "você em geral", e três outros itens apresentaram tendência de correlação, como, "humor" (p=0,081), “amigos" $(p=0,063)$ e “capacidade para fazer tarefas" $(p=0,085)$. Na versão CQdV, encontramos associações com os itens "disposição", "humor", "memória", "família", "casamento", "amigos", "você em geral", "capacidade para fazer tarefas", "capacidade para fazer atividades de lazer". Os resultados dos valores de alfa, para as três versões, permanecem elevados, sendo considerados excelentes. Na escala PQdV, obtivemos o valor de 0,81; na escala C-PQdV, o valor de 0,75 e na CQdV, o valor de 0,88 .

A Tabela 12 apresenta os índices de correlação e a consistência interna da escala QdV-DA nos pacientes com DA moderada. 
Tabela 12 - Índices de correlação entre os itens e a consistência interna da QdV- DA em pacientes com DA moderada

\begin{tabular}{|c|c|c|c|c|c|c|}
\hline \multirow[b]{2}{*}{ Itens } & \multicolumn{2}{|c|}{ (1) } & \multicolumn{2}{|c|}{ (2) } & \multicolumn{2}{|c|}{ (3) } \\
\hline & $\mathbf{A}$ & B & $\mathbf{A}$ & B & $\mathbf{A}$ & B \\
\hline 1. Saúde física & $0,78^{* *}$ & 0,27 & $0,53^{* *}$ & 0,23 & $0,60 * *$ & $0,44^{*}$ \\
\hline 2. Disposição & $0,70 * *$ & 0,17 & $0,81^{* *}$ & 0,29 & $0,61^{* *}$ & $0,37^{*}$ \\
\hline 3. Humor & $0,43^{*}$ & 0,23 & $0,63^{* *}$ & $0,48^{* *}$ & $0,65^{* *}$ & $0,55^{* *}$ \\
\hline 4. Moradia & $0,39 *$ & 0,19 & $0,48^{* *}$ & 0,32 & $0,45^{* *}$ & 0,22 \\
\hline 5. Memória & $0,45^{*}$ & 0,28 & $0,54^{* *}$ & 0,21 & $0,57^{* *}$ & 0,28 \\
\hline 6. Família & $0,43^{*}$ & 0,14 & $0,64^{* *}$ & 0,29 & $0,57^{* *}$ & 0,14 \\
\hline 7. Casamento & 0,35 & 0,16 & $0,75^{* *}$ & 0,30 & $0,49 * *$ & $0,38^{*}$ \\
\hline 8. Amigos & 0,15 & 0,26 & $0,44^{* *}$ & 0,23 & $0,57^{* *}$ & 0,30 \\
\hline 9. Você em geral & $0,69 * *$ & $0,59 * *$ & $0,58^{* *}$ & $0,41^{* *}$ & $0,58^{* *}$ & $0,52^{* *}$ \\
\hline $\begin{array}{l}\text { 10. Capacidade para } \\
\text { fazer tarefas }\end{array}$ & $0,66^{* *}$ & 0,26 & $0,59 * *$ & 0,22 & $0,38^{*}$ & $-0,07$ \\
\hline $\begin{array}{l}\text { 11. Capacidade para } \\
\text { fazer atividades de } \\
\text { lazer }\end{array}$ & $0,73^{* *}$ & $0,41^{*}$ & $0,47^{* *}$ & 0,20 & $0,43^{* *}$ & 0,26 \\
\hline 12. Dinheiro & $0,52^{* *}$ & 0,16 & $0,48^{* *}$ & 0,01 & $0,61^{* *}$ & $0,45^{*}$ \\
\hline 13. Vida em geral & $0,57^{* *}$ & ----- & $0,52^{* *}$ & ----- & $0,72^{* *}$ & ----- \\
\hline Coeficiente Alfa & 0,80 & & 0,83 & & 0,80 & \\
\hline
\end{tabular}

${ }^{*} P<0,05 ;{ }^{* *} P<0,01$

A - Total; B - "vida em geral”;

(1) PQdV (Relato do paciente sobre sua QV)

(2) C-PQdV (Relato do cuidador sobre a QV do paciente)

(3) CQdV (Relato do cuidador/familiar sobre sua própria QV)

Os índices de correlação de Pearson permanecem elevados e estatisticamente significativos para a maioria dos itens com a pontuação total, nas três versões. Na versão PQdV, o item "casamento" apresentou tendência de correlação $(p=0,056)$. Na correlação dos itens com um item genérico, observamos uma diminuição de correlação da maioria dos itens nas três versões. Os valores de alfa são $\geq 0,80$, nas três versões da escala, no grupo de pacientes moderados. 
A partir da Tabela 13, são apresentados os resultados da validade de constructo da escala QdV-DA.

A Tabela 13 apresenta os resultados da validade de constructo das versões: PQdV, C-PQdV e a versão composta nos pacientes com DA leve.

Tabela 13 - Validade de constructo das versões PQdV, C-PQdV e da versão composta nos pacientes com DA leve

\begin{tabular}{lccc}
\hline \multicolumn{1}{c}{ Avaliações } & PQdV $^{\mathbf{a}}$ & C-PQdV & $\begin{array}{c}\text { Versão } \\
\text { Composta }^{\mathbf{d}}\end{array}$ \\
\hline MEEMe & 0,04 & 0,03 & 0,05 \\
GDS $^{f}$ & $-0,76^{* *}$ & $-0,48^{* *}$ & $-0,78^{* *}$ \\
Escala de Depressão de Cornell & $-0,53^{* *}$ & $-0,57^{* *}$ & $-0,63^{* *}$ \\
INPg & $-0,46^{*}$ & $-0,62^{* *}$ & $-0,59^{* *}$ \\
Inventário de Depressão de Beck & $-0,11$ & $-0,28$ & $-0,19$ \\
AIVDsh & 0,14 & $-0,36$ & $-0,02$ \\
ABVDsi & 0,08 & $-0,17$ & $-0,12$ \\
Nível socioeconômicoj & 0,14 & $-0,06$ & 0,09 \\
PQdVa & & $0,41^{*}$ & $0,94^{* *}$ \\
C-PQdVb & $0,41^{*}$ & & $0,70^{* *}$ \\
CQdVc & 0,06 & 0,26 & 0,15 \\
\hline
\end{tabular}

${ }^{*} p<0,05 ;{ }^{* *} p<0,01$

a PQdV (Relato do paciente sobre sua QV); b C-PQdV (Relato do cuidador sobre a QV do paciente); c CQdV (Relato do cuidador/familiar sobre sua própria QV); d Versão composta pelo relato do paciente e do cuidador sobre a QV do paciente; $\mathrm{e}$ Mini-exame do estado Mental; ${ }^{\mathrm{f}}$ Escala de Depressão Geriátrica; g Inventário Neuropsiquiátrico; h Atividades instrumentais da vida diária; iAtividades básicas da vida diária; i Classificação socioeconômica;

Na validade de constructo da versão PQdV no grupo de pacientes com DA leve, observamos as mesmas correlações apresentadas na amostra total. As correlações estatisticamente significativas foram com sintomas depressivos apresentados pelo paciente, com alterações de comportamento e com a versão C-PQdV. 
A versão C-PQdV obteve correlações significativas com sintomas depressivos apresentados pelo paciente, alterações de comportamento e a versão PQdV. Observamos tendência de correlação na associação com o item $\operatorname{AIVDs}(\mathrm{p}=0,052)$.

Na versão composta, as correlações significativas obtidas foram com sintomas depressivos apresentados pelo paciente, alterações de comportamento, com a versão PQdV e a versão C-PQdV.

A Tabela 14 apresenta os resultados da validade de constructo das versões PQdV, C-PQdV e a versão composta nos pacientes com DA moderada.

Tabela 14 - Validade de constructo das versões: PQdV, C-PQdVA e a versão composta nos pacientes com DA moderada

\begin{tabular}{|c|c|c|c|}
\hline Avaliações & PQdVa & C-PQdVb & $\begin{array}{c}\text { Versão } \\
\text { Composta }^{d}\end{array}$ \\
\hline MEEMe & 0,04 & 0,27 & 0,15 \\
\hline GDSf $^{2}$ & $-0,45^{*}$ & $-0,30$ & $-0,48^{* *}$ \\
\hline Escala de Depressão de Cornell & $-0,46^{* *}$ & $-0,68^{* *}$ & $-0,66^{* *}$ \\
\hline INPg & $-0,31$ & $-0,67^{* *}$ & $-0,53^{* *}$ \\
\hline Inventário de Depressão de Beck & 0,02 & $-0,33^{*}$ & $-0,13$ \\
\hline AIVDs (Lawton) ${ }^{\mathrm{h}}$ & $-0,02$ & $-0,41^{*}$ & $-0,19$ \\
\hline ABVDs (Lawton) ${ }^{\mathrm{i}}$ & $-0,29$ & $-0,49^{* *}$ & $-0,43^{* *}$ \\
\hline Classificação socioeconômica ${ }^{j}$ & 0,34 & 0,29 & $0,39 *$ \\
\hline PQdVa & & 0,31 & $0,91^{* *}$ \\
\hline C-PQdVb & 0,31 & & $0,67^{* *}$ \\
\hline CQdV-DAc & 0,21 & $0,48^{* *}$ & $0,37^{*}$ \\
\hline
\end{tabular}

A correlação encontrada na versão PQdV, nos pacientes com DA moderada, foi com sintomas depressivos apresentados pelo paciente. Os resultados apontam tendência estatística a haver correlações com alterações 
de comportamento $(p=0,097)$, nível socioeconômico $(p=0,067)$ e com o relato do cuidador sobre a QV do paciente (C-PQdV; $p=0,097)$. A versão C-PQdV apresentou correlações significativas com sintomas depressivos apresentados pelos pacientes e também pelos cuidadores, alterações de comportamento, AIVDS, ABVDs e a versão CQdV. Os resultados apontam tendência a existir correlação com nível socioeconômico $(p=0,06)$ e com versão PQdV ( $\mathrm{p}=0,097)$.

A versão composta apresentou correlações significativas com sintomas depressivos apresentados pelos pacientes, com ABVDs, nível socioeconômico, com a versão PQdV, C-PQdV e CQdV, no grupo de pacientes moderados.

A Tabela 15 apresenta as correlações da versão CQdV nos cuidadores de pacientes com DA leve e moderada.

Tabela 15 - Validade de constructo da versão CQdV nos cuidadores de pacientes com DA leve e moderada

\begin{tabular}{|c|c|c|}
\hline Avaliações & $\begin{array}{c}\text { CQdVc } \\
\text { DA leve }\end{array}$ & $\begin{array}{c}\text { CQdVc } \\
\text { DA moderada }\end{array}$ \\
\hline PQdVa & 0,06 & 0,21 \\
\hline C-PQdVb & 0,26 & $0,48^{* *}$ \\
\hline Versão compostad & 0,15 & $0,37^{*}$ \\
\hline MEEMe & $-0,13$ & 0,22 \\
\hline GDS $^{f}$ & $-0,14$ & $-0,05$ \\
\hline Escala de Depressão de Cornell & $-0,20$ & $-0,27$ \\
\hline Inventário de Depressão de Beck & $-0,67^{* *}$ & $-0,54^{* *}$ \\
\hline INPg & $-0,43^{*}$ & $-0,23$ \\
\hline AIVDs (Lawton) ${ }^{\mathrm{h}}$ & $-0,35$ & $-0,28$ \\
\hline ABVDs (Lawton) ${ }^{\mathrm{i}}$ & $-0,02$ & $-0,38^{*}$ \\
\hline Nível socioeconômico & $-0,10$ & $-0,38^{*}$ \\
\hline
\end{tabular}


$\mathrm{Na}$ validade de constructo da versão CQdV no grupo de DA leve, observamos correlações significativas com sintomas depressivos apresentados pelos cuidadores e alterações de comportamento. Os resultados demonstram tendência de correlação com as variáveis AIVDs $(p=0,060)$ e com a versão PQdV ( $p=0,078)$.

$\mathrm{Na}$ validade de constructo da versão CQdV no grupo de pacientes com DA moderada, obtivemos correlações significativas com as variáveis sintomas depressivos apresentados pelos cuidadores, com ABVDs, nível socioeconômico e com as versões C-PQdV e com a versão composta.

A Tabela 16 apresenta os índices de correlação entre a versão PQdV e o instrumento WHOQOL-breve.

Tabela 16 - Validade de constructo da versão PQdV no grupo de pacientes leves: índices de correlação entre os itens com os domínios do WHOQOL-breve

\begin{tabular}{lc}
\hline Itens da PQdVa X Domínios do WHOQOL-breve & Índices de Correlação \\
\hline Saúde física x Domínio físico & 0,32 \\
Disposição x Domínio físico & 0,20 \\
Humor x Domínio psicológico & $0,79^{* *}$ \\
Moradia x Meio ambiente & 0,39 \\
Família x Relações sociais & 0,61 \\
Casamento x Relações sociais & 0,61 \\
Amigos x Relações sociais & $0,64^{*}$ \\
Capacidade para fazer tarefas x Domínio físico & 0,59 \\
Capacidade para fazer atividades de lazer x & 0,07 \\
Domínio psicológico & \\
Capacidade para fazer atividades de lazer x Meio & 0,58 \\
ambiente & \\
Dinheiro x Meio ambiente & 0,58 \\
Vida em geral x Questão 1 & 0,56 \\
Pontuação Total x Questão 1 & $0,69^{*}$ \\
Pontuação Total x Somatório & $0,89^{* *}$ \\
\hline${ }^{*} p<0,05 ; * * p 0,01$ & \\
a PQdV (Relato do paciente sobre sua QV); & \\
&
\end{tabular}


$\mathrm{Na}$ validade de constructo da versão PQdV no grupo de pacientes com DA leve, foram encontradas associações significativas nos itens "humor", “amigos" e a pontuação total com a questão 1 e com o somatório. Dos 19 itens associados, quatro apresentaram correlações significativas com os itens do WHOQOL-breve. Dos itens restantes, seis apresentaram tendência de correlação: “família" $(p=0,06)$, “casamento" $(p=0,06)$, “capacidade para fazer tarefas" $(p=0,07)$, “capacidade para fazer atividades de lazer" $(p=0,08)$, “dinheiro" $(p=0,08)$ e "vida em geral" $(p=0,09)$.

A Tabela 17 apresenta os índices de correlação entre a versão C-PQdV e o instrumento WHOQOL-breve.

Tabela 17 - Validade de constructo da versão C-PQdV no grupo de pacientes leves: índices de correlação entre os itens com os domínios do WHOQOL-breve

Itens da C-PQdVb X Domínios do WHOQOL-breve Índices de Correlação

Saúde física $x$ Domínio físico 0,21

Disposição $x$ Domínio físico 0,62

Humor x Domínio psicológico 0,16

Moradia x Meio ambiente 0,18

Família x Relações sociais 0,00

Casamento $x$ Relações sociais 0,39

Amigos x Relações sociais 0,46

Capacidade para fazer tarefas $x$ Domínio físico $0,70 *$

Capacidade para fazer atividades de lazer x Domínio 0,44 psicológico

Capacidade para fazer atividades de lazer x Meio $\quad 0,08$ ambiente

Dinheiro x Meio ambiente

Vida em geral x Questão 1 0,56

Pontuação Total x Questão 1 $0,65^{*}$

Pontuação Total $x$ Somatório $1,00^{* *}$ 
A versão C-PQdV obteve correlações estatisticamente significativas nos itens "capacidade para fazer tarefas", "dinheiro" e na pontuação total com a questão 1 e no somatório. Os resultados demonstram tendência de correlação no item “disposição" ( $\mathrm{p}=0,060)$.

A Tabela 18 apresenta os índices de correlação apresentados pela versão CQdV e o instrumento WHOQOL-breve, no grupo de DA leve.

Tabela 18 - Validade de constructo da versão CQdV no grupo de pacientes leves: índices de correlação entre os itens com os domínios do WHOQOL-breve

\begin{tabular}{lc}
\hline Itens da CQdVc X Domínios do WHOQOL-breve & Índices de Correlação \\
\hline Saúde física x Domínio físico & $0,71^{*}$ \\
Disposição x Domínio físico & $0,67^{*}$ \\
Humor x Domínio psicológico & 0,63 \\
Moradia x Meio ambiente & 0,50 \\
Família x Relações sociais & 0,53 \\
Casamento x Relações sociais & 0,51 \\
Amigos x Relações sociais & 0,51 \\
Capacidade para fazer tarefas x Domínio físico & $0,82^{* *}$ \\
Capacidade para fazer atividades de lazer x & 0,21 \\
Domínio psicológico & \\
Capacidade para fazer atividades de lazer x Meio & 0,45 \\
ambiente & \\
Dinheiro x Meio ambiente & $0,70^{*}$ \\
Vida em geral x Questão 1 & 0,45 \\
Pontuação Total x Questão 1 & 0,59 \\
Pontuação Total x Somatório & $0,83^{* *}$ \\
\hline${ }^{*} p<0,05 ; * 0<, 01 ;$ \\
${ }^{*}$ CQdV (Relato do cuidador/familiar sobre sua própria QV);
\end{tabular}

$\mathrm{Na}$ versão $\mathrm{CQdV}$, as correlações estatisticamente significativas encontradas foram nos itens "saúde física", "disposição", "capacidade para fazer tarefas", "dinheiro" e pontuação total com o somatório. Dois dos itens 
apresentaram tendência de correlação: "humor" ( $p=0,050)$ e a pontuação total com a questão $1(p=0,070)$.

A Tabela 19 apresenta os índices de correlação da versão PQdV, no grupo de DA moderada.

Tabela 19 - Validade de constructo da versão PQdV: índices de correlação entre os itens no grupo de pacientes com DA moderada

\begin{tabular}{lc}
\hline Itens da PQdVa X Domínios do WHOQOL-breve & Índices de Correlação \\
\hline Saúde física x Domínio físico & $-0,14$ \\
Disposição x Domínio físico & 0,47 \\
Humor x Domínio psicológico & $0,65^{*}$ \\
Moradia x Meio ambiente & 0,00 \\
Família x Relações sociais & $-0,17$ \\
Casamento x Relações sociais & 0,22 \\
Amigos x Relações sociais & 0,11 \\
Capacidade para fazer tarefas x Domínio físico & 0,59 \\
Capacidade para fazer atividades de lazer x & 0,47 \\
Domínio psicológico & \\
Capacidade para fazer atividades de lazer x Meio & $-0,20$ \\
ambiente & \\
Dinheiro x Meio ambiente & $-0,22$ \\
Vida em geral x Questão 1 & 0,56 \\
Pontuação Total x Questão 1 & $0,71^{*}$ \\
Pontuação Total x Somatório & $0,90^{*}$ \\
\hline${ }^{*} p<0,05 ; * * p<0,01$ \\
a PQdV (Relato do paciente sobre sua QV);
\end{tabular}

A versão PQdV, no grupo de pacientes com DA moderada, apresentou correlações significativas nos itens: "humor" e na pontuação total com a questão 1 e com o somatório. Dois itens apresentam tendência de correlação: “capacidade para fazer tarefas" $(p=0,070)$ e "vida em geral" $(p=0,094)$. 
A Tabela 20 apresenta os índices de correlação entre a versão C-PQdV e o instrumento WHOQOL-breve no grupo de pacientes com DA moderada.

Tabela 20 - Validade de constructo da versão C-PQdV: índices de correlação entre os itens no grupo de pacientes com DA moderada

\begin{tabular}{lc}
\hline Itens da C-PQdV ${ }^{\mathbf{b}}$ X Domínios do WHOQOL-breve & Índices de Correlação \\
\hline Saúde física x Domínio físico & $-0,08$ \\
Disposição x Domínio físico & 0,30 \\
Humor x Domínio psicológico & $0,65^{*}$ \\
Moradia x Meio ambiente & 0,30 \\
Família x Relações sociais & $0,84^{* *}$ \\
Casamento x Relações sociais & $0,66^{*}$ \\
Amigos x Relações sociais & 0,16 \\
Capacidade para fazer tarefas x Domínio físico & 0,18 \\
Capacidade para fazer atividades de lazer x Domínio & 0,03 \\
psicológico & \\
Capacidade para fazer atividades de lazer x Meio & 0,17 \\
ambiente & \\
Dinheiro x Meio ambiente & 0,38 \\
Vida em geral x Questão 1 & $1,00^{* *}$ \\
Pontuação Total x Questão 1 & $0,64^{*}$ \\
Pontuação Total x Somatório & $0,69^{*}$ \\
\hline${ }^{*} p<0,05 ; * * p<0,01$ \\
bC-PQdV (Relato do cuidador sobre a QV do paciente);
\end{tabular}

$\mathrm{Na}$ versão C-PQdV as correlações encontradas foram com os itens "humor", "família", "casamento", "vida em geral" e a pontuação total com a questão 1 e com o somatório. A Tabela 21 apresenta os índices de correlação da versão CQdV no grupo de DA moderada. 
Tabela 21 - Validade de constructo da versão CQdV: índices de correlação entre os itens no grupo de pacientes com DA moderada

\begin{tabular}{lc}
\hline Itens da CQdVc X Domínios do WHOQOL-breve & Índices de Correlação \\
\hline Saúde física x Domínio físico & 0,46 \\
Disposição x Domínio físico & 0,25 \\
Humor x Domínio psicológico & 0,50 \\
Moradia x Meio ambiente & 0,33 \\
Família x Relações sociais & $0,69^{*}$ \\
Casamento x Relações sociais & 0,59 \\
Amigos x Relações sociais & 0,43 \\
Capacidade para fazer tarefas x Domínio físico & 0,33 \\
Capacidade para fazer atividades de lazer x & 0,27 \\
Domínio psicológico & \\
Capacidade para fazer atividades de lazer x Meio & 0,60 \\
ambiente & \\
Dinheiro x Meio ambiente & 0,22 \\
Vida em geral x Questão 1 & 0,56 \\
Pontuação Total x Questão 1 & $0,70^{*}$ \\
Pontuação Total x Somatório & $0,80^{* *}$ \\
\hline *p<0,05; **< $<01$ & \\
${ }^{*}$ CQdV (Relato do cuidador/familiar sobre sua própria QV); &
\end{tabular}

A versão $C Q d V$, no grupo de pacientes com DA moderada, apresentou correlações significativas nos itens "família" e a pontuação total com a questão 1 e com o somatório. Três itens apresentam tendência estatística de correlação: “casamento" ( $\mathrm{p}=0,071)$, “capacidade para fazer atividades de lazer" $(p=0,067)$ e "vida em geral" $(p=0,093)$. 


\subsection{Comparação entre os relatos dos pacientes e dos cuidadores}

$\mathrm{Na}$ comparação entre os relatos dos pacientes e dos cuidadores/familiares, mantivemos a apresentação dos resultados dos grupos em função da gravidade da doença, com o objetivo de identificar o grau de concordância entre os relatos, associados à intensidade dos sintomas.

Na Tabela 22 são apresentados os resultados da correlação entre os relatos dos pacientes com DA leve e seus respectivos cuidadores/familiares.

Tabela 22 - Médias, desvios-padrão e correlações entre os relatos dos pacientes com DA leve e seus respectivos cuidadores/familiares

\begin{tabular}{lccc}
\hline \multicolumn{1}{c}{ Itens } & PQdVa & C-PQdV $\mathbf{b}$ & Índices de correlação \\
\hline Saúde física & $2,80 \pm 0,80$ & $2,63 \pm 0,76$ & $0,48^{* *}$ \\
Disposição & $2,87 \pm 0,68$ & $2,47 \pm 0,73$ & 0,06 \\
Humor & $2,67 \pm 0,48$ & $2,67 \pm 0,61$ & 0,10 \\
Moradia & $3,23 \pm 0,77$ & $3,23 \pm 0,63$ & 0,32 \\
Memória & $1,83 \pm 0,65$ & $1,63 \pm 0,57$ & 0,24 \\
Família & $3,13 \pm 0,63$ & $2,93 \pm 0,69$ & $-0,06$ \\
Casamento & $3,23 \pm 0,86$ & $2,87 \pm 0,78$ & 0,19 \\
Amigos & $3,37 \pm 0,49$ & $2,67 \pm 0,92$ & $-0,28$ \\
Você no geral & $2,73 \pm 0,74$ & $2,57 \pm 0,73$ & 0,08 \\
Capacidade para & $2,93 \pm 0,64$ & $2,40 \pm 0,93$ & 0,09 \\
fazer tarefas & & & 0,24 \\
Capacidade para & $2,80 \pm 0,85$ & $2,13 \pm 0,97$ & \\
fazer atividades & & & $0,55^{* *}$ \\
de lazer & $2,40 \pm 0,81$ & $2,50 \pm 0,82$ & 0,16 \\
Dinheiro & $2,83 \pm 0,70$ & $2,63 \pm 0,73$ & $0,37^{*}$ \\
Vida em geral & $36,83 \pm 5,17$ & $33,33 \pm 4,98$ & \\
Pontuação Total & & & \\
\hline p< 0,05*, $p<0,01^{* *}$ \\
a PQdV - relato do paciente sobre sua QV
\end{tabular}


Os itens que apresentaram índices de correlação estatisticamente significativos foram "saúde física", "dinheiro" e a pontuação total. O item "moradia" apresentou tendência estatística de correlação $(p=0,081)$. Nos itens mais afetados pela DA, não obtivemos correlações significativas.

A Tabela 23 apresenta os resultados da correlação entre os relatos dos pacientes com DA moderada e seus respectivos cuidadores/familiares.

Tabela 23 - Médias, desvios-padrão e correlações entre os relatos dos pacientes com DA moderada e seus respectivos cuidadores/familiares

\begin{tabular}{lccc}
\hline \multicolumn{1}{c}{ Itens } & $\mathbf{P Q d V}^{\mathbf{a}}$ & $\mathbf{C - P Q d V} \mathbf{b}$ & Índices de correlação \\
\hline Saúde física & $2,57 \pm 0,93$ & $2,50 \pm 0,86$ & $0,46^{*}$ \\
Disposição & $2,60 \pm 0,62$ & $2,13 \pm 0,82$ & $0,35^{*}$ \\
Humor & $2,80 \pm 0,80$ & $2,10 \pm 0,80$ & 0,23 \\
Moradia & $3,17 \pm 0,65$ & $2,90 \pm 0,76$ & $-0,04$ \\
Memória & $2,10 \pm 0,71$ & $1,20 \pm 0,48$ & 0,18 \\
Família & $3,23 \pm 0,68$ & $2,73 \pm 0,78$ & 0,13 \\
Casamento & $3,23 \pm 0,57$ & $2,37 \pm 0,96$ & $-0,03$ \\
Amigos & $2,87 \pm 0,57$ & $2,53 \pm 0,94$ & 0,05 \\
Você no geral & $2,80 \pm 0,85$ & $2,07 \pm 0,83$ & 0,02 \\
Capacidade para fazer & $2,93 \pm 0,74$ & $1,73 \pm 0,74$ & $-0,04$ \\
tarefas & & & \\
Capacidade para fazer & $2,47 \pm 1,00$ & $1,80 \pm 0,80$ & $-0,02$ \\
atividades de lazer & & & 0,15 \\
Dinheiro & $2,50 \pm 0,82$ & $2,23 \pm 0,86$ & 0,19 \\
Vida em geral & $2,87 \pm 0,68$ & $2,03 \pm 0,72$ & 0,32 \\
Pontuação Total & $36,13 \pm 5,35$ & $28,33 \pm 5,97$ & \\
\hline
\end{tabular}
$p<0,05^{*}, p<0,01^{* *}$

a PQdV - relato do paciente sobre sua QV

${ }^{b} \mathrm{C}-\mathrm{PQdV}$ - relato do cuidador sobre a $\mathrm{QV}$ do paciente

Os resultados apresentados nesta tabela mostram correlações estatisticamente significativas nos itens "saúde física" e "disposição". A pontuação total apresentou tendência de correlação $(p=0,083)$. Nos demais itens, houve uma diminuição e até a obtenção de correlações negativas nos índices apresentados, quando comparados ao grupo de DA leve. 
A Tabela 24 apresenta os resultados dos testes estatísticos utilizados para a verificação da influência das variáveis demográficas (idade, escolaridade e gênero) sobre a avaliação de QV, nas três versões.

Tabela 24 - Valores de $p$ dos testes estatísticos relativos à influência das variáveis demográficas sobre as versões PQdV, C-PQdV e CQdV

\begin{tabular}{lccc}
\hline Variáveis & PQdV & C-PQdV & CQdV \\
\hline Idade $^{\mathrm{a}}$ & 0,129 & 0,814 & 0,136 \\
Escolaridade $^{\mathrm{a}}$ & 0,045 & 0,569 & 0,239 \\
Gênero $^{\mathrm{b}}$ & 0,276 & 0,525 & 0,216 \\
\hline
\end{tabular}

a Teste Kruskal-Wallis

$\mathrm{b}$ Teste Qui-quadrado

$\mathrm{Na}$ análise da influência de fatores demográficos (idade, escolaridade e gênero) sobre a avaliação de QV dos pacientes e cuidadores/familiares, identificamos que a versão PQdV sofreu influência da variável escolaridade. As outras versões não sofreram influência de nenhuma das variáveis analisadas.

A Tabela 25 apresenta as médias de pontuação e o tempo, em minutos, gasto na aplicação das três versões da escala QdV-DA, nos grupos de pacientes com DA leve e moderada.

Tabela 25 - Distribuição das médias e desvios-padrão do tempo de aplicação em minutos nos grupos de pacientes com DA leve e moderada

\begin{tabular}{lcc}
\hline \multicolumn{1}{c}{ Aplicação da QdV-DA } & DA leve & DA moderada \\
\hline Tempo de aplicação PQdV & $5,33^{\mathrm{a}} \pm 1,65^{\mathrm{b}}$ & $5,73^{\mathrm{a}} \pm 1,55^{\mathrm{b}}$ \\
Tempo de aplicação C-PQdV & $5,13^{\mathrm{a}} \pm 2,28^{\mathrm{b}}$ & $4,53^{\mathrm{a}} \pm 2,46^{\mathrm{b}}$ \\
Tempo de aplicação CQdV & $5,20^{\mathrm{a}} \pm 2,02^{\mathrm{b}}$ & $4,67^{\mathrm{a}} \pm 1,52^{\mathrm{b}}$ \\
\hline
\end{tabular}

a Médias

b Desvios-padrão

O tempo gasto na aplicação das versões das escalas foi similar em ambos os grupos de gravidade da doença e nas três versões da escala QdV-DA. O gasto médio na aplicação foi de aproximadamente seis minutos. 
7. DISCUSSÃO 
A avaliação de QV tem sido o foco de muitos estudos na área da Saúde, o que demonstra a importância que essa variável vem adquirindo como medida de resultado de intervenções, ao lado de parâmetros já consagrados.

Na escolha de um instrumento de avaliação de QV, vemos a importância de analisarmos as propriedades psicométricas do instrumento selecionado confiabilidade e validade - determinando assim a capacidade do instrumento de apreciar o que se propõe a medir.

A validação de um instrumento envolve muitas etapas, iniciando-se pela verificação da confiabilidade, seguindo até a constatação de que o instrumento avalia o que se propõe a avaliar. Na metodologia de validação, são propostos três aspectos a serem verificados: validade de conteúdo, validade de critério e validade de constructo.

Este estudo considerou que a validade de conteúdo, da escala QdV-DA, foi verificada quando a escala foi construída, devido à metodologia de criação dos itens que envolveu a condução de grupos focais com especialistas da área de Gerontologia e grupos focais com pacientes e cuidadores, identificando itens considerados relevantes na avaliação de QV em demência.

A validade de critério é uma outra forma de verificar a validade de um instrumento, mas que não pode ser conduzida neste estudo, devido ao fato de não haver disponível, em Português, uma escala de avaliação de QV na DA que pudesse servir de "padrão-ouro" para a comparação.

A literatura aponta que a validade de constructo é a forma mais importante de avaliação do instrumento e a mais difícil de ser realizada. A validade de constructo é a metodologia mais utilizada nos estudos de validação de instrumentos de avaliação de QV na demência. 
Até o início deste estudo, não era disponível, em Português, um instrumento de avaliação confiável e válido para avaliar QV em demência.

A escala de avaliação proposta por Logsdon et al. (1999) foi selecionada devido à facilidade em sua aplicação e por apresentar versões que avaliam a QV do paciente e do cuidador/familiar. Essa escala apresentou dados de confiabilidade e validade excelentes.

Neste estudo foram verificadas a confiabilidade da escala adaptada (QDV-DA) em suas três versões (PQdV, C-PQdV e CQdV) e a validade de constructo da escala adaptada em suas três versões mais a versão composta pelo relato do paciente e do cuidador sobre a QV do paciente. A confiabilidade foi avaliada pela análise do alfa de Cronbach e a validade de constructo através da análise de hipóteses e da validade convergentediscriminante.

$\mathrm{Na}$ análise de hipóteses, a escala QdV-DA foi associada a outros instrumentos de avaliação que são utilizados na identificação de sintomas comuns na DA. Na verificação da validade convergente, a escala foi comparada a um instrumento genérico de avaliação de QV.

Com base nos resultados apresentados por este estudo, verificamos que a escala QdV-DA é uma medida promissora para investigação de QV na demência.

A escala nos permite avaliar a QV do paciente utilizando duas das três formas empregadas para avaliar a QV na demência - versão do paciente (auto-relato) e do cuidador/familiar (proxy) sobre a QV do paciente. A escala também possui uma versão que nos permite avaliar a QV do cuidador/familiar, o que torna a avaliação mais completa.

Na Tabela 26, são apresentados os resultados de confiabilidade obtidos neste estudo em comparação com os outros estudos da literatura, visando facilitar a comparação entre esses resultados. 
Tabela 26 - Comparação dos resultados de confiabilidade (alfa de Cronbach) da escala QDV-DA com os dados da literatura

\begin{tabular}{lccc}
\hline Estudos da literatura & Versão PQdV & Versão C-PQdV & Versão CQdV \\
\hline Logsdon et al. 1999 & 0,88 & 0,87 & 0,89 \\
Thorgrimsen et al. 2003 & 0,82 & ----- & ---- \\
Hoe et al. 2005 & 0,78 & ----- & ---- \\
Matsui et al. 2006 & 0,84 & 0,82 & ---- \\
Novelli et al. 2005 & 0,81 & 0,85 & 0,84 \\
\hline Presente estudo & 0,80 & 0,83 & 0,86 \\
\hline
\end{tabular}

Comparando os resultados de confiabilidade obtidos pela escala QdVDA aos estudos já conduzidos, observamos similaridades nos valores obtidos. A versão PQdV apresentou valor de alfa de 0,80, e a versão C-PQdV, alfa de 0,83 . A análise do valor de alfa da versão CQdV pode ser feita através da comparação com o valor obtido com a versão original em Inglês, a partir de dados enviados pela autora da escala: valor de alfa de 0,89 na versão original (Logsdon, comunicação pessoal) e de 0,86 na versão em Português.

Pela qualificação proposta por Gifford e Cummings (1999), valores de alfa maiores de 0,80 são considerados excelentes. Por essa qualificação a escala QdV-DA apresenta valores considerados excelentes nas três versões do instrumento, o que demonstra que todos os itens que compõem a escala avaliam o mesmo fenômeno.

Para a verificação da validade da escala QdV-DA, nos estudos realizados até o momento em que essa validade foi verificada, observamos que a escala foi correlacionada a diversos instrumentos de avaliação dos sintomas comuns à demência. 
A Tabela 27 apresenta os resultados de validação de constructo obtidos neste estudo em comparação com os estudos já conduzidos.

Tabela 27 - Comparação dos resultados de validação de constructo da escala QdV-DA com os dados da literatura

\section{Variáveis}

Logsdon et al. 1999:

- Prejuízo cognitivo

- ABVDs

- AIVDs

-Sintomas depressivos (paciente)

-Sintomas depressivos (cuidador)

\section{PQdVa}

C-PQdV ${ }^{b}$

Composta

$\begin{array}{llll}0,24^{*} & 0,02 & 0,19 & ---- \\ -0,33^{* *} & -0,32^{* *} & -0,37^{* * *} & ---- \\ -0,12 & -0,08 & -0,13 & --- \\ -0,56^{* * *} & -0,14 & -0,49^{* * *} & ---- \\ 0,00 & -0,23^{*} & -0,07 & -0,64^{* *}\end{array}$

Thorgrimsen et al. 2003:

- Euroqol-5D scale

- D-QOL

-Sintomas depressivos (paciente)
$0,54^{* *}$
0,69 **
$-0,20 * *$

Hoe et al. 2005:

-Alterações de comportamento

(apatia)

-Sintomas depressivos (paciente)

-Sintomas depressivos (cuidador)

- Habilidade funcional

- HSQ-12 (saúde física)

- HSQ-12 (saúde mental)

Matsui et al. 2006:

- Alterações de comportamento

$$
-0,56^{* *}
$$

\section{Presente estudo:}

- Prejuízo cognitivo

$$
0,07
$$

$-0,59 * *$

$0,41^{\text {** }}$

0,24

0,23

-Sintomas depressivos (paciente)

0,05

$-0,36^{* *}$

$-0,61^{\text {** }}$

$-0,05$

-Sintomas depressivos (cuidador)

- Alterações de comportamento

$-0,36^{* *}$

$-0,27^{*}$

$-0,16$

$-0,59$ **

- ABVDs

$-0,21$

$-0,71^{* *}$

$-0,58^{* *}$

$-0,39 * *$

- AIVDs

0,01

$-0,51^{* *}$

$-0,38^{* *}$

$-0,32^{*}$

- Nível socioeconômico

$-0,22$

$-0,52^{* *}$

$-0,22$

$-0,41^{* *}$

- PQdV

$----$

0,06

0,19

0,06

- C-PQdV

$0,35^{* *}$

$0,35^{* *}$

0,91 **

0,14

0,14

- CQdV

$p<0,05^{*}, p<0,01^{* *} e p<0,001^{* * *} ;$

aPQdV - relato do paciente sobre sua QV;

bC-PQdV - relato do cuidador sobre a QV do paciente;

c Versão composta pelos relatos dos pacientes e dos cuidadores sobre a QV do paciente;

d CQdV - relato do cuidador sobre sua própria QV. 
Comparando os resultados da literatura com os resultados encontrados neste estudo, podemos identificar valores similares nas associações identificadas entre a escala QdV-DA e os outros instrumentos de avaliação e, conseqüentemente, confirmar a validade de constructo da escala QdV-DA.

Analisando os resultados apresentados pela versão PQdV, observamos que as correlações encontradas por este estudo também foram identificadas nos estudos de Logsdon et al. (1999) e Hoe et al. (2005). A correlação com desempenho funcional, que havia sido proposta inicialmente, não foi identificada. Como os dados da literatura demonstram que não há correlação entre o prejuízo cognitivo e o auto-relato do paciente, essa hipótese não foi feita, mas foi analisada e nossos resultados são similares aos estudos anteriores, não sendo identificada a correlação entre o auto-relato do paciente sobre sua QV e prejuízo cognitivo. Na análise destes dados podemos dizer que o fato de não termos encontrado correlação entre QV e prejuízo cognitivo não significa dizer que o prejuízo cognitivo não afeta a QV do indivíduo, mas que outras variáveis podem ter uma influência maior, como alterações de comportamento e sintomas depressivos apresentados pelos pacientes, como mostram os resultados. O mesmo raciocínio se aplica ao desempenho funcional.

Discutindo os resultados apresentados pela versão C-PQdV, observamos que essa versão apresentou correlações com todas as variáveis propostas inicialmente, apresentando correlação também com prejuízo cognitivo, que não havia sido aventada. Essa associação foi identificada no relato do cuidador sobre a QV do paciente, possivelmente devido ao fato de ele considerar o funcionamento cognitivo como uma variável de bem-estar, algo que, no entanto, não apareceu nos relatos dos pacientes. Analisando as associações encontradas nesta versão, com exceção do funcionamento cognitivo, observamos que essas associações também se assemelham aos resultados dos estudos realizados anteriormente (Logsdon et al., 1999; 
Thorgrimsen et al., 2003; Hoe et al., 2005), onde foram identificadas correlações com as mesmas variáveis.

$\mathrm{Na}$ análise dos resultados da versão composta identificamos que todas as hipóteses iniciais foram confirmadas. O único estudo que fez essa análise foi o estudo original e podemos observar que as correlações, em ambos os estudos, são idênticas.

Das três versões propostas para avaliar QV do paciente (PQdV, C-PQdV e a versão composta) identificamos que a versão composta é a que apresenta melhor validade de constructo quando associada aos outros instrumentos de avaliação. A versão composta pode também ser considerada como uma boa opção de avaliação de QV na demência, por contemplar duas das três formas mais utilizadas para avaliar o fenômeno (auto-relato e o proxy) e por privilegiar a subjetividade através do auto-relato.

Os resultados da literatura sobre a validade da versão CQdV ainda não foram publicados. Segundo a autora da escala (Logsdon, comunicação pessoal), a validade desta versão $\mathrm{CQdV}$ foi determinada pela comparação com as seguintes variáveis: sintomas depressivos apresentados pelo cuidador, sobrecarga no cuidado e com a versão C-PQdV.

No presente estudo, as possibilidades de associações foram ampliadas, considerando variáveis associadas ao paciente e ao cuidador. Dentre as variáveis relacionadas ao paciente, incluímos desempenho funcional (AIVDs e ABVDs), alterações de comportamento, sintomas depressivos apresentados pelos pacientes. Nas variáveis associadas ao cuidador mantivemos a associação com sintomas depressivos apresentados pelo cuidador.

A análise dos resultados demonstra que essa versão apresentou correlações significativas com todas as variáveis aventadas inicialmente, acrescentando a associação com a versão composta, o que confirma a validade de constructo da versão em Português do instrumento.

Interpretando esses resultados, podemos identificar que a QV dos cuidadores é afetada não só por variáveis associadas ao cuidador, como 
sintomas depressivos identificados pelo auto-relato, mas também por sintomas apresentados pelo paciente, como alterações de comportamento, sintomas depressivos e comprometimento funcional. Pela interpretação destes resultados fica evidente o impacto da DA sobre a QV do paciente e do cuidador.

$\mathrm{Na}$ análise da validade convergente da escala realizada através da comparação com um instrumento genérico de avaliação de QV, identificamos que o único estudo que conduziu essa análise foi o estudo de Thorgrimsen et al. (2003), através da comparação da escala QdV-DA com dois instrumentos de avaliação de QV - um genérico (Euroqol) e um específico (D-QOL), encontrando associações significativas com ambos os instrumentos. Como não é disponível, em Português, um instrumento específico para avaliar QV em demência, conduzimos a análise através da comparação com um instrumento genérico de avaliação de QV (WHOQOL-breve).

$\mathrm{Na}$ análise da validade convergente da versão PQdV, observamos correlações significativas na maioria dos itens com os domínios e, como era esperado, da pontuação total da escala com o somatório do instrumento genérico.

Na versão C-PQdV, também encontramos correlações significativas da maioria dos itens com os domínios e da pontuação total da escala com o somatório do instrumento genérico.

$\mathrm{Na}$ análise da validade convergente da versão CQdV, observamos que a maioria dos itens apresentaram correlações com os domínios e a pontuação total com o somatório.

$\mathrm{Na}$ análise dos resultados, identificamos que a versão CQdV foi a que obteve maior número de correlações de itens com os domínios do WHOQOL-breve, seguida da versão PQdV e, posteriormente, da versão CPQdV-DA. Apesar das diferenças nas correlações, os coeficientes obtidos na associação entre a pontuação total da escala QdV-DA e o somatório do WHOQOL-breve são muito elevados, sendo todos maiores que 0,70 nas três 
versões da escala. Esses resultados confirmam a validade convergente da escala QdV-DA, nas três versões, com o WHOQOL-breve.

Apesar da alta correlação entre os dois instrumentos, o uso de um instrumento específico apresenta vantagens sobre o instrumento genérico devido às características dos indivíduos com DA. O instrumento específico possui uma linguagem mais simples, com questões mais curtas, e a qualificação possui apenas quatro pontos sendo eles bem distintos uns dos outros, o que facilita a compreensão e, conseqüentemente, a qualificação da resposta. Além disso, o instrumento específico inclui itens que foram considerados importantes na avaliação dos pacientes e dos cuidadores, o que não é contemplado pelo instrumento genérico.

Uma crítica comum às avaliações de QV nas síndromes demenciais é a dificuldade de se estabelecer até que ponto de prejuízo cognitivo o indivíduo é capaz de avaliar sua própria QV. A avaliação do impacto do prejuízo cognitivo sobre a confiabilidade e a validade da escala foi proposta na tentativa de responder a essa indagação.

Em relação à confiabilidade da escala, observamos que os valores de alfa obtidos no grupo de DA leve, tanto para a versão PQDV como para a versão CQdV são elevados, 0,81 e 0,88, respectivamente, e na versão C-PQdV observamos um valor de 0,75 , considerado bom. Analisando os resultados da escala no grupo de DA moderada, constatamos que todas as três versões apresentaram valores de alfa elevados e excelentes, $\geq 0,80$. Esses resultados demonstram que a consistência interna da escala QdV-DA é mantida a despeito da gravidade da doença.

$\mathrm{Na}$ avaliação do impacto cognitivo sobre a validade de constructo da escala, feita através da associação com outras medidas de avaliação, observamos que a validade também é mantida apesar do aumento da gravidade da doença.

Na análise da versão PQdV, no grupo de DA leve, identificamos que as associações encontradas são idênticas às encontradas no estudo original, 
inclusive a não-associação com desempenho em AIVDs (Logsdon et al., 1999) e similares às associações encontradas nas análises na amostra total. Nas análises em função da gravidade começamos a identificar associações significativas relacionadas aos sintomas mais comuns presentes nos diferentes estágios da doença, como associação com sintomas depressivos apresentados pelos pacientes e alterações de comportamento.

Na versão C-PQdV no grupo de DA leve, associações com os sintomas comuns nesta fase da doença também foram encontradas, como associação com sintomas depressivos apresentados pelo paciente e alterações de comportamento. Em relação ao desempenho funcional, os resultados demonstram uma tendência de associação negativa entre QV e desempenho em AIVDs, o que era esperado, pois são as atividades mais comprometidas nos estágios iniciais da doença.

Esta versão apresentou correlações com todas as variáveis consideradas nas hipóteses do estudo, e as associações encontradas foram similares às análises conduzidas na amostra total, com exceção do prejuízo cognitivo e desempenho em ABVDs. Como já citado anteriormente, a não-associação com o prejuízo cognitivo não significa que essa variável não afete a QV dos indivíduos, visto que é devido ao problema cognitivo que outros sintomas aparecem, como alterações de comportamento e comprometimento funcional, mas talvez que outros fatores tenham maior peso nos relatos dos pacientes e dos cuidadores. Era esperado que não encontrássemos associação com desempenho em ABVDs, pois pacientes neste estágio da doença não costumam ter dificuldades de desempenho nessas atividades.

Os resultados demonstram que existe correlação entre o relato do paciente e do cuidador/familiar, neste estágio da doença.

A versão composta, no grupo de DA leve, apresentou correlações com a maioria dos itens propostos inicialmente, com exceção da associação com desempenho em AIVDs. 
Analisando a validade de constructo no grupo de DA moderada, identificamos que a versão PQdV apresentou associações relacionadas aos sintomas mais comuns neste estágio da doença como, por exemplo, associação com sintomas depressivos, alterações de comportamento e desempenho funcional em ABVDs. Como era esperado, esta versão apresentou associação com ABVDs, pois são as atividades mais comprometidas neste estágio da doença.

$\mathrm{Na}$ versão C-PQdV, no grupo de DA moderada, quatro das cinco hipóteses foram confirmadas por correlações significativas. Analisando esses resultados, identificamos que a percepção do cuidador sobre a QV do paciente, neste estágio da doença, é afetada pelos sintomas comuns nesta fase.

Os resultados apontam que, no grupo de DA moderada, existe uma tendência de correlação $(p=0,095)$ entre o relato do paciente sobre sua QV (PQdV) e a versão do cuidador sobre a QV do paciente (CPQdV).

A versão composta, no grupo de DA moderada, apresentou correlações com todas as variáveis propostas inicialmente.

$\mathrm{Na}$ versão do cuidador sobre sua própria QV (CQdV), no grupo de pacientes leves, identificamos que a presença de alterações de comportamento e de sintomas depressivos apresentados pelo cuidador têm maior impacto sobre a QV do cuidador. Já na análise da mesma versão, no grupo de DA moderada, identificamos que os sintomas depressivos apresentados pelos cuidadores e o desempenho funcional em ABVDs são os fatores de maior associação com a QV do cuidador. Observamos também uma associação entre QV e nível socioeconômico, na percepção do cuidador.

As associações encontradas, no estudo de validade de constructo através da correlação com outros instrumentos de avaliação refletem, na sua grande maioria, o impacto dos sintomas mais comuns presentes nas fases leve e moderada da doença sobre a percepção de QV do paciente e do cuidador/familiar, em todas as versões da escala QdV-DA. 
Analisando a influência do prejuízo cognitivo sobre a validade convergente da escala QdV-DA, identificamos que as associações entre os itens e os domínios do WHOQOL-breve diminuem com o aumento da gravidade da doença, em todas as versões analisadas. Entretanto na associação entre a pontuação total da escala QdV-DA e o somatório do WHOQOL-breve, identificamos que os coeficientes de correlação mantiveram-se elevados em todas as versões, em ambos os grupos de gravidade.

Tanto na versão PQdV como na versão $C Q d V$, os coeficientes de correlação mantiveram-se acima de 0,80, em ambos os grupos de gravidade. Na versão CPQdV, os coeficientes foram de 1,00 (DA leve) e 0,69 (DA moderada).

Esses resultados demonstram que a validade convergente da escala QdVDA é mantida apesar da gravidade da doença.

A análise dos resultados do impacto do prejuízo cognitivo sobre a confiabilidade e sobre a validade da escala QdV-DA demonstra que tanto a confiabilidade como a validade da escala não foram comprometidas pelo prejuízo cognitivo, pelo menos até a fase moderada da doença.

$\mathrm{Na}$ comparação entre os relatos dos pacientes (PQdV) e dos cuidadores/familiares (C-PQdV), os resultados do estudo original (Logsdon et al., 1999) apresentam uma concordância baixa nos itens mais afetados pela demência, como memória, humor e capacidade para fazer tarefas. O presente estudo também identificou discordâncias entre os relatos dos pacientes e dos cuidadores/familiares, que diferem de acordo com a gravidade da DA.

$\mathrm{Na}$ análise do grupo de pacientes leves, observamos que os itens mais afetados pela demência do paciente, como disposição, humor, relacionamento com familiares, capacidade para fazer tarefas e você em geral, as correlações foram baixas.

Analisando o grupo de pacientes moderados, observamos que, também nos itens mais afetados pela demência, a correlação diminuiu ou até houve a obtenção de correlações negativas, quando comparado ao grupo de pacientes leves. 
Essas discordâncias nos relatos dos pacientes e dos cuidadores/familiares foram identificada em outros estudos (Kiyak et al., 1994; Logsdon et al., 1999; Bressan, 2005). No estudo de Kiyak et al. (1994), as discordâncias entre os relatos dos pacientes e dos cuidadores/familiares foram relacionadas às habilidades funcionais dos pacientes, onde a habilidade relatada pelo paciente era melhor do que a descrita na avaliação do cuidador/familiar.

No estudo conduzido por Bressan (2005), foi identificado que os cuidadores, quando avaliavam a capacidade funcional dos pacientes subestimavam a capacidade do paciente quando comparada aos resultados obtidos pela observação direta do paciente em atividade.

As diferenças nos relatos podem ser atribuídas a diversos fatores. Fatores associados ao paciente e fatores associados ao cuidador. Dentre os associados ao paciente, temos que o prejuízo de julgamento e crítica vai se agravando com a progressão da doença, dificultando ao paciente avaliar sua condição de forma fidedigna. Em relação ao cuidador, temos que observar que ele, ao avaliar a QV do paciente, na maioria das vezes utiliza seus padrões de referência. Esses padrões podem ser influenciados por diversos aspectos, como o desgaste físico e emocional vivenciado pelo cuidador no cuidado diário e/ou o simples fato de o paciente estar acometido por uma doença degenerativa já pressupor uma QV ruim.

Ressaltamos que, na avaliação de QV, é de suma importância considerar a percepção do indivíduo, contemplando a subjetividade. No entanto, como a DA é uma doença progressiva, considerar a percepção do cuidador/familiar sobre a QV do paciente pode minimizar as limitações próprias da doença e complementar a avaliação de QV pelo paciente, principalmente se estivermos diante de estágios mais avançados da doença. Além disso, identificamos que, pelos resultados discutidos até aqui, a versão composta pelos relatos dos pacientes e dos cuidadores/familiares sobre a QV do paciente foi a versão que demonstrou maior validade de constructo em ambos os grupos de gravidade da doença. 
Quando analisamos as médias de pontuação nas três versões da escala (PQdV, C-PQdV e CQdV), nos grupos de DA leve e moderada, observamos um decréscimo nas médias com a aumento da gravidade da doença, o que era esperado devido ao caráter progressivo da doença.

No auto-relato do paciente (PQdV), apesar de haver um decréscimo na média, os valores estão muito próximos, e o prejuízo de julgamento nos pacientes moderados pode ser uma justificativa para essa proximidade de valores. Além do prejuízo de julgamento nos pacientes moderados, um outro fator pode contribuir para essa pouca diferença: o senso crítico dos pacientes leves pode estar relativamente preservado diante das situações do dia-a-dia, fazendo com que eles tenham consciência de suas perdas e limitações, o que diminui a pontuação de seu relato.

$\mathrm{Na}$ avaliação do cuidador/familiar sobre a QV do paciente (C-PQdV), observamos também uma diminuição nas médias de pontuação com o aumento da gravidade da doença. Os sintomas comumente apresentados pelo paciente, como maior comprometimento cognitivo, aumento na dependência para a execução de atividades do dia-a-dia, alterações de comportamento afetando o humor e o relacionamento com familiares e amigos e ainda a presença de sintomas depressivos podem ser os parâmetros utilizados pelo cuidador/familiar para avaliar a QV do paciente fazendo com que essa pontuação diminua.

Um outro ponto a ser considerado, como fator de impacto para a avaliação do cuidador sobre a QV do paciente e também a da sua própria, são os fatores associados aos sintomas depressivos decorrentes do cuidado e da alteração na rotina do cuidador, a sobrecarga vivenciada no cuidado devido à falta de informação sobre a doença e sua evolução, e a falta de redes de suporte que o auxiliem.

Analisando os resultados apresentados pela avaliação da influência das variáveis demográficas (idade, gênero e escolaridade) sobre a aplicação da escala QdV-DA, podemos observar que os resultados não demonstraram a 
influência de nenhuma das variáveis demográficas analisadas sobre as versões C-PQdV e CQdV. A única versão que demonstrou sofrer influência da variável escolaridade foi a versão PQdV, onde as médias de pontuação na avaliação de QV são mais altas nos indivíduos com nível de escolaridade mais elevado.

Em relação ao tempo médio de aplicação, a escala QdV-DA levou em média seis minutos para sua aplicação nas três versões, independentemente da gravidade da doença, mostrando ser uma escala de rápida aplicação. Comparando nossos resultados ao estudo original (Logsdon et al., 1999), identificamos que o tempo gasto na aplicação da versão PQdV foi menor e que nas outras duas versões (C-PQdV e CPQdV), ele foi similar.

Como limitações do presente estudo, podemos considerar que o tamanho da amostra dificulta a generalização dos dados, sendo eles restritos a essa população. Um estudo com uma amostra maior advindas de diferentes localidades nos permitiria identificar a estabilização dos dados. Outra limitação do estudo foi a impossibilidade de avaliar a validade de critério da escala devido à falta de outro instrumento específico de avaliação de QV em demência em Português.

Estudos futuros deveriam ser direcionados para a complementação do processo de validação da versão em Português da escala QdV-DA, envolvendo aspectos relacionados à validade de critério e à normatização da escala.

A versão em Português da escala $Q O L-A D$, sendo uma escala confiável e válida, nos permite realizar, a partir de agora, estudos qualitativos em relação à variável QV para a identificação de variáveis, sintomatológicas ou não, que possam ter impacto sobre a QV do paciente e a QV do cuidador/familiar ao longo do desenvolvimento da doença. Essa versão nos permite também participar de estudos multicêntricos envolvendo diferentes países com o intuito de identificar variáveis associadas às características culturais dos países que possam ter impacto sobre a QV dos indivíduos afetados pela doença e também sobre a QV de seus cuidadores/familiares. 
8. CONCLUSÕES 
1. A consistência interna dos itens da escala $Q d V-D A$ reflete que a escala constitui uma medida adequada do fenômeno que se propõe a avaliar, com valores de alfa de Cronbach, considerados excelentes em todas as três versões do instrumento (PQdV, C-PQdV e CQdV).

2. Ao analisar a validade de constructo das três versões da escala (PQdV, C-PQdV, CQdV e a versão composta), através da associação com outros instrumentos de avaliação, foram encontradas associações importantes entre a escala e as hipóteses propostas, o que demonstra uma validade de constructo adequada. A versão composta foi a versão que apresentou melhor validade de constructo quando comparada às outras versões.

3. Na avaliação da validade de constructo (validade convergente) obtida pela correlação da escala com um instrumento genérico (WHOQOLbreve), pudemos demonstrar que ambos os instrumentos apresentavam correlações positivas e significativas, nas três versões.

4. Ao analisar o impacto do comprometimento cognitivo sobre a confiabilidade e a validade da escala, os resultados mostraram que tanto a confiabilidade como a validade foram mantidas, nas três versões, independentemente do aumento da gravidade da doença. A versão composta é a que mais se associa às hipóteses levantadas nos grupos de pacientes com DA leve e moderada. 
5. A correlação entre os relatos dos pacientes e dos cuidadores/familiares apresentou discordâncias que diferem de acordo com a gravidade da doença.

6. A versão PQdV apresentou influência da escolaridade na amostra estudada.

7. Em síntese, a escala QdV-DA, em suas três versões, é uma escala de fácil e rápida aplicação, mostrando-se confiável e válida para investigação de QV na DA. 


\section{ANEXOS}


Anexo A

Critérios para diagnóstico clínico de Doença de Alzheimer (NINCDS/ADRDA)

\section{Alzheimer Provável}

\begin{tabular}{|c|c|c|c|}
\hline & \multicolumn{3}{|c|}{ Critério } \\
\hline & $\begin{array}{l}\text { Presente/ } \\
\text { Sim }\end{array}$ & $\begin{array}{l}\text { Ausente/ } \\
\text { Não }\end{array}$ & Incerto \\
\hline \multicolumn{4}{|l|}{ I Critério } \\
\hline 1. Demência estabelecida por exame clínico & $\mathrm{O}$ & o & o \\
\hline a. documentado pelo Mini-Exame do Estado Mental ou similar & $\mathrm{O}$ & O & O \\
\hline b. confirmado por avaliação neuropsicológica & $\mathrm{O}$ & $\mathrm{O}$ & o \\
\hline 2. Déficit em duas ou mais áreas da cognição & O & O & O \\
\hline 3. Piora progressiva da memória e de outras funções cognitivas & $\mathrm{O}$ & $\mathrm{O}$ & $\mathrm{O}$ \\
\hline 4. Sem distúrbio da consciência & O & $\mathrm{O}$ & $\mathrm{O}$ \\
\hline 5. Início entre 40 e 90 anos de idade & $\mathrm{O}$ & O & $\mathrm{O}$ \\
\hline $\begin{array}{l}\text { 6. Ausência de doenças sistêmicas ou cerebrais que poderiam } \\
\text { provocar déficit progressivo da memória e cognição }\end{array}$ & o & $\mathrm{O}$ & $\mathrm{O}$ \\
\hline \multicolumn{4}{|l|}{ II Dados de suporte } \\
\hline $\begin{array}{l}\text { 1. Deterioração progressiva de funções cognitivas específicas como } \\
\text { linguagem, habilidades motoras e perceptivas }\end{array}$ & $\mathrm{O}$ & $\mathrm{O}$ & o \\
\hline 2. Atividades de vida diária comprometidas & $\mathrm{O}$ & $\mathrm{O}$ & $\mathrm{O}$ \\
\hline 3. História familiar de desordem semelhante & $\mathrm{O}$ & O & O \\
\hline $\begin{array}{l}\text { 4. Análise de LCR normal, alterações não específicas no EEG e } \\
\text { evidência de atrofia cerebral em TC }\end{array}$ & $\mathrm{O}$ & O & O \\
\hline \multicolumn{4}{|l|}{ III Compatível com } \\
\hline 1. Ocorrência de platôs no curso da doença & o & $\mathrm{O}$ & $\mathrm{O}$ \\
\hline $\begin{array}{l}\text { 2. Sintomas associados como alteração do comportamento, } \\
\text { distúrbio do sono e perda de peso }\end{array}$ & o & $\mathrm{O}$ & o \\
\hline $\begin{array}{l}\text { 3. Outras anormalidades neurológicas em alguns pacientes como } \\
\text { sinais motores (hipertonia, mioclonias, alteração da marcha na } \\
\text { fase doença avançada da doença) }\end{array}$ & $\mathrm{O}$ & $\mathrm{O}$ & $\mathrm{O}$ \\
\hline 4. Crises convulsivas na fase avançada da doença & $\mathrm{O}$ & $\mathrm{O}$ & o \\
\hline 5. TC normal para idade & $\mathrm{O}$ & O & O \\
\hline \multicolumn{4}{|l|}{ IV Quadros que tornam o diagnóstico improvável } \\
\hline 1. Início súbito, apoplético & $\mathrm{O}$ & $\mathrm{O}$ & $\mathrm{O}$ \\
\hline 2. Sinais neurológicos focais & $\mathrm{O}$ & $\mathrm{O}$ & $\mathrm{O}$ \\
\hline $\begin{array}{l}\text { 3. Distúrbio de marcha ou crises convulsivas no início ou } \\
\text { precocemente no curso da doença }\end{array}$ & $\mathrm{O}$ & o & o \\
\hline
\end{tabular}




\section{Alzheimer Possível}

V. Critério

1. Síndrome demencial com início, apresentação ou evolução atípicas

O

O

O

2. Uma segunda desordem sistêmica ou cerebral suficiente para

$\mathrm{O}$

O

O

produzir demência mas não considerada como causa da demência pode estar presente

3. Presença de um único déficit progressivo pode ser suficiente para o diagnóstico, para fins de pesquisa 
Anexo B

Critério de gravidade da demência (DSM-III-R)

\begin{tabular}{lc}
\hline & $\begin{array}{c}\text { Assinalar } \\
\text { um }\end{array}$ \\
\hline 0. Normal & $\mathrm{o}$ \\
$\begin{array}{l}\text { 1. Leve (Embora significativamente alterado, mantém capacidade } \\
\text { para vida independente ) }\end{array}$ & $\mathrm{c}$ \\
2. Moderado (Vida independente oferece riscos) & $\mathrm{o}$ \\
$\begin{array}{l}\text { 3. Grave (Atividades de vida diária estão tão comprometidas que o } \\
\text { paciente requer supervisão contínua) }\end{array}$ & $\mathrm{o}$ \\
\hline
\end{tabular}


Anexo C

\begin{tabular}{|c|c|c|c|c|}
\hline Envelhecimento e & $\begin{array}{l}\text { ência: } \\
\text { ão do } 1\end{array}$ & $\begin{array}{l}\text { alidade } d \\
\text { ente) }\end{array}$ & da na $L$ & \\
\hline Nome do sujeito & avaliaçấ & & Data d & revista \\
\hline $\begin{array}{l}\text { O entrevistador aplica de acordo } \\
\text { Faça um circulo ao redor da respo }\end{array}$ & as instr & es padror & das. & \\
\hline 1. Saúde Física & Ruim & Regular & Bom & Excelente \\
\hline 2. Disposição & Ruim & Regular & Bom & Excelente \\
\hline 3. Humor & Ruim & Regular & Bom & Excelente \\
\hline 4. Moradia & Ruim & Regular & Bom & Excelente \\
\hline 5. Memória & Ruim & Regular & Bom & Excelente \\
\hline 6. Família & Ruim & Regular & Bom & Excelente \\
\hline 7. Casamento & Ruim & Regular & Bom & Excelente \\
\hline 8. Amigos & Ruim & Regular & Bom & Excelente \\
\hline 9. Você em geral & Ruim & Regular & Bom & Excelente \\
\hline 10. Capacidade para fazer tarefas & Ruim & Regular & Bom & Excelente \\
\hline $\begin{array}{l}\text { 11. Capacidade para fazer } \\
\text { atividades de lazer }\end{array}$ & Ruim & Regular & Bom & Excelente \\
\hline 12. Dinheiro & Ruim & Regular & Bom & Excelente \\
\hline 13. Vida em geral & Ruim & Regular & Bom & Excelente \\
\hline
\end{tabular}

\section{Comentários:}

\section{Total:}




\section{Qualidade de Vida - DA \\ Instruções para entrevistadores}

O teste QdV-DA é administrado em formato de entrevista para indivíduos com demência, seguindo as instruções abaixo.

Entregue o formulário ao participante, de forma que ele (a) possa acompanhá-lo enquanto você dá as seguintes instruções. (instruções devem seguir à risca as palavras em negrito).

Eu quero fazer a você algumas perguntas sobre sua qualidade de vida e que você avalie vários aspectos da sua vida usando uma das quatros palavras: Ruim, Regular, Bom ou Excelente.

Aponte cada palavra (Ruim, Regular, Bom, Excelente) no formulário enquanto você as fala.

Quando você pensa sobre sua vida, existem diferentes aspectos, como sua saúde física, energia, família, dinheiro e outros. Eu vou pedir para você avaliar cada um destes aspectos. Nós queremos descobrir como você se sente em relação à sua situação atual em cada área.

Se você não tem certeza sobre o que uma questão significa, você pode me perguntar. Se você tiver dificuldade para avaliar algum item, dê somente a resposta que representa como você se sente a maior parte do tempo.

É usualmente aparente se um indivíduo entende as perguntas e a maioria dos indivíduos que são aptos a se comunicar e responder a perguntas simples podem entender o instrumento de avaliação. Se todas as respostas do participante forem iguais ou se ele disser alguma coisa que indique falta de entendimento, o entrevistador é encorajado a esclarecer a pergunta. No entanto, sob nenhuma circunstância deve-se sugerir uma resposta específica. Cada uma das quatro respostas possíveis deve ser apresentada e o paciente deve escolher uma das quatro.

Se o participante é incapaz de escolher uma resposta para um item ou itens específicos, isto deve ser anotado nos comentários. Se o participante não puder compreender e/ou responder a dois ou mais itens o teste pode ser descontinuado e isto deve ser anotado nos comentários.

Enquanto você lê os itens listados abaixo, peça ao participante para circular sua resposta. Se o participante tiver dificuldades para circular a palavra você pode pedir a ele para apontar a palavra ou dizê-la e você pode circular a palavra para ele (a). Você deve deixar o participante segurar a sua própria cópia da avaliação e acompanhar enquanto você lê cada item: 
1. Em primeiro lugar, como você se sente em relação à sua saúde física? Você diria que é ruim, regular, boa ou excelente? Circule qualquer palavra que você acha que melhor descreve sua saúde física agora.

2. Como você se sente sobre seu nível de disposição? Você acha que é ruim, regular, bom ou excelente? Se o participante disser que alguns dias são melhores que outros, peça a ele (a) para avaliar como tem se sentido a maior parte do tempo ultimamente.

3. Como tem estado seu humor ultimamente? Seu estado de espírito tem estado bom ou você tem se sentido desanimado? Você avaliaria seu humor como ruim, regular, bom ou excelente?

4. Como você se sente em relação a sua moradia? Como você se sente em relação ao lugar em que você vive agora? Você diria que está ruim, regular, bom ou excelente?

5. Como está sua memória? Você diria que está ruim, regular, boa ou excelente?

6. E sobre sua família e sua relação com os membros da família? Você descreveria como ruim, regular, boa ou excelente? Se o participante disser que não tem família, pergunte sobre irmãos, irmãs, crianças, sobrinhos e sobrinhas.

7. Como você se sente em relação ao seu casamento? Como é sua relação com (nome da esposa (o))? Você sente que é ruim, regular, boa ou excelente? Alguns participantes poderão ser solteiros, viúvos, ou divorciados. Quando este for o caso, pergunte como ele se sente sobre a pessoa com quem mantêm uma relação íntima, (seja quem for) se este é um membro da família ou amigo. Se houver um cuidador familiar, pergunte sobre sua relação com esta pessoa. Caso não exista ninguém nestas condições, marque "não se aplica".

8. Como você descreveria sua atual relação com seus amigos? Você diria que é ruim, regular, boa ou excelente? Se o participante responder que ele (a) não tem amigos ou que todos os seus amigos já morreram, investigue mais profundamente. Você tem alguém com quem gosta de estar, além de sua família? Você chamaria essa pessoa de amigo? Se o participante ainda disser que não tem amigos, pergunte como ele (a) se sente sobre não ter amigos - se ruim, regular, bom ou excelente?

9. Como você se sente sobre você mesmo? Quando você pensa sobre sua vida como um todo, e diferentes coisas sobre você, você diria que é ruim, regular, bom ou excelente? 
10. O que você acha sobre sua capacidade para realizar tarefas domésticas ou outras coisas que você precise fazer? Você diria que é ruim, regular, bom, ou excelente?

11.E sobre sua capacidade para fazer atividades de lazer, coisas que você goste? Você diria que é ruim, regular, bom ou excelente?

12. Como você se sente sobre sua atual situação financeira? Você sente que é ruim, regular, boa ou excelente? Se o participante hesitar, explique que você não quer saber qual é a situação financeira dele (a) apenas como ele (a), se sente a respeito disso.

13. Como você descreveria sua vida em geral? Quando você pensa na sua vida em geral, como você se sente? Você diria que sua vida é ruim, regular, boa ou excelente?

Instruções para pontuação do teste QdV:

Pontos são atribuídos para cada item como a seguir: ruim 1 , regular=2, bom=3, excelente $=4$.

O total de pontos é a soma da pontuação para cada um dos 13 itens. 


\section{Envelhecimento e Demência: Qualidade de vida na DA \\ (Versão familiar)}

Nome do sujeito Número da avaliação Data da entrevista

As questões a seguir são sobre a qualidade de vida de seu parente

Quando você pensa sobre a vida de seu parente, existem diferentes aspectos, alguns dos quais são listados abaixo.

Por favor, pense sobre cada item e marque qualidade de vida atual de seu parente em cada área usando uma das quatro palavras: Ruim, Regular, Bom, ou Excelente. Por favor, marque estes itens baseado na vida de seu parente no presente momento (ex. Dentro de poucas semanas).

Se você tiver dúvidas sobre qualquer item, por favor, peça à pessoa que the de assistência.

Circule suas respostas

\begin{tabular}{|ll|l|l|l|l|}
\hline 1. & Saúde Física & Ruim & Regular & Bom & Excelente \\
\hline 2. $\quad$ Disposição & Ruim & Regular & Bom & Excelente \\
\hline 3. Humor & Ruim & Regular & Bom & Excelente \\
\hline 4. Moradia & Ruim & Regular & Bom & Excelente \\
\hline 5. $\quad$ Memória & Ruim & Regular & Bom & Excelente \\
\hline 6. $\quad$ Família & Ruim & Regular & Bom & Excelente \\
\hline 7. Casamento & Ruim & Regular & Bom & Excelente \\
\hline 8. Amigos & Ruim & Regular & Bom & Excelente \\
\hline 9. Você em geral & Ruim & Regular & Bom & Excelente \\
\hline $\begin{array}{l}\text { 10. Capacidade para realizar } \\
\text { tarefas }\end{array}$ & Ruim & Regular & Bom & Excelente \\
\hline $\begin{array}{l}\text { 11. Capacidade para fazer } \\
\text { atividades de lazer }\end{array}$ & Ruim & Regular & Bom & Excelente \\
\hline 12. Dinheiro & Ruim & Regular & Bom & Excelente \\
\hline 13. A vida em geral & Ruim & Regular & Bom & Excelente \\
& & & & \\
\hline
\end{tabular}

Pontos: 


\begin{tabular}{|c|c|c|c|c|c|c|c|}
\hline \multicolumn{8}{|c|}{$\begin{array}{c}\text { Envelhecimento e Demência: Qualidade de vida na DA } \\
\text { (Versão do cuidador) }\end{array}$} \\
\hline \multicolumn{3}{|c|}{ Nome do sujeito } & \multicolumn{2}{|c|}{ Número da avaliação } & \multicolumn{3}{|c|}{ Data da entrevista } \\
\hline \multicolumn{8}{|c|}{$\begin{array}{l}\text { Instruções: Por favor, avalie o quanto cada item é importante para sua qualidade de vida } \\
\text { como um todo e em seguida avalie sua atual situação, como você a vê. Indique suas } \\
\text { escolhas colocando um X no quadrado apropriado. No ultimo item, por favor, avalie sua } \\
\text { qualidade de vida como um todo, como você a vê. } \\
\text { Importância } \\
\text { Situação Atual }\end{array}$} \\
\hline \multirow[t]{13}{*}{ Muito } & Razoável & Nada & & Ruim & Regular & Bom & Excelente \\
\hline & & & 1. Saúde Física & & & & \\
\hline & & & 2. Disposição & & & & \\
\hline & & & 3. Humor & & & & \\
\hline & & & 4. Moradia & & & & \\
\hline & & & 5. Memória & & & & \\
\hline & & & 6. Família & & & & \\
\hline & & & 7. Casamento & & & & \\
\hline & & & 8. Amigos & & & & \\
\hline & & & 9. Você em geral & & & & \\
\hline & & & $\begin{array}{l}\text { 10. Capacidade para } \\
\text { fazer tarefas. }\end{array}$ & & & & \\
\hline & & & $\begin{array}{l}\text { 11. Capacidade para } \\
\text { fazer atividades de } \\
\text { lazer }\end{array}$ & & & & \\
\hline & & & 12. Dinheiro & & & & \\
\hline & & & 13. A vida em geral & & & & \\
\hline
\end{tabular}




\section{Anexo D}

Autorização para adaptação e validação do “QOL-AD”

\section{AUTHORIZATION}

Dear Marcia, I hereby authorize you to use the Quality of Life-AD in your investigation of quality of life in people with Alzheimer's disease and their caregivers. This is certainly an important area of research, and I await your findings with interest. I will also be available for additional questions or consultation, as needed, during your investigation.

Sincerely,

Rebecca Logsdon

Rebecca Logsdon, Ph.D.

Research Associate Professor

Psychosocial \& Community Health

Box 357263

University of Washington

Seattle, WA 98195-7263

Phone:(206)685-1758

Fax:(206)685-9551 
Anexo E

Parecer da Comissão de Ética para Análises de Projetos de Pesquisa do HCFMUSP

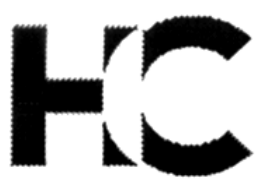

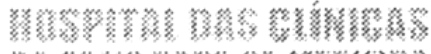

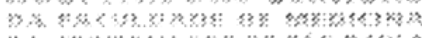

DIRETORIA CLÍNICA

Comissão de Ética para Análise de Projetos de Pesquisa APROVACGÃO

A Comissão de Ética para Análise de Projetos de Pesquisa - CAPPesq da Diretoria Clínica do Hospital das Clínicas e da Faculdade de Medicina da Universidade de São Paulo, em sessão de 27.11.03, APROVOU o Protocolo de Pesquisa $n^{\circ}$ 904/03. intitulado: "Validação da escala de Qualidade de Vida ( QdV-DA) para pacientes com doença de Alzheimer $e$ seus respectivos cuidadores/familiares" apresentado pelo Departamento de NEUROLOGIA, inclusive o Termo de Consentimento Livre e Esclarecido.

Pesquisador(a) Responsável: Dr. Paulo Caramelli

Pesquisador(a) Executante: Sra. Márcia Maria Pires Camargo Novelli

CAPPesq, 27 de Novembro de 2003.

Ually dollt

PROF. DR. EUCLIDES AYRES DE CASTILHO

Presidente da Comissão de Ética para Análise de Projetos de Pesquisa

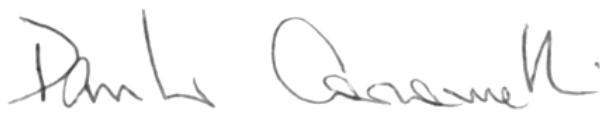


Anexo F

HOSPITAL DAS CLÍNICAS

DA

FACULDADE DE MEDICINA DA UNIVERSIDADE DE SÃO PAULO

TERMO DE CONSENTIMENTO LIVRE E ESCLARECIDO

I - DADOS DE IDENTIFICAÇÃO DO SUJEITO DA PESQUISA OU RESPONSÁVEL LEGAL

1.NOME DO PACIENTE:

DOCUMENTO DE IDENTIDADE No: SEXO: $M \quad F$

DATA NASCIMENTO: ........................

ENDEREÇO:

$\mathrm{N}^{\circ}$

APTO:

BAIRRO

CIDADE

CEP:

TELEFONE:DDD(

..)

2.RESPONSÁVEL LEGAL

NATUREZA (grau de parentesco, tutor, curador etc.)

DOCUMENTO DE IDENTIDADE:

SEXO: $M \quad F$

DATA NASCIMENTO.: .....................

ENDEREÇO: $\mathrm{N}^{\circ}$

APTO:

BAIRRO: CIDADE:

CEP:

TELEFONE:DDD

).

\section{II - DADOS SOBRE A PESQUISA CIENTÍFICA}

1. TÍTULO DO PROTOCOLO DE PESQUISA: "Validação da escala de Qualidade de Vida (QdVDA) para pacientes com doença de Alzheimer e seus respectivos cuidadores/familiares".

Pesquisador: Márcia Maria Pires Camargo Novelli

CARGO/FUNÇÃO: Pós-graduanda

INSCRIÇÃO CONSELHO REGIONAL No: 3331 - TO

UNIDADE DO HCFMUSP: Neurologia

3. AVALIAÇÃO DO RISCO DA PESQUISA:

SEM RISCO X

RISCO MÍNIMO

RISCO MÉDIO

RISCO MAIOR

4.DURAÇÃO DA PESQUISA : 03 ANOS 


\section{III - REGISTRO DAS EXPLICAÇÕES DO PESQUISADOR AO PACIENTE OU SEU REPRESENTANTE LEGAL SOBRE A PESQUISA CONSIGNANDO:}

1. justificativa e os objetivos da pesquisa

2. procedimentos que serão utilizados e propósitos, incluindo a identificação dos procedimentos que são experimentais.

3. desconfortos e riscos esperados

4. benefícios que poderão ser obtidos

5. procedimentos alternativos que possam ser vantajosos para o indivíduo

O senhor (a) está sendo convidado a participar de um estudo sobre qualidade de vida de pessoas com Alzheimer e de seus cuidadores/familiares. O objetivo é identificarmos através dos questionários que o senhor (a) e seu familiar irão responder quais os fatores mais importantes para sua qualidade de vida e da pessoa que Ihe auxilia. Esta pesquisa vai nos ajudar a conhecer melhor esta doença e seu impacto no dia-a-dia de vocês, possibilitando que no futuro $\mathrm{o}$ atendimento e o tratamento levem em conta estas informações.

\section{IV - ESCLARECIMENTOS DADOS PELO PESQUISADOR SOBRE GARANTIAS DO SUJEITO DA PESQUISA CONSIGNANDO:}

1. acesso, a qualquer tempo, às informações sobre procedimentos, riscos e benefícios relacionados à pesquisa, inclusive para dirimir eventuais dúvidas.

2. liberdade de retirar seu consentimento a qualquer momento e de deixar de participar do estudo, sem que isto traga prejuízo à continuidade da assistência.

3. salvaguarda da confidencialidade, sigilo e privacidade.

4. disponibilidade de assistência no HCFMUSP, por eventuais danos à saúde, decorrentes da pesquisa.

5. viabilidade de indenização por eventuais danos à saúde decorrentes da pesquisa.

\section{INFORMAÇÕES DE NOMES, ENDEREÇOS E TELEFONES DOS RESPONSÁVEIS PELO ACOMPANHAMENTO DA PESQUISA, PARA CONTATO EM CASO DE INTERCORRÊNCIAS CLÍNICAS E REAÇÕES ADVERSAS.}

Dr. Paulo Caramelli ou Marcia Maria Pires Camargo Novelli Fone - 3069-6401

\section{OBSERVAÇÕES COMPLEMENTARES:}

\section{VII - CONSENTIMENTO PÓS-ESCLARECIDO}

Declaro que, após convenientemente esclarecido pelo pesquisador e ter entendido o que me foi explicado, consinto em participar do presente Protocolo de Pesquisa.

São Paulo, de de 200 . 
Anexo G

Caracterização da amostra de pacientes

\section{$\underline{\text { Identificação }}$}

Nome:

Idade:

Data de Nascimento:

Endereço:

Telefone:

Escolaridade:

Sexo:

Grau de gravidade:

Nome do cuidador principal:

Grau de parentesco:

Data da entrevista: Início:

Término:

Tempo de aplicação do PQdV-DA:

Tempo de C-PQdV-DA:

Tempo de CQdV-DA: 
Anexo H

Caracterização da amostra de cuidadores

\section{Identificação}

Nome:

Idade:

Data de Nascimento:

Endereço:

Telefone:

Escolaridade:

Sexo: 


\section{Anexo I}

\section{MINI EXAME DO ESTADO MENTAL (BRUCKI, 2003)}

1. Que dia é hoje? ( )

2. Em que mês nós estamos? ( )

3. Em que ano nós estamos? ( )

4. Em que dia da semana estamos? ( )

5. Qual a hora aproximada? (Considere a variação de mais ou menos uma hora) ( )

6. Em que local nós estamos? ( ) ( apontando para o chão - Consultório, dormitório)

7. Que local é este aqui? ( ) (apontando ao redor em um sentido mais amplo hospital, cãs de repouso, própria casa) .

8. Em que bairro nós estamos ou qual o nome de uma rua próxima? ( )

9. Em que cidade nós estamos?( )

10. Em que estado nós estamos? ( )

11. Eu vou dizer três palavras e você vai repeti-las a seguir. (dê 1 ponto para cada palavra repetida acertadamente na $1^{\mathrm{a}}$ vez, embora possa repeti-las até três vezes para o aprendizado, se houver erros). Vaso ( ) Carro ( ) Tijolo ( )

12. Cálculo - subtração de sete seriadamente
a) $93($ )
d) $72($ )
b) $86($ )
e) $65($ ( )
c) $79(\quad)$

13. Repita as palavras que Sr. (a). repetiu a pouco.<smiles>[Te]</smiles>
( )

14. Nomeie os objetos. Mostre o relógio e repita com uma caneta.
Relógio ( )
Caneta ( )

15. Eu vou dizer uma frase e quero que o Sr. (a). repita depois de mim:"NEM AQUI, NEM ALI, NEM LÁ". ( )

16. Pegue o papel com sua mão direita

Dobre-o ao meio

Ponha-o no chão

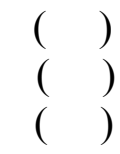

17. Faça o que eu estou mandando (cartão):

\section{"FECHE OS OLHOS" ( )}

18. Escreva uma frase:

19. Copie este desenho (cartão): ( ) 


\section{Anexo J}

\section{Escalas das Atividades daVida Diária (Lawton e Brody)}

Instruções: As questões seguintes descrevem os problemas com o cuidado diário vividos por alguns indivíduos. Por favor, marque com um X cada item que corresponde ao seu familiar.

\section{Higiene}

\section{Parte 1. Escala de Auto Cuidado.}

Independente no auto cuidado, sem incontinência.

Necessita ser lembrado ou de ajuda para se auto-cuidar, ou tem raros acidentes.

Evacua ou urina enquanto dorme mais de uma vez por semana.

Evacua ou urina enquanto acordado mais de uma vez por semana.

Não controla os esfíncteres.

\section{Alimentação}

Alimenta-se sem ajuda.

Alimenta-se com ajuda mínima e ou precisa de ajuda para preparar suas refeições, ou precisa de ajuda para se limpar após as refeições.

Alimenta-se com ajuda moderada e não consegue manter-se limpo.

Necessita de ajuda constante em todas as refeições.

Não se alimenta sozinho e resiste aos esforços de outros para alimentá-lo (a).

\section{Vestuário}

Consegue vestir-se e despir-se e escolhe suas roupas no armário.

Consegue vestir-se e despir-se com ajuda mínima.

Necessita de ajuda moderada para vestir-se e ou selecionar roupas.

Necessita de ajuda constante para vestir-se, mas coopera com os esforços de outros para ajuda-lo (a).

Completamente incapaz de vestir-se e/ou resiste ao auxilio de outros para vesti-lo.

4. Cuidados pessoais (limpeza, cabelo, unhas, mãos, face, roupas).

Sempre vestido adequadamente, bem cuidado, sem ajuda.

Auto cuidado adequado com pouca ajuda, por exemplo, no momento de barbear-se.

Necessita de moderada ajuda ou regular supervisão no cuidado.

Necessita de total ajuda, mas pode permanecer bem cuidado após a ajuda de outros.

Nega ativamente todos os esforços de outros para mantê-lo bem cuidado.

\section{Banho}

Toma banho sozinho (banheira, chuveiro).

Toma banho sozinho com ajuda para entrar e sair do chuveiro ou banheira.

Lava somente o rosto e as mãos, e não consegue lavar o resto do corpo.

Não toma banho sozinho, mas coopera com aqueles que o ajudam.

Não tenta lavar-se sozinho e resiste aos esforços de outros para o banho. 


\section{Locomocão}

Locomove-se pela cidade.

Locomove-se em casa ou até um quarteirão de distância.

Locomove-se com assistência (marque uma resposta):

$\square$ de bengala

De cadeira de rodas:

de corrimão

$\square$ andador

Senta-se e levanta-se sem ajuda

Necessita de ajuda para sentar-se e levantar-se.

Senta sem apoio em uma cadeira ou cadeira de rodas, mas não consegue movimentar a cadeira sem ajuda.

Fica a maior parte do tempo na cama.

\section{Parte 2. Escala de Atividades Instrumentais da Vida Diária.}

Indique se seu parente pode ser capaz de fazer cada atividade considerando se ele (a) foi capaz no passado.

\section{Habilidade para usar o telefone}

$\square$ Opera o telefone com iniciativa própria - consulta e disca os números, etc.

Disca alguns números conhecidos.

$\square \quad$ Atende ao telefone, mas não faz ligações.

$\square \quad$ Não usa o telefone.

\section{Compras}

$\square \quad$ Faz todas as compras sozinha (o).

Faz pequenas compras sozinha (o).

$\square \quad$ Precisa ser acompanhado em qualquer compra.

\section{Preparacão de refeicões}

Planeja, prepara e serve refeições independentemente.

Prepara adequadamente as refeições se os ingredientes forem fornecidos.

Esquenta e serve refeições já prontas, ou prepara as refeições, mas não mantém uma dieta adequada.

Precisa que suas refeições sejam preparadas e servidas.

\section{Cuidados da Casa}

Cuida da casa sozinha (o) ou com ocasional assistência (por exemplo, tem ajuda doméstica para trabalhos pesados).

Faz tarefas diárias simples, como lavar a louça e arrumar a cama.

Faz tarefas diárias simples, mas não consegue manter um nível de limpeza. aceitável.

Precisa de ajuda em todas as tarefas da casa.

Não participa de nenhuma tarefa da casa. 


\section{Lavagem de roupas}

Lava suas roupas independentemente.

Lava pequenas peças - roupas intímas, meias, lenços, etc.

Toda a lavagem das roupas é feita por outros.

\section{Meios de transporte}

Viaja sozinho em transporte publico ou dirige seu próprio carro.

Organiza a própria viagem de táxi, mas não usa transporte publico.

Viaja em transporte publico quando acompanhado por alguém.

Viaja limitado táxi ou automóvel com ajuda de outra pessoa.

Não utiliza meios de transporte.

\section{Responsabilidade por seu Medicamento}

Consegue tomar a medicação na dosagem e horários corretos.

Consegue tomar medicação se ela é preparada com antecedência e separada nas dosagens corretas.

Não é capaz de cuidar da própria medicação.

\section{Capacidade para cuidar do seu dinheiro}

Cuida de assuntos financeiros sem ajuda (orçamento, assina cheques, paga o aluguel e as contas, vai ao banco), mantém-se informado sobre sua renda.

Cuida das compras do dia-a-dia, mas precisa de ajuda com tarefas bancárias e compras maiores, etc.

Incapaz de cuidar do próprio dinheiro.

\section{Instruções de pontuação:}

Um valor de 1 (para mais independente e sucessivamente 3, 4, ou 5 (dependendo do numero de opções) é dado para cada item, e então somado separadamente para a Parte 1(Auto Manutenção física) e para a Parte 2 (Atividades Instrumentais da Vida Diária).

Instruções especiais para a parte 1, Item número 6, onde "Locomove-se com assistência" tem opções múltiplas (ex. ajuda de uma outra pessoa, auxilio de barras, uso de bengala, uso de andador, cadeira de rodas): Esta opção recebe uma pontuação de 3 pontos independente do tipo de assistência que a pessoa necessita. 
Anexo K

Inventário Neuropsiquiátrico (INP) (Cummings, 1994)

\begin{tabular}{|l|c|c|c|c|c|c|}
\hline \multicolumn{1}{|c|}{ Item } & NA & Aus. & Freq. & Int. & Fx I & Desgaste \\
\hline Delírios & $\mathrm{x}$ & 0 & 1234 & 123 & & 12345 \\
\hline Alucinações & $\mathrm{x}$ & 0 & 1234 & 123 & & 12345 \\
\hline Agitação & $\mathrm{x}$ & 0 & 1234 & 123 & & 12345 \\
\hline $\begin{array}{l}\text { Depressão/ } \\
\text { Disforia }\end{array}$ & $\mathrm{x}$ & 0 & 1234 & 123 & & 12345 \\
\hline $\begin{array}{l}\text { Ansiedade } \\
\text { Euforia/Elação }\end{array}$ & $\mathrm{x}$ & 0 & 1234 & 123 & & 12345 \\
\hline $\begin{array}{l}\text { Apatia/Indiferença } \\
\text { Alimentares }\end{array}$ & $\mathrm{x}$ & 0 & 1234 & 123 & & 12345 \\
\hline $\begin{array}{l}\text { Desinibição } \\
\text { Noturnos }\end{array}$ & $\mathrm{x}$ & 0 & 1234 & 123 & & 12345 \\
\hline $\begin{array}{l}\text { Irritabilidade/ } \\
\text { Mabilidade }\end{array}$ & $\mathrm{x}$ & 0 & 1234 & 123 & & 12345 \\
\hline & $\mathrm{x}$ & 0 & 1234 & 123 & & \\
\hline
\end{tabular}




\section{Anexo L}

\section{Escala de Depressão Geriátrica (YESAVAGE, 1994)}

1. Você está, no geral, satisfeito com sua vida?

Sim/Não

2. Você abandonou muito das suas atividades e interesses?

Sim/Não

3. Você sente que sua vida está vazia?

Sim/Não

4. Você está sempre entediado, amolado, chateado?

Sim/Não

5. Você está sem esperanças no futuro?

6. Você se sente incomodado por pensamentos que não saem da sua cabeça? Sim/Não

7. Você está de bom humor a maior parte do tempo?

Sim/Não

8. Você tem medo de que alguma coisa ruim aconteça com você?

$\operatorname{Sim} / \mathrm{Não}$

9. Você se sente feliz a maior parte do tempo?

Sim/Não

10. Você se sente um pobre coitado?

Sim/Não

11. Você se sente sempre cansado?

Sim/Não

12. Você sempre prefere ficar em casa à noite a conhecer coisas novas?

Sim/Não

13. Você está sempre preocupado com o futuro?

$\operatorname{Sim} / \mathrm{Não}$

14. Você sente que tem mais problemas de memória do que a maioria das pessoas?

15. Você acha que é maravilhoso estar vivo agora?

16. Você se sente sempre triste e deprimido?

17. Você se sente sempre pior do que está agora?

18. Você se preocupa muito com seu passado?

19. Você acha a vida muito excitante?

20. Para você, é difícil iniciar novos projetos?

21. Você se sente cheio de energia?

22. Você acha que para seu caso não há jeito?

23. Você acha que a maioria das pessoas está em melhores condições que você?

24. Você sempre fica triste por pequenos acontecimentos?

25. Você quase chora freqüentemente?

26. Você tem dificuldade de se concentrar?

27. Você gosta de levantar-se pela manhã?

28. Você prefere evitar reuniões sociais?

29. Para você, é fácil tomar decisões?

30. Sua mente está clara como sempre foi?

Sim/Não

Sim/Não

Sim/Não

Sim/Não

Sim/Não

Sim/Não

Sim/Não

Sim/Não

Sim/Não

Sim/Não

Sim/Não

Sim/Não

Sim/Não

Sim/Não

Sim/Não

Sim/Não

Sim/Não

\section{PONTOS:}




\section{Anexo M}

\section{ESCALA CORNELL PARA DEPRESSÃO EM DEMÊNCIA}

A Escala Cornell é um instrumento de 19 itens para classificar os sintomas de depressão em pacientes com demência. Como a classificação baseia-se em duas entrevistas (com o cuidador, e depois rapidamente com o paciente) e devem ser realizadas avaliações clínicas complexas, os itens foram desenhado para serem ambíguos e devem ser classificados fundamentalmente com base na observação do comportamento relatado pelo cuidador.

As avaliações devem ser baseadas nos sintomas e sinais que ocorreram durante a semana anterior à entrevista. Não se deve marcar ponto se o sintoma for resultado de uma incapacidade física ou de uma doença.

\begin{tabular}{|l|c|c|c|c|}
\hline & $\begin{array}{c}\text { Impossibilitado } \\
\text { de } \\
\text { avaliação (U) }\end{array}$ & $\begin{array}{c}\text { Ausente } \\
\text { (0) }\end{array}$ & $\begin{array}{c}\text { Leve ou } \\
\text { Intermitente } \\
\text { (1) }\end{array}$ & $\begin{array}{c}\text { Intenso } \\
\text { (2) }\end{array}$ \\
\hline A- Sinais relacionados ao humor & $\square$ & $\square$ & $\square$ & $\square$ \\
\hline $\begin{array}{l}\text { 1. Ansiedade (expressão ansiosa, } \\
\text { ruminações, preocupações) }\end{array}$ & $\square$ & $\square$ & $\square$ & $\square$ \\
\hline $\begin{array}{l}\text { 2. Tristeza (expressão triste, voz } \\
\text { triste, choroso) }\end{array}$ & $\square$ & $\square$ & $\square$ & $\square$ \\
\hline $\begin{array}{l}\text { 3. Falta de reação e ventos } \\
\text { prazerosos }\end{array}$ & $\square$ & $\square$ & $\square$ & $\square$ \\
\hline $\begin{array}{l}\text { 4. Irritabilidade (facilmente } \\
\text { aborrecido, temperamento } \\
\text { explosivo) }\end{array}$ & $\square$ & $\square$ & $\square$ & $\square$ \\
\hline $\begin{array}{l}\text { B- Distúrbio de Comportamento } \\
\text { 5. Agitação (inquietação, agitação } \\
\text { constante das mãos, puxa o cabelo) }\end{array}$ & $\square$ & $\square$ & $\square$ & $\square$ \\
\hline $\begin{array}{l}\text { 6. Retardo (movimentos lentos, fala } \\
\text { lenta, reação lenta) }\end{array}$ & $\square$ & $\square$ & $\square$ & $\square$ \\
\hline $\begin{array}{l}\text { 7. Queixas físicas múltiplas (escore } \\
\text { 0 se forem apenas sintomas } \\
\text { gastrintestinais) }\end{array}$ & $\square$ & $\square$ & $\square$ & $\square$ \\
\hline $\begin{array}{l}\text { 8. Perda de interesse (menor } \\
\text { movimento em atividades usuais, } \\
\text { pontue apenas se a alteração } \\
\text { ocorre agudamente , i. e, em menos } \\
\text { de um mês) }\end{array}$ & $\square$ & $\square$ & $\square$ & $\square$ \\
\hline $\begin{array}{l}|c| \\
\text { C- Sinais Físicos }\end{array}$ & $\square$ & $\square$ & $\square$ & $\square$ \\
\hline $\begin{array}{l}\text { 9. Perda do apetite (como menos } \\
\text { que o usual) }\end{array}$ & $\square$ & $\square$ & $\square$ \\
\hline $\begin{array}{l}\text { 10. Perda de peso (marque 2 } \\
\text { pontos se for maior que 2,2kg em } \\
\text { um mês) }\end{array}$ & $\square$ & $\square$ & $\square$ \\
\hline $\begin{array}{l}\text { 11. Falta de energia (facilmente } \\
\text { fatigado, incapaz de sustentar } \\
\text { atividade; marque pontos apenas se } \\
\text { a alteração ocorrer rapidamente, i. } \\
\text { e, em menos de um mês) }\end{array}$ & $\square$ & $\square$ & $\square$ \\
\hline
\end{tabular}




\begin{tabular}{|c|c|c|c|c|}
\hline \multicolumn{5}{|l|}{ D- Funções Cíclicas } \\
\hline $\begin{array}{l}\text { 12. Variação diurna de humor (os } \\
\text { sintomas são piores pela manhã) }\end{array}$ & $\square$ & $\square$ & $\square$ & $\square$ \\
\hline $\begin{array}{l}\text { 13. Dificuldades para dormir (esta } \\
\text { indo dormir mais tarde que o usual } \\
\text { para este indivíduo) }\end{array}$ & $\square$ & $\square$ & $\square$ & $\square$ \\
\hline $\begin{array}{l}\text { 14. Desperte muitas vezes durante } \\
\text { o sono }\end{array}$ & $\square$ & $\square$ & $\square$ & $\square$ \\
\hline $\begin{array}{l}\text { 15. Desperte precoce (mais cedo } \\
\text { que o usual para este indivíduo) }\end{array}$ & $\square$ & $\square$ & $\square$ & $\square$ \\
\hline \multicolumn{5}{|l|}{ E- Distúrbio de Ideação } \\
\hline $\begin{array}{l}\text { 16. Suicídio (sente que a vida não } \\
\text { vale a pena, tem desejos suicidas } \\
\text { ou faz tentativas suicidas) }\end{array}$ & $\square$ & $\square$ & $\square$ & $\square$ \\
\hline $\begin{array}{l}\text { 17. Baixa auto- estima (culpa-se, } \\
\text { deprecia-se, sentimentos de } \\
\text { fracasso) }\end{array}$ & $\square$ & $\square$ & $\square$ & $\square$ \\
\hline 18. Pessimismo (antecipa o pior) & $\square$ & $\square$ & $\square$ & $\square$ \\
\hline $\begin{array}{l}\text { 19- Delírios congruentes com o } \\
\text { humor (delírios de pobreza, doença } \\
\text { ou perda) }\end{array}$ & $\square$ & $\square$ & $\square$ & $\square$ \\
\hline $\begin{array}{l}\text { Acrescente o Escore Total na } \\
\text { Página de Avaliação para Escore } \\
\text { na Ficha Clínica. }\end{array}$ & Total: & Total: & Total: & Total: \\
\hline
\end{tabular}

Nome do examinador:

Iniciais do examinador :

Hora em que o teste foi aplicado: 


\section{Anexo N}

V - CLASSIFICAÇÃO SÓCIO-ECONÔMICA (Graciano et al., 1999)

Quadro 01 - SITUAÇÃO ECONÔMICA DA FAMÍLIA

Renda bruta mensal

$00-\mid 1 / 2 \quad$ SM

Pontos

$1 / 2-02$ SM

01

$02-\mid 04$ SM

02

03

$04-09$ SM

05

$09-\mid 15 \quad$ SM

09

$15-30$ SM

12

$30-60$ SM

14

$60-\mid 100$ SM

18

$100 \mathrm{ou}+\mathrm{SM}$

21

Obs.: Tipo de Rendimento:

( ) salário

( ) lucro

( ) rendimento financeiro

( ) honorários

( ) aposentadoria

( ) outros:

SM = Salário Mínimo

Quadro 02 - NÚMERO DE MEMBROS RESIDENTES NA FAMÍLIA

Número

Até 02 Pontos

$03-\mid 04$

06

$04-\mid 06$

04

$06-\mid 08$

08 ou +

01

Quadro 03 - ESCOLARIDADE DOS MEMBROS DA FAMÍLIA

(Pontuação = Maior nível educacional $/$ responsável)

Nível educacional

Superior

Superior incompleto/colégio completo

Colégio incompleto/ginásio completo

Ginásio incompleto/ primário completo

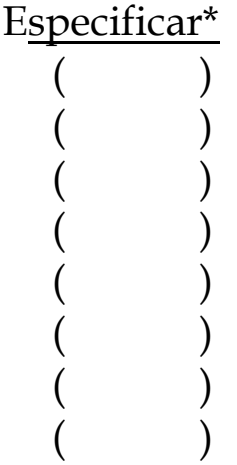

$\underline{\text { Pontos }}$

07

05

Primário incompleto

Sem escolaridade/ alfabetizado

Sem escolaridade/ analfabeto

Sem idade escolar

* Especificar apenas o nível do familiar responsável: (P) Pai; (M) Mãe; (F) Filho(a); (Pc) Paciente; (O) Outros 
Quadro 04 - HABITAÇÃO

Condição/situação Precária Insufic. $\underline{\text { Regular }}$ Boa Ótima

Própria

$06 \quad 07$

08

10

Financiada

$05 \quad 06$

07

09

Alugada

$04 \quad 05$

06

08

08

Cedida $\mathrm{p} /$ benefício $\quad 02$

Outras(barraco/favela) 0

03

04

07

06

0

05

02

Localidade: Urbana ( ） Rural ( ）

Quadro 05- OCUPAÇÃO DOS MEMBROS DA FAMÍLIA

(Pontuação = Maior nível ocupacional $/$ responsável $)$

Ocupação / setor / membros

$\underline{\text { Membros }}^{*}$ Setor $^{* *}$ Pontos

- Empresários: proprietários na agricultura, agroindústria, comércio, sistema financeiro, serviços, etc.

- Trabalhadores da alta administração: juízes, promotores, diretores, administradores, gerentes, supervisores, assessores, consultores, etc.

- Profissionais liberais autônomos: médicos, advogados, contadores, arquitetos, engenheiros, dentistas, representantes comerciais, oculistas, auditores, etc.

- Trabalhadores assalariados administrativos, téc-

nicos e cientificos: chefias em geral, assistentes, ocupações de nível superior, analistas, ocupações de nível médio, atletas profissionais, técnicos em geral, servidores públicos de nível superior, etc.

- Trabalhadores assalariados: ocupações da produção, da administração (indústria, comércio, serviços, setor público e sistema financeiro), ajudantes, auxiliares, etc.

- Trabalhadores por conta própria: pedreiros, caminhonhoneiros, marceneiros, feirantes, cabelereiros, taxistas, vendedores autônomos, etc.

Com empregado

Sem empregado

- Pequenos produtores rurais: meeiros, parceiro, chacareiros, etc.

Com assalariado

Sem assalariado 
- Empregados domésticos: jardineiros, diaristas, mensalistas, faxineiros, cozinheiros, mordomos, babás, motoristas particulares, atendentes, etc.

Urbano

Rural

- Trabalhadores rurais assalariados, volantes e assemelhados: ambulantes, chapas, Bóias-frias, ajudantes gerais, etc.

- Aposentados

* Especificar apenas o nível do familiar responsável: (P) Pai; (M) Mãe; (F) Filho(a); (Pc) Paciente; (O) Outro

* Setor: (I) Indústria; (C) Comércio; (S) Serviços; (SF) Sistema Financeiro; (SPr) Setor primário; (SP) Setor Público; (O) Outros

\begin{tabular}{|c|c|c|c|}
\hline Pontos & Classificação & $\underline{\text { Siglas }}$ & Códigos \\
\hline $00-20$ & Baixa inferior & $\mathrm{BI}$ & F ou 6 \\
\hline $20-1$ & Baixa Superior & BS & E ou 5 \\
\hline $30-40$ & Média inferior & MI & D ou 4 \\
\hline $40-47$ & Média & ME & Cou 3 \\
\hline $47-54$ & Média Superior & MS & B ou 2 \\
\hline 54 ou + & Alta & AL & A ou 1 \\
\hline
\end{tabular}




\title{
Anexo O
}

\author{
INVENTÁRIO de DepressaO de Beck
}

Beck Depression Inventory - BDI (Beck et al., 1961) - versão revisada (Beck et al., 1979)

Este questionário consiste em 21 grupos de afirmações. Depois de ler cuidadosamente cada grupo, faça um circulo em torno do número $(0,1,2$, ou 3) próximo a afirmaçáo. em cada grupo, que descreve melhor a maneira que vocé tem se sentido na última semana, incluindo hoje. Se várias afirmações em um grupo parecerem se aplicar igualmente bem, faça um circulo em cada uma. Tome o cuidado de ler todas as afirmaçōes, em cada grupo, antes de fazer a sua escolha.

1. 0 Não me sinto triste.

1 Eu me sinto uiste.

2 Estou sempre triste e nảo consigo sair disto.

3 Estou tăo triste ou inteliz que náo consigo suportar.

2. 0 Nảo estou especialmente desanimado quanto ao futuro.

1 Eu me sinto desanimado quanto ao futuro.

2 Acho que nada tenho a esperar.

3 Acho o futuro sem esperança e tenho a impressáo de que as coisas não podem melhorar.

3. 0 Nảo me sinto um fracasso.

1 Acho que fracassei mass do que urna pessoa comum.

2 Quando olho para tras, na minha vida, tudo o que posso ver é um monte de fracassos.

3 Acho que, como pessoa, sou um completo tracasso.

4. 0 Tenho tanto prazer ern tudo como antes.

1 Náo sinto maıs prazer nas coisas como antes.

2 Náo encontro um prazer real em mais nada.

3 Estou insatisterto ou aborrecido com tudo.

5. 0 Năo me sinto especialmente culpado.

1 Eu me sinto culpado grande parte do tempo.

2 Eu me sinto culpado na maior parte do tempo.

3 Eu me sinto sempre culpado.

6. $\quad$ Náo acho que esteja sendo punido

1 Acho que posso ser punido.

2 Creio que serei punido.

3 Acho que estou sendo punido.

7. 0 Nảo me sinto decepcionado comigo mesmo.

1 Estou decepcionado comigo mesmo.

2 Estou enojado de mim.

3 Eu me odeio.

8. O Năo me sinto, de qualquer modo, pior que os outros.

1 Sou critico em relaçăo a mim por minhas traquezas ou erros.

2 Eu me culpo sempre por minhas falhas.

3 Eu me culpo por tudo de mau que acontece.

9. 0 Não tenho quaisquer idéias de me matar.

1 Tenho idéias de me matar, mas não as executaria.

2 Gostaria de me matar.

3 Eu me mataria se tivesse oportunidade.

10. 0 Não choro mais co que o habitual.

1 Choro mais agora do que costurnava.

2 Agore, choro o tempo todo.

3 Costumava ser capaz de chorar, mas agora nảo consigo, mesmo que o queira. 
11. 0 Não sou mais irritado agora do que jả lui.

1 Fico aborrecido ou irritado mais facilmente do que costumava.

2 Alualmente me sinto irritado o tempo todo.

3 Năo me irrito mais com as coisas que costumavam me irritar.

12. 0 Não perdi o interesse pelas outras pessoas.

1 Estou menos interessado pelas outras pessoas do que costumava estar.

2 Perdi a maior parte do meu interesse pelas outras pessoas.

3 Perdi todo o meu interesse pelas outras pessoas.

13. 0 Tomo decisōes tảo bem quanto antes

1 Adio as tomadas de decisōes mais do que costumava.

2 Tenho mais dificuldade em tomar decisōes do que antes.

3 Não consigo mais tomar decisōes.

14. 0 Não acho que minha aparéncia esteja pior do que costumava ser.

1 Estou preocupado por estar parecendo velho ou sem atrativos.

2 Acho que há mudanças permanentes na minha aparéncia que ıne fazem parecer sem atrativos

3 Acredito que pareço teio.

15. 0 Posso trabalhar tão bem quanto antes.

1 Preciso de um esforço extra dara fazer alguma coisa.

2 Tenho que me esforçar muito para fazer alguma coisa.

3 Não consigo mais fazer trabalho algum.

16. 0 Consıgo dormir táo bern como o habitual.

1 Não đurmo tão bem quanto costumava.

2 Acoroo uma a duas horas mais cedo que habitualmente e tenho dificuldade em voltar a dormir.

3 Acordo várias horas mais cedo do que costumava e não consigo voltar a dormir.

17. O Nảo fico mais cansado do que o habitual.

1 Fico cansado com mais facilidade do que costumava

2 Sinto-me cansado ao tazer qualquer coisa.

3 Estou cansado demais para fazer qualquer coisa.

18. 0 Meu apetite não está pior do que o habitual.

1 Meu apetite não e tão bom quanto costumava ser

Meu apetite está muito pior agora

3 Não tenho mais nenhum apetite.

19. 0 Náo tenho perdido muito peso. se é que perdi algum recentemente.

1 Perdi mais de dois quilos e meio.

2 Perdi mais de cinco quilos.

3 Perdi mais de sete quilos.

Estou tentando perder peso de propósito. comendo menos: Sim ( ) Não( )

20. 0 Não estou mais preocupado com minha saude do que o habitual.

Estou preocupado com problemas fisicos, tais como dores, indisposição do estómago ou prisão de ventre.

Estou muito preocupado com problemas fisicos e é dificil pensar em outra coisa.

3 Estou tão preocupado com meus problemas fisicos que não consigo pensar em qualquer outra coisa.

21. 0 Não notei qualquer mudança recente no meu interesse por sexo.

1 Estou menos interessado por sexo do que costumava estar.

2 Estou muito menos interessado em sexo ativalmente.

3 Perdi completamente o interesse por sexo 


\section{Anexo P}

\section{WHOQOL - ABREVIADO}

\section{Instruções}

Este questionário ć sobre como você se sente a respcito de sua qualidade de vida, saúce e outras áreas de sua vida. Por favor responda a todas as questöes. Sc você não tem ccrteza sobre que resposta dar em uma questão, por favor, cscolha entre as alternativas a que lhe parece mais apropriada. Esta, muitas vezes, poderá ser sua primeira escolha.

Por favor, tenha em mente seus valores, aspirações, prazères e preocupações. Nós estarnos perguntando o que você acha de sua vida, tomando como referência as duas últimas semanas. Por exemplo, pensando nas últimas duas semanas, uma questão poderia ser:

\begin{tabular}{|c|c|c|c|c|c|}
\hline \multirow{2}{*}{$\begin{array}{l}\text { Você recebe dos outros o apoio } \\
\text { de que necessita? }\end{array}$} & nada & Mutito pouco & médio & muito & compictamente \\
\hline & 1 & 2 & 3 & 4 & 5 \\
\hline
\end{tabular}

Você deve circular o número que melhor corresponde ao quanto você recebe 'ỏos outros o apoio de que necessita nestas últimas duas scmanas.

Portanto, você deve circular o númcro 4 se você recebcu "muito" apoio como abaixo.

\begin{tabular}{|c|c|c|c|c|c|}
\hline & nada & Muito pouco & médio & muito & completamente \\
\hline $\begin{array}{l}\text { Você recebe dos outros o apoio } \\
\text { de que necessita? }\end{array}$ & 1 & 2 & 3 & $\downarrow$ & 5 \\
\hline
\end{tabular}

Você deve circular o númcro 1 se você não recebcu "nada" de apoio.

Por favor, leia cada questaio, veja o que você acha e circule no número c lhe parece a melhor resposta.

\begin{tabular}{|c|c|c|c|c|c|c|}
\hline \multicolumn{2}{|c|}{} & muito ruim & ruim & nem ruim/nem boa & boa & muito boa \\
\hline 1 & $\begin{array}{c}\text { Como você avaliaria sua } \\
\text { qualidade de vida ? }\end{array}$ & 1 & 2 & 3 & 4 & 5 \\
\hline
\end{tabular}

\begin{tabular}{|c|c|c|c|c|c|c|}
\hline \multicolumn{2}{|c|}{} & $\begin{array}{c}\text { muito } \\
\text { insatisfeito }\end{array}$ & insatisfeito & $\begin{array}{c}\text { nem satisfcito/nem } \\
\text { insatisfeito }\end{array}$ & satisfeito & muito satisfeito \\
\hline 2 & $\begin{array}{l}\text { Quão satisfeito(a) } \\
\text { você está com a sua } \\
\text { saúde? }\end{array}$ & 1 & 2 & 3 & 4 & 5 \\
\hline
\end{tabular}

\begin{tabular}{|c|c|c|c|c|c|c|}
\hline \multicolumn{2}{|c|}{ As questões scguintes são sobre o quanto você tem sentido algumas coisas nas últinas duas semanas. } \\
\hline 3 & $\begin{array}{c}\text { Em que medida você acha que sua } \\
\text { dor (fisica) impede você de fazer o } \\
\text { que você precisa? }\end{array}$ & 1 & 2 & 3 & 4 & 5 \\
\hline 4 & $\begin{array}{c}\text { O quanto você precisa dc algum } \\
\text { tratamento médico para levar sua } \\
\text { vida diária? }\end{array}$ & 1 & 2 & 3 & 4 & 5 \\
\hline 5 & O quanto você aproveita a vidâ? & 1 & 2 & 3 & 4 & 5 \\
\hline 6 & $\begin{array}{c}\text { Em que medida você acha que a } \\
\text { sua vida tem sentido? }\end{array}$ & 1 & 2 & 3 & 4 & 5 \\
\hline
\end{tabular}




\begin{tabular}{|c|c|c|c|c|c|c|}
\hline & & & & & \\
\hline 7 & $\begin{array}{c}\text { O quanto você consegue se } \\
\text { concentrar? }\end{array}$ & 1 & 2 & 3 & 4 & 5 \\
\hline 8 & $\begin{array}{c}\text { Quão seguro(a) você sc scntc cm } \\
\text { sua vida diária? }\end{array}$ & 1 & 2 & 3 & 4 & 5 \\
\hline 9 & $\begin{array}{c}\text { Quão saudável é o scu ambiente } \\
\text { fisico (clima, barulho, poluição, } \\
\text { atrativos)? }\end{array}$ & 1 & 2 & 3 & 4 & 5 \\
\hline
\end{tabular}

\begin{tabular}{|c|c|c|c|c|c|c|}
\hline $\begin{array}{l}\text { As q } \\
\text { coisa }\end{array}$ & $\begin{array}{l}\text { estōes seguintes perguntam sobre q } \\
\text { nestas últimas duas scmanas. }\end{array}$ & มี̃o co & letamente vc & tem ser & ou é & az de fazer certa \\
\hline & & $\overline{\text { nada }}$ & muito pouco & médio & muito & completainente \\
\hline 10 & $\begin{array}{l}\text { Você tem energia suficiente para } \\
\text { seu dia-a-dia? }\end{array}$ & 1 & 2 & 3 & 4 & 5 \\
\hline 11 & $\begin{array}{l}\text { Você ć capaz de aceitar sua } \\
\text { aparĉncia fisica? }\end{array}$ & 1 & 2 & 3 & 4 & 5 \\
\hline 12 & $\begin{array}{l}\text { Você tcm dinhciro suficiente para } \\
\text { satisfazer suas neccssidades? }\end{array}$ & 1 & 2 & 3 & 4 & 5 \\
\hline 13 & $\begin{array}{l}\text { Quño disponivcis para você cstão } \\
\text { as informaçõcs que precisa no } \\
\text { scu dia-a-dia? }\end{array}$ & 1 & 2 & 3 & 4 & 5 \\
\hline 14 & $\begin{array}{c}\text { Em que medida você tem } \\
\text { oportunidades de atividadc de } \\
\text { lazer? }\end{array}$ & 1 & 2 & 3 & 4 & 5 \\
\hline
\end{tabular}

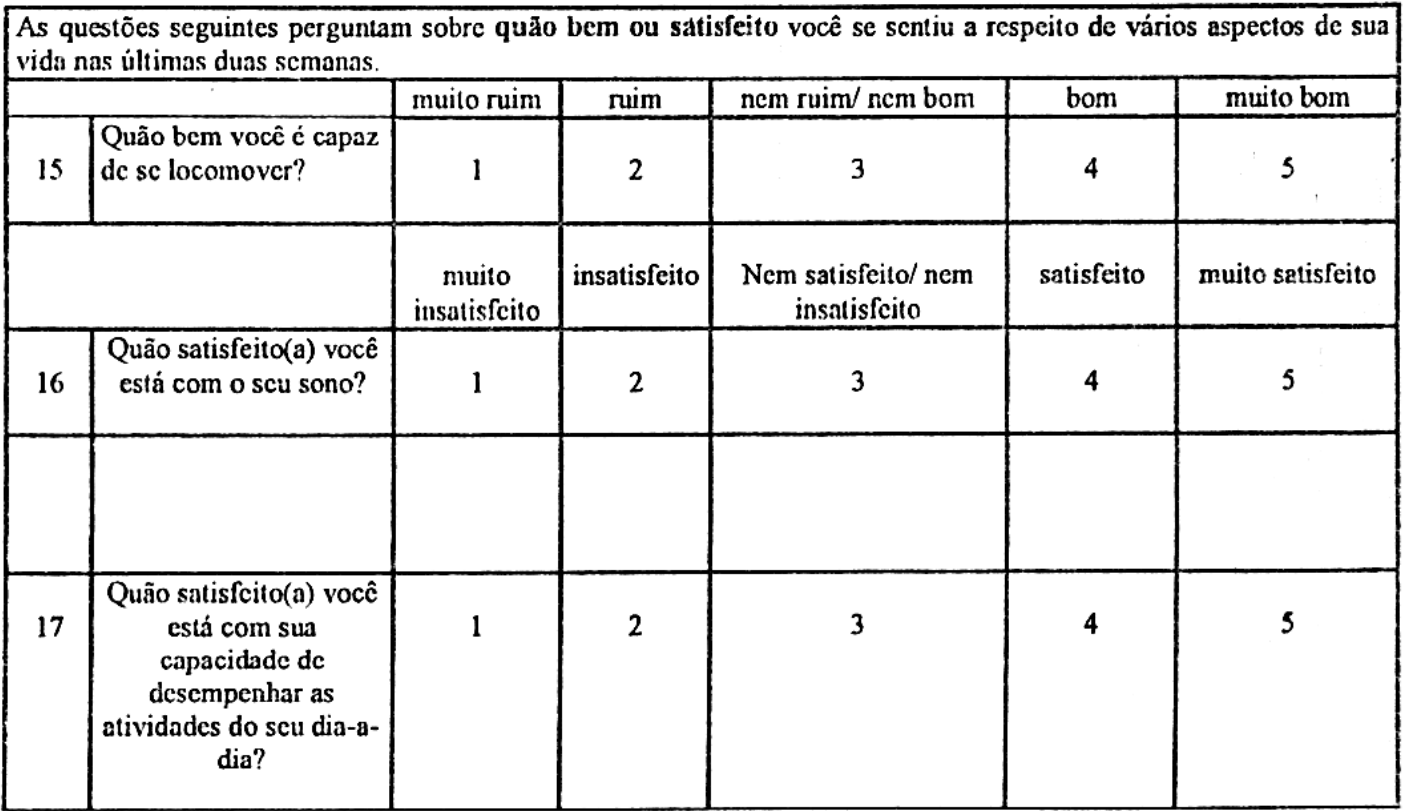




\begin{tabular}{|c|c|c|c|c|c|c|}
\hline & & $\begin{array}{c}\text { muito } \\
\text { insatisfeito }\end{array}$ & insatisfcito & $\begin{array}{c}\text { Nem satisfeito/ nem } \\
\text { insatisfeito }\end{array}$ & satisfcito & muito satisfeito \\
\hline 18 & $\begin{array}{l}\text { Quão satisfeito(a) você } \\
\text { está com sua } \\
\text { capacidade para o } \\
\text { truballho? }\end{array}$ & 1 & 2 & 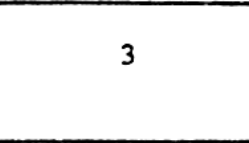 & 4 & 5 \\
\hline 19 & $\begin{array}{l}\text { Quão satisfcito(a) vocề } \\
\text { está consigo mesmo? }\end{array}$ & 1 & 2 & 3 & 4 & 5 \\
\hline 2.0 & $\begin{array}{l}\text { Quâo satisfcito(a) você } \\
\text { cstá com suas relaçõcs } \\
\text { pessoais (amigos. } \\
\text { parentcs, conhecidos, } \\
\text { colegas)? }\end{array}$ & 1 & 2 & 3 & 4 & 5 \\
\hline 21 & $\begin{array}{l}\text { Quão satisfcito(a) você } \\
\text { cstá com sua vida } \\
\text { sexual? }\end{array}$ & 1 & 2 & 3 & 4 & 5 \\
\hline 22 & $\begin{array}{l}\text { Quão satisf́ito(a) você } \\
\text { está com o apoio que } \\
\text { você recebe de scus } \\
\text { amigos? }\end{array}$ & 1 & 2 & 3 & 4 & 5 \\
\hline 23 & $\begin{array}{l}\text { Quâo satisfeito(a) você } \\
\text { está com as condiçốcs } \\
\text { do local onde mora? }\end{array}$ & 1 & 2 & 3 & 4 & 5 \\
\hline 24 & $\begin{array}{l}\text { Quão satisfeito(a) você } \\
\text { está com o scu accsso } \\
\text { nos scrviços de saudde? }\end{array}$ & 1 & 2 & 3 & 4 & 5 \\
\hline 25 & $\begin{array}{l}\text { Quão satisfeito(a) você } \\
\text { está com o scu meio de } \\
\text { transporte? }\end{array}$ & 1 & 2 & 3 & 4 & 5 \\
\hline
\end{tabular}

A questão seguinte refere-se a com que freqüência você sentiu ou experimentou certas coisas nas últimas duas scmanas.

\begin{tabular}{|l|l|c|c|c|c|c|}
\hline & nunca & Algumas vezcs & freqúcntcmentc & $\begin{array}{c}\text { Muito } \\
\text { freqücntemente }\end{array}$ & scmpre \\
\hline 26 & $\begin{array}{l}\text { Com que freqücencia } \\
\text { você tcm } \\
\text { sentimentos } \\
\text { negativos tais como } \\
\text { mau humor, } \\
\text { desespero, } \\
\text { ansiedade, } \\
\text { depressão? }\end{array}$ & 1 & 2 & 3 & 4 & 5 \\
\hline
\end{tabular}


10. REFERÊNCIAS 
ALBERT SM, CASTANADA CC, JACOBS DM, SANO M, BELL K, MERCHANT C, SMALL S, STERN Y. Proxy- Reported quality of Life in Alzheimer's Patients: Comparison of Clinical and Population-Based samples. In: ALBERT SM, LOGSDON RG ed. Assessing quality of life in Alzheimer's Disease. Springer Publishing Company; 2000, 69-80.

ALMEIDA OP, ALMEIDA SA. Confiabilidade da versão brasileira da escala de depressão em geriatria (GDS) versão reduzida. Arq Neuropsiquiatr. 1999; 57(2B): 412-6.

ALEXOPOULOS GS, CHESTER JG, YOUNG RC, SHAMOIAN CA. Cornell scale for Depression in dementia. Biol. Psychiatry. 1988; 23: 271 - 284.

ALEXOPOULOS GS, CHESTER JG. Outcomes of geriatric depression. Clin. Geriatr. Med. 1992; 8 (2):363-76

AMERICAN PSYCHIATRIC ASSOCIATION. Diagnostic and Statistical Manual of Mental Disorders. $3^{\text {rd }}$ ed. Ver. Washington, DC: American Psychiatric Association, 1987

AMERICAN PSYCHIATRIC ASSOCIATION. Diagnostic and Statistical Manual of Mental Disorders. 4. ed. Washigton, DC: American Psychiatric Association, 1994.

BECK AT, WARD CH, MENDELSON M, MOCK J, ERBAUGH G. An inventory for measuring depression. Arch Gen Psychiatry. 1961; 4: 53-63.

BECK AT, STEER RA, GARBIAN MG. Psychometric properties of the Beck Depression Inventory: twenty-five years of evaluation. Clin Psychol Rev. 1988; 8: 77 - 100.

BERTOLUCCI PH, BRUCKI SM, CAMPACCI SR, JULIANO Y. The MiniMental State examination in a general population: impact of educational status. Arq Neuropsiquiatr. 1994; 52:1-7.

BOTTINO CMC, ALEMIDA OP. Demências: quadro clínico e critérios diagnósticos. In: ALMEIDA OP, NITRINI R, ed. Demências. São Paulo, Fundo editorial Byk; 1995, 13-29. 
BOTTINO CMC, CARVALHO IAM, ALVAREZ AMMA, ÁVILA R, ZUKAUSKAS PR, BUSTAMANTE SEZ, ANDRADE FC, HOTOTIAN SR, SAFFI F, CAMARGO CHP. Reabilitação Cognitiva em pacientes com doença de Alzheimer: Relato de trabalho em equipe multidisciplinar. Arq Neuropsiquiatr. 2002; 60(1): 70-79.

BRESSAN LA. O desempenho funcional do idoso com demência (Tese). Ribeirão Preto; Faculdade de Medicina de Ribeirão Preto; 2005.

BROD M, STEWART AL, SANDS L. Conceptualization of Quality of Life in Dementia. In: ALBERT SM, LOGSDON RG, eds. Assessing quality of life in Alzheimer's Disease. Springer Publishing Company; 2000, 3-16.

BRUCKI SMD. Curso clínico da doença de Alzheimer. In: FORLENZA OV, CARAMELLI P, eds. Neuropsiquiatria Geriátrica. São Paulo, Atheneu; 2000, 119-128.

BRUCKI SMD, NITRINI R, CARAMELLI P, BERTOLUCCI PHF, OKAMOTO IH. Sugestões para uso do Mini-exame do Estado Mental no Brasil. Arq Neuropsiquiatr. 2003; 61(3B): 777-81.

CARTHERY MT, AREZA R, SCHULTZ RR, OKAMOTO I, CARAMELLI P, BERTOLUCCI PHF, NITRINI R. Apresentação das versões brasileiras para a escala DAD (Disability Assessment for dementia) e para a escala de Cornell de depressão em demência. Arq Neuropsiquiatr. 2003; 63(suppl 2): 24-5.

CICONELLI RM. Tradução para o Português e validação do questionário genérico de avaliação de QV “Medical Outcomes Study 36- item Short- Form Health Survey (SF - 36)" (Tese). São Paulo; Universidade Federal de São Paulo - Escola Paulista de Medicina; 1997.

CICONELLI RM, FERRAZ MB, SANTOS W, MEINÃO I, QUARESMA MR. Tradução para língua portuguesa e validação do questionário genérico de avaliação de qualidade de vida SF-36 (Brasil SF-36). Rev Bras Reumatol. 1999; 39(3):143- 150.

CUMMINGS JL, MEGA M, GRAY K, ROSEMBERG-THOMPSON, CARUSI DA, GORNBEIN J. The Neuropsychiatry Inventory: Assessing Psychopathology in Dementia Patients. Neurology. 1994; 44: 2308-14.

CUMMINGS JL, MEGA M. Neuropsychiatry and behavioral neuroscience. Oxford University Press; 2003. 
DEVINSKY O, CRAMER J. Health-Related quality of life scales for epilepsy. In: HERNDON RM. Handbook of Neurologic Rating Scales. Demos Vermade; 1997, 209- 23.

DORIA FILHO U. Introdução a Bioestatística: para simples mortais. Negócio Editora; 1999.

DUARTE YAO. Família: Rede de suporte ou fator estressor. A ótica de idosos e cuidadores familiares (Tese). São Paulo; Escola de Enfermagem Universidade de São Paulo, 2001.

FAYERS PM, MACHIN D. Quality of life. Assessment, Analyses and interpretation. Wiley \& Sons; 2000, 3-41.

FERRANS CE, POWERS MJ. Quality of life index: development and psychometric properties. Adv Nurs Sci. 1985; 8(1): 15-24.

FLANAGAN J. Measurement of quality of life: current state of the art. Arch Phsysical Med Reab. 1982; 63:56-9.

FLECK MPA, LOUSADA S, XAVIER $M$ et al. Aplicação da versão em português do instrumento de avaliação de qualidade de vida da Organização Mundial de Saúde (WHOQOL-100). Rev Saúde Pública. 1999; 33(2): 198-205.

FLECK MPA, LOUZADA S, XAVIER M et al. Aplicação da versão em português do instrumento abreviado de avaliação da qualidade de vida “WHOQOL-bref". Rev Saúde Publica. 2000; 34(2): 178-183.

FLECK MPA, CHACHAMOVICH E, TRENTINI CM. Projeto WHOQOLOLD: métodos e resultados de grupos focais no Brasil. Rev Saúde Pública. 2003; 37(6): 793-9.

FLETCHER RH, FLETCHER SW, WAGNER EH. Epidemiologia Clínica: Elementos Essenciais. Porto Alegre; Editora Artes Médicas; 1996.

FOLSTEIN SE, MCHUGH PR. Mini mental state: a practical method for grading the cognitive state of patients for the clinician. J Psychiatr Res. 1975; 12:189-198.

GIFFORD DR, CUMMINGS JL. Evaluating dementia screening tests Methodologic standards to rate their performace. Neurology. 1999; 52(2):224-7. 
GILL TM, FEINSTEIN AR. A critical Appraisal of the quality of quality-oflife measurements. JAMA. 1994; 272(8):619-26.

GORENSTEIN C, ANDRADE L. Inventário de Depressão de Beck Propriedades psicométricas da versão em Português. In: Escalas de Avaliação clínica em Psiquiatria e Psicofarmacologia, Editorial Lemos; 2000, 89-95.

GUILLEMIN F, BOMBARDIER C, BEATON D. Cross-cultural adaptation of health-related quality of life measures: literature review and proposed guidelines. J Clin Epidemiol. 1993; 46(12): 1417-32.

GUILLEMIN F. Measuring health status across cultures. Rheum Eur. 1995; 2: 102-3.

GUYATT GH, FEENY DH, PATRICK DL. Measuring Health-related quality of life. Ann Inter Med. 1993; 118: 622-9.

GUYATT GH. A taxonomy of health status instruments. J. Rheumatol. 1995; 22:1188-90.

GRACIANO MIG, LEHFELD NA, NEVES-FILHO A. Critérios de avaliação para classificação socioeconômica: elementos de atualização. Serv. Social Realid. 1999; 8(1):109-28.

HERNDON RM. Intoduction to clinical neurological scales. In: HERNDON RM ed. Handbook of Neurologic Rating Scales; Demos Vermade; 1997, 1-6.

HERRERA E JR, CARAMELLI P, SILVEIRA ASB, NITRINI R. Epidemiological survey of dementia in community-dwelling Brazilian population. Alzheimer Dis Assoc Disord. 2002; 16:103-8.

HOE J, KATONA C, ROCH B, LIVINGSTON G. Use of the QOL -AD for measuring quality of life in people with severe dementia - the LASER-AD study. Age and Aging. 2005; 34(2):130-5.

HULLEY SB, CUMMINGS SR. Planning the Measurements: Precision and Accuracy. In: Hulley SB, CUMMINGS SR. Designing Clinical Research. Willinas and Wilkins; 1998, 31-41.

HULLEY SB, MARTIN JN, CUMMINGS SR. Planejando as Medições: Precisão e Acurácia. In: HULLEY SB et al., Delineando a pesquisa clinica. Uma abordagem epidemiológica. ARTMED Editora; 2003, 55-68. 
HYLAND ME. A brief guide to the selection of quality of life instrument. Health and Quality of life outcomes. 2003; 1:24.

INSTITUTO BRASILEIRO DE GEOGRAFIA E ESTATÍSTICA - IBGE. Perfil dos idosos responsáveis pelos domicílios no Brasil 2000. Disponível em : <http://www.ibge.com.br> Acesso em: 20 set. 2005.

KALACHE A, VERAS R, RAMOS L. The aging of the world populations: a new challenge. Rev Saúde Pública. 1987; 21(3):200-10.

KIMURA M. Tradução para o Português e Validação do "Quality of life Index" de Ferrans e Powers (Livre docência). São Paulo; Escola de Enfermagem- Universidade de São Paulo; 1999.

KINNEAR PR, GRAY CD. SPSS For Windows Made Simple- Release 10. Department of Psychology, University of Aberdeen; 2001.

KIYAK HA, TERI L, BORSON S. Physical and functional health assessment in normal aging in Alzheimer's disease: Self-reports vs. family reports. Gerontologist. 1994; 34: 324-30.

LAWTON MP. Assessment of older people: Self Maintaining and instrumental activities of daily living. Gerontologist. 1969; 9:179 -185.

LAWTON MP. Environment and other determinants of well-being in older people. Gerontologist. 1983; 4(23):349-57.

LAWTON MP. Assessing quality of Life in Alzheimer Disease Research. Alzheimer Dis Assoc Disord. 1997; 11(6):91-9.

LAWTON MP, HAITSMA KV, PERKINSON M, RUCKDESCHEL K. Observed Affect and Quality of life in Dementia: Further Affirmations and Problems. . In: ALBERT SM, LOGSDON RG, eds. Assessing quality of life in Alzheimer's Disease. Springer Publishing Company; 2000, 95-110.

LENTZ RA, COSTERANO RGS, GONÇALVEZ LHT, NASSAR SM. O profissional de enfermagem e a qualidade de vida: uma abordagem fundamentada nas dimensões propostas por Flanagan. Rev. Latino-am. Enfermagem. 2000, 8(4):7-14.

LOGSDON RG, GIBBONS LE, MCCURRY SM, TERI L. Quality of life in Alzheimer's disease: Patient and Caregiver Reports. J Mental Health Aging. 1999; 5: 21-32. 
LOGSDON RG, ALBERT SM. Assessing quality of life in Alzheimer's Disease: Conceptual and methodological Issues. In: ALBERT SM, LOGSDON RG, eds. Assessing quality of life in Alzheimer's Disease. Springer Publishing Company; 2000, ix - xi.

LOGSDON RG, GIBBONS LE, MC CURRY SM, TERI L. Assessing Quality of life in Older Adults with Cognitive Impairment. Psychosom. Med. 2002; 64(3):510-9.

LOGSDON RG, GIBBONS LE, MCCURRY S, TERI L. Assessing changes in quality of life in Alzheimer's Disease. Neurobiol Aging. 2004; 25 (S2), S72.

LOPES MA, BOTTINO CMC. Prevalência de demência em diversas regiões do mundo. Arq Neuropsiqquiatr. 2002; 60(1): 61-69.

MATSUI T, NAKAAKI S, MURATA Y, SATO J, SHINAGAWA Y, TATSUMI $\mathrm{H}$, FURUKAWA TA. Determinants of quality of life in Alzheimer's disease Patients as assessed by Japenese version of the quality of life - Alzheimer's Disease scale. Dement Geriatr Cogn Disord. 2006; 21(3):182-191.

MCKHANN G, DRACHMAN D, FOLSTEIN M, KATZMAN R, PRICE D, STADLAN EM. Clinical diagnosis of Alzheimer's disease: report of the NINCDS-ADRDA work group under the auspice of Department of Health and Human Services Task Force on Alzheimer's disease. Neurology. 1984; 34:939-44.

MENEZES PR, NASCIMENTO AF. Validade e Confiabilidade das escalas de avaliação em Psiquiatria. In: GORENSTEIN C, ANDRADE LHSC, ZUARDI AW eds. Escalas de Avaliação Clínica em Psiquiatria e Psicofarmacologia. Lemos Editorial; 2000, 23-7.

MINAYO MCS, HARTZ ZMA, BUSS PM. Qualidade de vida e saúde: um debate necessário. Ciência \& Saúde Coletiva. 2000; 5(1): 7-18.

MONTAÑO MB, RAMOS L. Validity of the Portuguese version of Clinical Dementia Rating. Rev Saúde Pública. 2005; 39(6):1-5.

NITRINI R, CARAMELLI P, HERRERA E, BAHIA VS, CAIXETA LF, RADANOVIC M, ANGUINAH R, CHARCHAT-FICHMAN H, PORTO CS, CARTHERY MT, HARTMAN AP, HUANG N, SMID J, LIMA EP, TAKADA LT, TAKAHASHI D. Incidence of dementia in a community-dweling brazilian population. Alzheimer Dis Assoc Disord. 2004; 18(4): 241-6. 
NOVELLI MMPC, NITRINI R, BAHIA VS, CARAMELLI P. Cuidadores de pacientes com demência: perfil sociodemográfico e impacto diário. Arq Neuropsiquiatr. 2001; 59 (3): 3.

NOVELLI MMPC. Adaptação transcultural da escala de avaliação de qualidade de vida na doença de Alzheimer (Dissertação). São Paulo; Faculdade de Medicina da Universidade de São Paulo; 2003.

NOVELLI MMPC, ROVERE HH, NITRINI R, CARAMELLI P. CrossCultural Adaptation of the quality of life assessment scale on Alzheimer Disease. Arq Neuropsiquiatr. 2005; 63(2-A):201-6.

PAPALÉO NETTO, M. O estudo da velhice no século XX: Histórico, definição de campos e termos básicos. In: FREITAS, EV; PY, L; NÉRI, AL; CANÇADO FAX, GORZONI M L, ROCHA SM, eds. Tratado de Geriatria e Gerontologia. Rio de Janeiro; Guanabara-Koogan; 2002, 2-12.

PASCHOAL SMP. Qualidade de vida do idoso: um instrumento que privilegia sua opinião (Dissertação); São Paulo; Faculdade de Medicina da Universidade de São Paulo; 2000.

PASCHOAL SMP. Qualidade de vida na velhice. In: Tratado de Geriatria e Gerontologia. Rio de Janeiro; Guanabara-Koogan; 2002, 19-84.

PAQUALLI L. Teoria e Métodos de medida em ciências do comportamento. UnB: INEP; 1996.

PAVARINI SCI et al. De necessidades à intervenção: etapas na organização de um serviço de orientação para cuidadores de idosos. Universidade Federal de São Carlos, SP, 2000.

POLGAR JM. Avaliação Crítica. In: NEISTADT, ME; CREPEAU, EB. Terapia ocupacional. Rio de Janeiro; Guanabara-Koogan; 2002;153-166.

RABINS PV, KASPER JD, KLEINMAN L, BLACK BS, PATRICK DL. Concepts and methods in the development of the ADRQOL: An instrument for Assessing Health-related quality of life in persons with Alzheimer's disease. In: ALBERT SM, LOGSDON RG, eds. Assessing quality of life in Alzheimer's Disease. Springer Publishing Company; 2000, 51-68.

RAMOS LR, VERAS RP, KALACHE A. Envelhecimento populacional: uma realidade brasileira. Rev Saúde Publica. 1987; 21(3): 211- 24. 
RAMOS LR. Epidemiologia do envelhecimento. In: FREITAS EV, PY L, NÉRI AL, CANÇADO FAX, GORZONI ML, ROCHA SM, eds. Tratado de Geriatria e Gerontologia. Rio de Janeiro; Guanabara-Koogan; 2002, 72-8.

SCIENTIFIC ADVISORY COMMITTEE OF THE MEDICAL OUTCOMES TRUST. Assessing health status and quality-of-life instruments: Attributes and review criteria. Quality of Life Research. 2002; 11:193-205.

SAMPAIO-BARROS PD, REZENDE SM, MARQUES NETO JF, SAMARA AM. Função pulmonar na espondilite anquilosante. Rev Bras Reumatol. 1999; 39(2): 87-90.

SAMPAIO-BARROS PD, SAMARA AM, MARQUES NETO JF. Estudo sobre as diferentes formas clínicas e escores cutâneos na esclerose sistêmica. Rev Bras Reumatol. 2004; 34(1): 1-8.

SANO M, ALBERT SM, TRACTENBERG R, SCHITTINI M. Developing Utilities: Quantifying quality of Life for stages of Alzheimer's Disease as Measured by the Clinical Dementia Rating. In: ALBERT SM, LOGSDON RG, eds. Assessing quality of life in Alzheimer's Disease. Springer Publishing Company; 2000, 81-91.

SMITH KW, AVIS NE, ASSMANN SF. Distinguishing between quality of life and health status in quality of life research: A meta-analysis. Quality of life research. 1999; 8(5): 447-59.

SELAI CE, TRIMBLE MR, ROSSOR MN, HARVEY RJ. The Quality of Life Assessment Schedule (QOLAS)- A New Method for Assessing quality of Life(QOL) in Dementia. In: ALBERT SM, LOGSDON RG, eds. Assessing quality of life in Alzheimer's Disease. Springer Publishing Company; 2000, 31-48.

SOUZA FF. Avaliação da qualidade de vida do idoso em hemodiálise: comparação de dois instrumentos genéricos (Dissertação). Campinas; Universidade Estadual de Campinas - Faculdade de Ciências Medicas; 2004.

THE WHOQOL GROUP. The World Health Organization quality of life assessment: position paper from the world health organization. Soc Sci Med. 1995; 41(10):1403- 9 .

THE WHOQOL GROUP. The World Health Organization quality of life assessment (WHOQOL): development and general psychometric properties.. Soc Sci Med. 1998; 46:1569-85. 
THORGRIMSEN L, SELWOOD A, SPECTOR A, ROYAN L, DE MADARIAGA LOPEZ M, WOODS RT, ORRELL M. Whose Quality of Life Is It Anyway?: The Validity and Reliability of the Quality of Life-Alzheimer's Disease (QOL-AD) Scale. Alzheimer Dis Assoc Disord. 2003; 17(4): 201-8.

TRENTINI CM. Qualidade de vida em idosos (Tese). Porto Alegre; Faculdade de Medicina-Universidade Federal do Rio Grande do Sul UFRGS; 2004.

VERAS RP. Epidemiologia do envelhecimento na América Latina. In: FORLENZA OV, CARAMELLI P, eds. Neuropsiquiatria Geriátrica. São Paulo, Atheneu; 2000, 7 -21.

VOLICER L, HURELY AC, CAMBERG L. A model of Psychological WellBeing in Advanced Dementia. In: ALBERT SM, LOGSDON RG, eds. Assessing quality of life in Alzheimer's Disease. Springer Publishing Company; 2000, 111-124.

WALKER MD, SALEK S. A Review of Quality of Life in Alzheimer's Disease. Part 1: Issues in Assessing Disease Impact. Pharmacoeconomics. 1998; 14: 499-530.

WARE JE, SHERBOURNE CD. The MOS 36-item Short-Form Health Survey (SF-36): I. Comceptual Framework and Item Selection. Med Care. 1992; 30:473-83.

WEYERER S, SCHÄUFELE M. The assessment of quality of life in dementia. International Psychogeriatrics. 2003; 15(3):213-18.

WHITEHOUSE PJ, RABINS PV. Quality of life and Dementia. Alzheimer Dis Assoc Disord. 1992; 6:135-7.

WHITEHOUSE PJ, ORGOGOZO JM, BECKER RE. Quality-of-life assessment in dementia drug development. Alzheimer Dis Assoc Disord. 1997; 11(3): 56-60.

WHITEHOUSE PJ. Quality of life: Future Directions. In: ALBERT, SM; LOGSDON, RG, eds. Assessing quality of life in Alzheimer's Disease. Springer Publishing Company; 2000, 179-184.

WHITEHOUSE PJ, PATTERSON MB, SAMIE SA. Quality of life in dementia: ten years later. Alzheimer Dis Assoc Disord. 2003; 17(4): 199-200.

YESAVAGE JA, BRINK TL, ROSE T. Development and Validation of a geriatric depression screening scale: A preliminary report. J Psychiat Res. 1983; 17:37- 49. 